DISTRIBUTION SHEET

\begin{tabular}{|c|c|c|c|c|c|}
\hline \multirow{2}{*}{$\begin{array}{l}\text { To } \\
\text { Distribution }\end{array}$} & \multirow{2}{*}{\multicolumn{3}{|c|}{$\begin{array}{l}\text { From } \\
\text { R. J. Parazin }\end{array}$}} & \multirow{2}{*}{\multicolumn{2}{|c|}{ Page 1 of 1}} \\
\hline & & & & & Date $5 / 25 / 95$ \\
\hline \multirow{2}{*}{\multicolumn{4}{|c|}{$\begin{array}{l}\text { Project Title/Work Order } \\
\text { WHC-SD-WM-TI-705, Rev. 0, Solid Waste Handling }\end{array}$}} & \multicolumn{2}{|c|}{ EDT No. 612132} \\
\hline & & & & \multicolumn{2}{|c|}{ ECN No. } \\
\hline Name & MSIN & $\begin{array}{c}\text { Text } \\
\text { With Al1 } \\
\text { Attach. }\end{array}$ & $\begin{array}{l}\text { Text } \\
\text { Only }\end{array}$ & $\begin{array}{l}\text { Attach./ } \\
\text { Appendix } \\
\text { Only }\end{array}$ & $\begin{array}{l}\text { EDT/ECN } \\
\text { Only }\end{array}$ \\
\hline $\begin{array}{l}\text { Central Files Coriq. +2) } \\
\text { OSTI (2) } \\
\text { S. K. Baker } \\
\text { A. L. Boldt } \\
\text { K. D. Boomer } \\
\text { J. S. Garfield } \\
\text { R. J. Parazin } \\
\text { G. F. Williamson }\end{array}$ & $\begin{array}{l}\text { L8-04 } \\
\text { L8-07 } \\
\text { H5-57 } \\
\text { H5-49 } \\
\text { H5-49 } \\
\text { H5-49 } \\
\text { H5-49 } \\
\text { G6-13 }\end{array}$ & $\begin{array}{l}x \\
x \\
x \\
x \\
x \\
x \\
x \\
x\end{array}$ & & & \\
\hline
\end{tabular}




\section{DISCLAIMER}

Portions of this document may be illegible in electronic image products. Images are produced from the best available original document. 


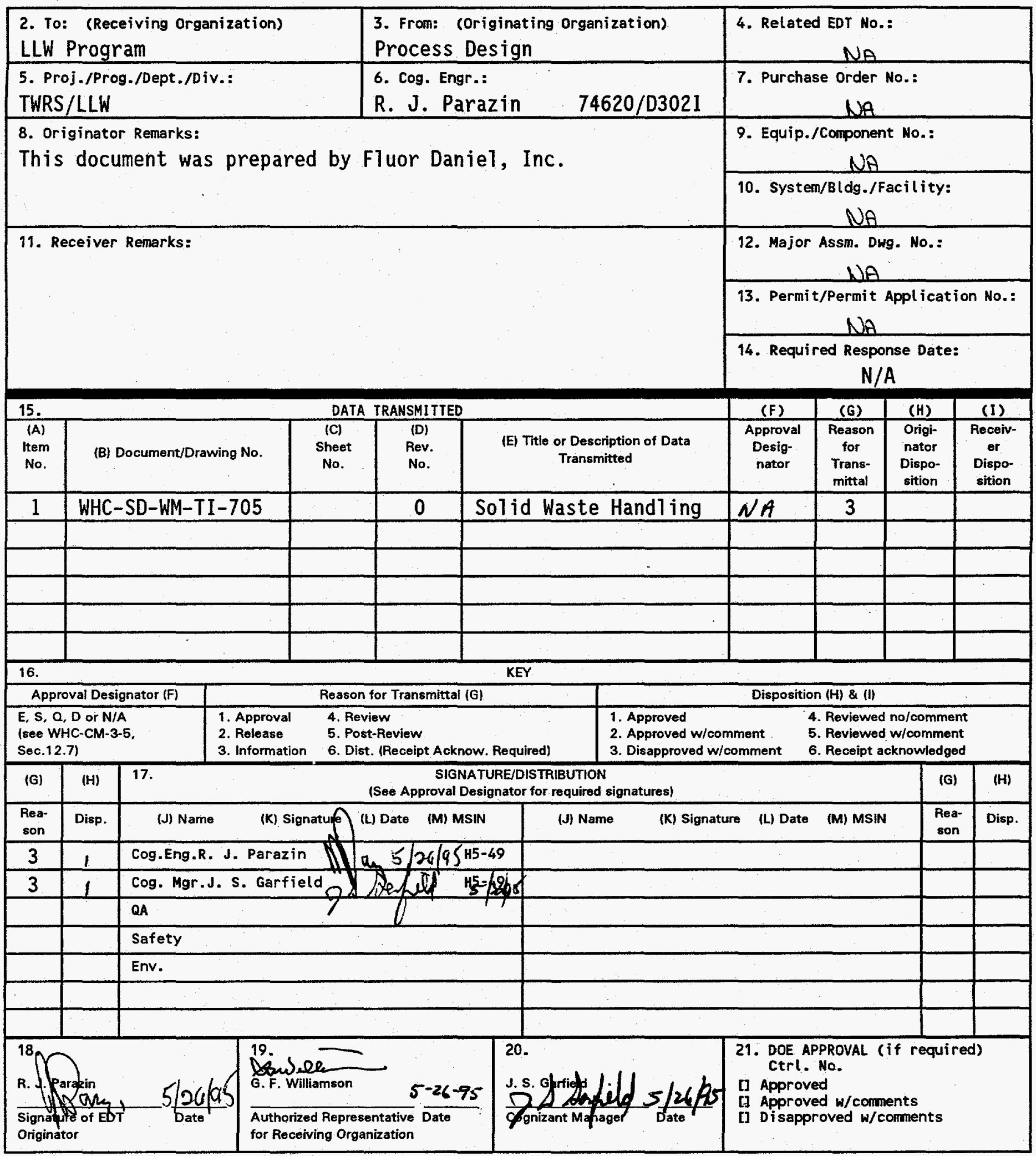

BD-7400-172-2 (04/94) GEF097 


\section{RELEASE AUTHORIZATION}

\begin{tabular}{|ll|}
\hline Document Number: & WHC-SD-WM-TI-705, Rev. 0 \\
\hline Document Title: & SOLID WASTE HANDLING \\
\hline Release Date: & $5 / 30 / 95$
\end{tabular}

This document was reviewed following the procedures described in WHC-CM-3-4 and is:

\section{APPROVED FOR PUBLIC RELEASE}

WHC Information Release Administration Specialist:

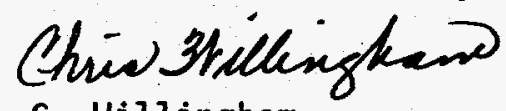

C. Willingham

TRADEMARK DISCLAIMER. Reference herein to any specific comercial product, process, or service by trade name, trademark, manufacturer, or otherwise, does not necessarily constitute or imply its endorsement, recomendation, or favoring by the United States Government or any agency thereof or its contractors or subcontractors.

This report has been reproduced from the best available copy. Available in paper copy and microfiche. Printed in the United States of America. Available to the U.S. Department of Energy and its contractors from:

\section{U.S. Department of Energy}

office of Scientific and Technical Information (OSTI)

P.0. Box 62

Oak Ridge, TN 37831

Telephone: (615) 576-8401

Available to the public from:

U.S. Department of Commerce

National Technical Information Service (NTIS)

5285 Port Royal Road

Springfield, VA 22161

Telephone: (703) 487-4650 


\begin{tabular}{|l|l|c|}
\hline $\begin{array}{l}\text { 2. Title } \\
\text { Solid Waste Handling }\end{array}$ & $\begin{array}{l}\text { 3. Number } \\
\text { WHC-SD-WM-TI-705 }\end{array}$ & \begin{tabular}{c} 
4. Rev No. \\
\hline 5. Key words
\end{tabular} \\
$\begin{array}{l}\text { Separations } \\
\text { low-level waste }\end{array}$ & $\begin{array}{l}\text { 6. Author } \\
\text { Signattie }\end{array}$ \\
\hline
\end{tabular}

\section{Abstract}

This study presents estimates of the solid radioactive waste quantities that will be generated in the Separations, Low-Level Waste Vitrification and High-Level Waste Vitrification facilities, collectively called the Tank Waste Remediation System Treatment. Complex, over the life of these facilities. This study then considers previous estimates from other 200 Area generators and compares alternative methods of handling (segregation, packaging, assaying, shipping, etc.).

This study was prepared by Fluor Daniel, Inc.

\section{DISCLAIMER}

This report was prepared as an account of work sponsored by an agency of the United States Government. Neither the United States Government nor any agency thereof, nor any of their employees, makes any warranty, express or implied, or assumes any legal liability or responsibility for the accuracy, completeness, or usefulness of any information, apparatus, product, or process disclosed, or represents that its use would not infringe privately owned rights. Reference herein to any specific commercial product, process, or service by trade name, trademark, manufacturer, or otherwise does not necessarily constitute or imply its endorsement, recommendation, or favoring by the United States Government or any agency thereof. The views and opinions of authors expressed herein do not necessarily state or reflect those of the United States Government or any agency thereof.
8. RELEASE STAMP

OFFOIAL RELEASE

BY VHC

DATE MAY 311995

35 station 21 
WHC-SD-WM-TI-705

Revision 0

\title{
SOLID WASTE HANDLING
}

\author{
May 1995
}

Prepared by Fluor Daniel, Inc. Irvine, California

Prepared for Westinghouse Hanford Company Richland, Washington 


\section{WHC-SD-WM-TI-705}

Revision 0

This page intentionally left blank. 


\section{CONTENTS}

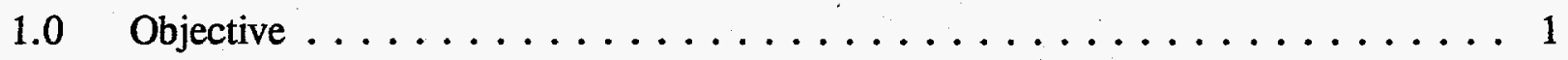

$1.1 \quad$ Background and Scope $\ldots \ldots \ldots \ldots \ldots \ldots \ldots \ldots \ldots$

1.2 Purpose and Need $\ldots \ldots \ldots \ldots \ldots \ldots \ldots \ldots \ldots \ldots$

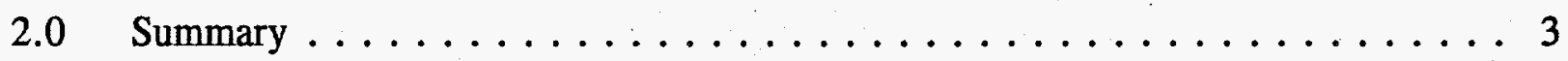

3.0 Technical Findings and Conclusions $\ldots \ldots \ldots \ldots \ldots \ldots \ldots \ldots \ldots \ldots$

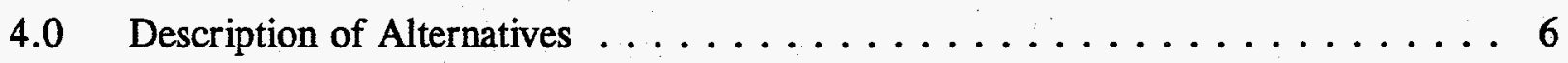

4.1 Handling Solid Waste Within Each Facility $\ldots \ldots \ldots \ldots \ldots \ldots$

4.1.1 High-Level Waste Facility $\ldots \ldots \ldots \ldots \ldots \ldots \ldots \ldots$

Figure $4.1 .1-1 \ldots \ldots \ldots \ldots \ldots \ldots$

4.1 .2 Separations/LLW Facility $\ldots \ldots \ldots \ldots \ldots \ldots$

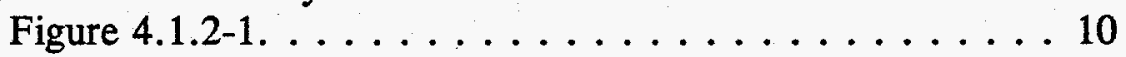

4.2 Handling Solid Waste at a Common Facility . . . . . . . . . 11

4.2.1 Common Solid Waste Handling Facility . . . . . . . . . 11

4.2.2 High-Level Waste Facility $\ldots \ldots \ldots \ldots \ldots \ldots \ldots \ldots \ldots$

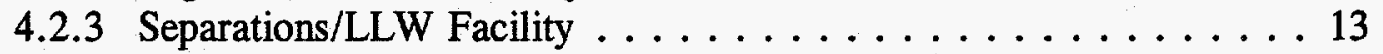

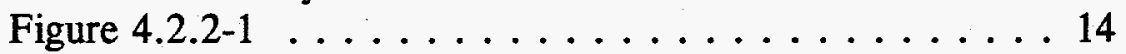

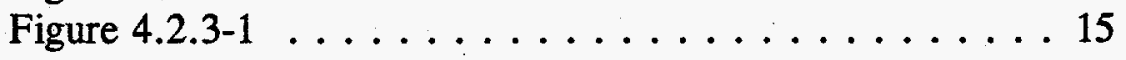

5.1 Function and Requirements $\ldots \ldots \ldots \ldots \ldots \ldots \ldots \ldots$

5.1.1 Handling Solid Waste Within Each Facility ... . . . . . . 18

5.1.2 Handling Solid Waste At A Common Facility $\ldots \ldots \ldots \ldots 18$

5.2 Assumptions and Uncertainties $\ldots \ldots \ldots \ldots \ldots \ldots \ldots \ldots \ldots$

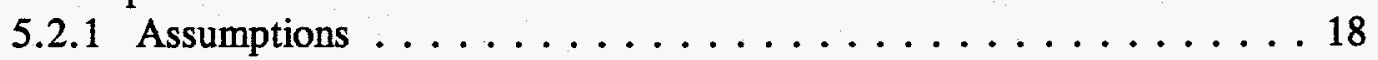

5.2 .2 Uncertainties . . . . . . . . . . . . . . 19

5.3 Summary ....................... 19

5.3.1 Process Flow Sheets/Facility Design Impacts . . . . . . . . . 19

5.3.1.1 Handling Solid Waste Within Each Facility . . . . 19

5.3.1.2 Handling Solid Waste In Common Facility . . . . . 19

5.3 .2 Operability Complexity . . . . . . . . . . . . . 19

5.3 .3 Maintainability . . . . . . . . . . . . . 19

5.3.4 Maturity of Technology . . . . . . . . . . . . . 19

5.3 .5 Schedule Impacts . . . . . . . . . . . . . . . 19

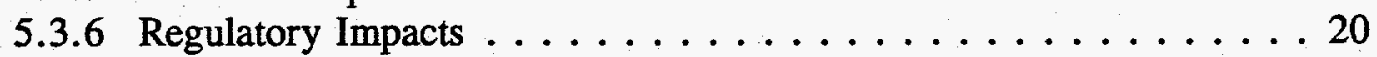

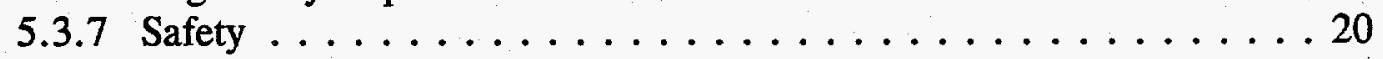

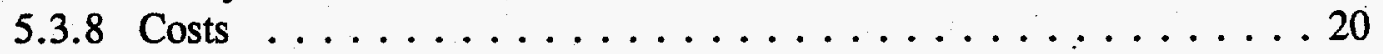


WHC-SD-WM-TI-705

Revision 0

APPENDIX A - SEPARATIONS/LOW-LEVEL WASTE INVENTORY $\ldots \ldots \ldots$ A-1

APPENDIX B - HIGH-LEVEL WASTE INVENTORY $\ldots \ldots \ldots \ldots \ldots \ldots$. . . . 
WHC-SD-WM-TI-705

Revision 0

SOLID WASTE HANDLING

\subsection{Objective}

This study presents estimates of the solid radioactive waste quantities that will be generated in the Separations, Low-Level Waste (LLW) Vitrification and High-Level Waste (HLW) Vitrification facilities, collectively called the Tank Waste Remediation System (TWRS) Treatment Complex, over the life of these facilities. This study then considers previous estimates from other 200 Area generators and compares alternative methods of handling (segregation, packaging, assaying, shipping, etc.).

Comparison of these alternatives is essential to provide bases for selecting a facility configuration for handling solid waste in an economical and safe manner.

\subsection{Background and Scope}

The handling of solid waste can be accomplished within each of the TWRS facilities or at a common facility.

The major discriminators for the selection of the method of handling the solid waste are safety and cost.

The solid waste estimates are made from equipment lists Case 3B, HLW 20 T/D Stand Alone, and Case 4C, Combined Separations with LLW Treatment, Low Cs DF and High Source Term.

Section 4 within this report addresses the movement of equipment within the Separations/LLW and HLW Facilities.

A previous study, Facility Design Philosophy Centralized vs. Dedicated Support Functions, CWBS 2001, evaluated the merits of processing solid waste of each of the TWRS Treatment Complex facilities or at a common facility. It was determined that processing solid waste at each facility was most cost effective. This study evaluates the next step.

\subsection{Purpose and Need}

The solid waste generated in the Separations/LLW Facility and the HLW Facility can be processed (decontaminated, cut up, and packaged) within the two facilities or it can be moved to a separate common TWRS facility for processing. 
Revision 0

This common solid waste handling facility will process all solid waste from the TWRS areas.

Before the conceptual design of the facilities can begin, a decision must be reached on the best systematic approach to the facilities configuration. The location of the solid waste facility has been identified as an item that could impact the facilities configuration. These alternatives must, therefore, be further defined and compared. There is a need to determine the volume of solid waste of each classification for storage and disposal planning. This study presents the results of this system definition, comparison, and estimating of the amount of solid waste. 
WHC-SD-WM-TI-705

Revision 0

2.0 Summary

The two alternatives for handling solid waste provide for acceptable methods of moving, decontamination, cut up, and packaging the equipment. Moving the equipment to a common facility for decon and packaging requires additional large containers and large container packaging and decon systems but eliminates some cut up and packaging equipment and both assay systems. The location of this common facility has not been determined in this study.

The total cumulative estimated weights of the various waste classifications for Separations/LLW and HLW Facilities are shown in Table 2-1.

Table 2-1. Estimated Solid Waste Produced During Operation of the Separations/LLW and HLW Facilities

\begin{tabular}{|l|r|r|r|r||}
\hline & \multicolumn{2}{|c|}{$\begin{array}{c}\text { Separations/LLW } \\
\text { Facility }\end{array}$} & \multicolumn{2}{c|}{ HLW Facility } \\
\cline { 2 - 5 } \multicolumn{1}{|c|}{ Solid Waste Classification } & Kilograms & $\begin{array}{c}\text { 55-Gallon } \\
\text { Drums }\end{array}$ & Kilograms & $\begin{array}{c}\text { 55-Gallon } \\
\text { Drums }\end{array}$ \\
\hline Transuranic & 0 & & 510,000 & 2,249 \\
\hline Mixed Transuranic & 0 & & 0 & 0 \\
\hline Low Level Category 1 & $1,398,000$ & 6,164 & 640,000 & 2,822 \\
\hline Mixed Low Level Category 1 & 1,860 & 410 & 3,400 & 750 \\
\hline Low Level Category 3 & 0 & & 202,000 & 890 \\
\hline Mixed Low Level Category 3 & 0 & & 230 & 51 \\
\hline Low Level Greater Than Waste \\
Category 3 & $3,464,000$ & 15,273 & 72,100 & 318 \\
\hline $\begin{array}{l}\text { Mixed Low level Greater Than } \\
\text { Waste Category 3 }\end{array}$ & 0 & & 0 & 0 \\
\hline \hline Totals & $4,893,860$ & 21,847 & $1,427,730$ & 7,080 \\
\hline
\end{tabular}

The total other TWRS solid waste is shown in Table 2-2 on the following page.

The solid waste produced in the Separations/LLW and HLW Facilities amount to $1 \frac{1 / 2}{2}$ percent of the total produced at TWRS. 
WHC-SD-WM-TI-705

Revision 0

Table 2-2. Solid Waste Generated at Other TWRS Facilities* (Sheet 1 of 2)

Waste Tank Safety and Operations Volumes (55-gallon drums)

\begin{tabular}{||l|r|r|c||}
\hline \hline Generator & $\begin{array}{c}\text { TRU/TRU } \\
\text { Mixed } \\
\text { Waste }\end{array}$ & $\begin{array}{c}\text { Low Level } \\
\text { Mixed } \\
\text { Waste }\end{array}$ & $\begin{array}{c}\text { Low-Level } \\
\text { Waste }\end{array}$ \\
\hline 200 East Tank Farms & 0 & 8,668 & 77,370 \\
\hline Lead & 0 & 0 & 0 \\
\hline Long-Length Equipment & 0 & 35,139 & 0 \\
\hline $\begin{array}{l}\text { Project W-030, Tank Farm Ventilation } \\
\text { Upgrade }\end{array}$ & 0 & 0 & 96 \\
\hline $\begin{array}{l}\text { Project W-058, Tank Farm Cross-Site } \\
\text { Transfer Line }\end{array}$ & 0 & 0 & 53 \\
\hline Project W-153, TRUEX Pilot Plant & 5 & 5 & 1,264 \\
\hline \hline $\begin{array}{l}\text { Waste Tank Safety and Operations } \\
\text { TOTAL }\end{array}$ & 0 & 43,812 & 78,783 \\
\hline
\end{tabular}


WHC-SD-WM-TI-705

Revision 0

Table 2-2. Solid Waste Generated at Other TWRS Facilities* (Sheet 2 of 2)

Tank Waste Disposal Volumes (55-gallon drums)

\begin{tabular}{||l|r|r|c|}
\hline Generator & $\begin{array}{c}\text { TRU/TRU } \\
\text { Mixed } \\
\text { Waste }\end{array}$ & \multicolumn{1}{|c|}{$\begin{array}{c}\text { Low Level } \\
\text { Mixed } \\
\text { Waste }\end{array}$} & $\begin{array}{c}\text { Low-Level } \\
\text { Waste }\end{array}$ \\
\hline $\begin{array}{l}\text { Project W-151, SH Tank Farm 101- } \\
\text { AZ Shielding }\end{array}$ & 476 & 0 & 0 \\
\hline $\begin{array}{l}\text { Project W-151, Tank 101-AZ } \\
\text { Retrieval }\end{array}$ & 139 & 0 & 856 \\
\hline $\begin{array}{l}\text { Double-Shell Tank Waste Pilot Scale } \\
\text { Retrieval }\end{array}$ & 4,413 & 0 & 2,572 \\
\hline Double-Shell Tank Process Tests & 269 & 0 & 524 \\
\hline Single-Shell Tank Retrieval & 0 & 141,139 & 473,370 \\
\hline $\begin{array}{l}\text { Double-Shell Tank Waste Retrieval } \\
\text { Contaminated Soil Under Single-Shell } \\
\text { Tanks }\end{array}$ & 4,707 & 6,077 & 0 \\
\hline $\begin{array}{l}\text { Single-Shell Tanks and Ancillary } \\
\text { Equipment }\end{array}$ & 0 & 480,769 & 0 \\
\hline \hline Tank Waste Disposal TOTAL & 10,004 & $1,323,004$ & 477,322 \\
\hline
\end{tabular}

* Reference: WHC-SD-WM-RPT-060, Rev. 0, Solid Waste Program Technical Baseline Description. 
WHC-SD-WM-TI-705

Revision 0

3.0 Technical Findings and Conclusions

The two alternatives studied for this report allow the handling of solid waste from removal of the equipment through packaging in 55-gallon drums ready for storage or burial.

Solid waste handling within each facility offers more advantages over a single common facility in that less additional solid waste is created during handling of the solid waste and the solid waste is handled fewer times.

\subsection{Description of Alternatives}

The description of handling the solid waste in this report is based on the layouts and equipment lists of the following cases:

\section{- $\quad$ Case 3B, Stand Alone HLW \\ - $\quad$ Case 4C, Separations/LLW.}

Other cases of Stand Alone Separation, Low Level Stand Alone, High Level, and various combinations of the three, will have similar equipment with similar flow of solid waste within each facility.

The removal pathway for solid waste generated in the facilities depends on the area of generation, radiation level, and waste classification. Equipment failure, equipment maintenance, equipment removal at the completion of vitrification, and analytical sampling and testing will account for the majority of solid waste. Implementation of a waste minimization plan will reduce the volume of waste or reduce its activity for classification into a lower waste class. For example, a failed piece of equipment can be drained and flushed in place to remove as much residual radioactive contamination as possible, then can be mechanically reduced in size, further decontamination, and then its components separated into waste classes such as TRU waste, LLW, or recycled when possible. Appendix A contains the inventory of waste types and quantities to be generated in the Separations/LLW facility and Appendix B contains the inventory of waste types and quantities to be generated in the HLW facility.

The definitions for the waste classification Solid TRU Waste and LLW Categories 1, 3 and greater than 3, as used in this report, are defined in WHC-EP-0063-4, Hanford Site Solid Waste Acceptance Criteria.

For purposes of this study, general removal pathways have been divided into two categories based on radiation exposure levels. Radiation exposure levels greater than $100 \mathrm{mrem} / \mathrm{h}$ must be considered to be remote handled $(\mathrm{RH})$, while radiation exposure levels less than $100 \mathrm{mrem} / \mathrm{h}$ are considered to be contact handled $(\mathrm{CH})$. Operations 
WHC-SD-WM-TI-705

Revision 0

requiring plant design consideration (e.g., segregation, packaging, assaying, storage) are discussed below. The purpose of waste removal pathways is to identify the sequence of operations to be performed when solid wastes are generated.

The movement of solid waste through the facilities will be similar for both concepts (within each facility or a common facility) until it reaches the cut-up cells or packaging cells as discussed in Sections 4.1 and 4.2. Within the HLW facilities, the Melter Cell (MC), Centrifuge/Evaporator Cell (C/EC), Canister Cooling Cell (CCC), Melter Cut-up Cell (MCUC), Remote Cut-up and Decon Cell (RCDC), Canister Fill Station, Canister Weld Station, Canister Decon Station, and Canister Load Station have the greatest potential for generating TRU waste based on exposure to operating media. Waste generated in these areas will be handled remotely. Waste originating in the Canister Smear Test Station and RCDC Crane Maintenance Area could require remote handling or contact handling.

Waste generated in the following areas will be $\mathrm{CH}$ : Overpack Weld Station, Overpack Smear Test Station, Overpack Decon Station, and Contact Filter Room.

Within the Separation/LLW Facility, the Ion Exchange, Separation, Offgas, Cullet Processing Cell, Melter Cell, Melter Cut-up Cell, and Remote Cut-up and Decon Cell are the areas where most of the remote handled waste will be produced.

Waste generated in the Contact Maintenance Area (CMA), Contact Filter Room, and equipment transfer area will be $\mathrm{CH}$.

\subsection{Handling Solid Waste Within Each Facility}

\subsubsection{High-Level Waste Facility}

In general, solid waste being removed from areas within the HLW Facility will flow and be handled with equipment as shown on the Block Flow Diagram, Figure 4.1.1-1.

The HLW melter will be moved to the MCUC on the melter cart which is part of the melter frame. In the MCUC, the HLW melter will be cut into pieces which can be placed in 55-gallon drums or other convenient sizes for moving to the RCDC.

All equipment (including the cut-up melter) which must be remote handled will be moved to the RCDC for aggressive decontamination, size reduction, and waste stream segregation. 


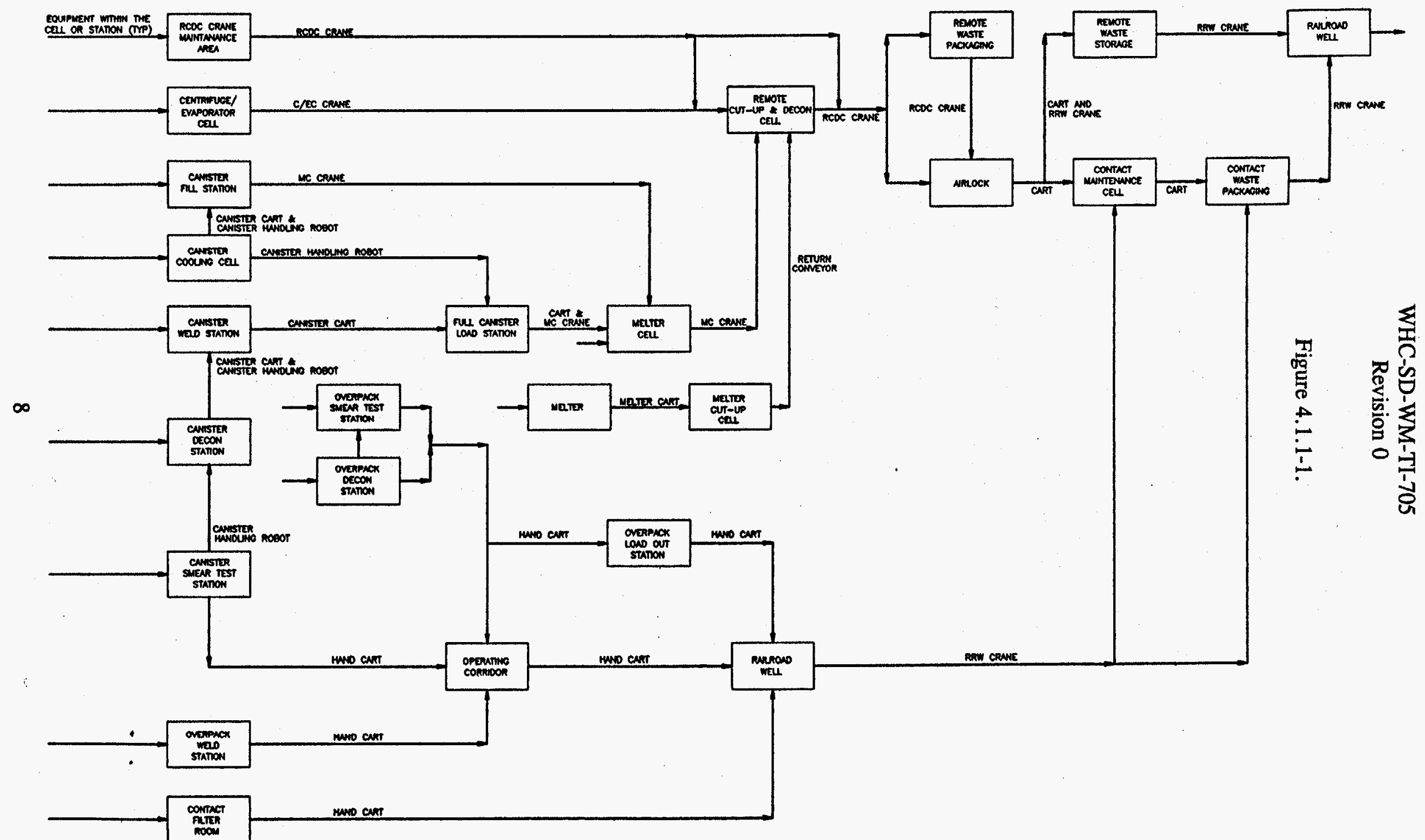

FIGURE 4.1.1-1

SOLID WASTE 
Waste that has a radiation level below $100 \mathrm{mrem} / \mathrm{h}$ will be transferred from the RCDC to the CMA. This transfer will be made using the RCDC crane by placing the waste on a cart in the air lock between the RCDC and the CMA. The cart will be used to move the waste to the CMA.

In the RCDC is the remote waste packaging station where drums and crates will be filled. This packaging station will have a weigh scale for determining the tare and contents weight of the containers. After filling the containers and placing the lids on them, the exterior surfaces of the containers must be smeared. The smear sample will be placed into a pneumatic transfer system and transferred to a smear station glove box. The smear sample will be counted. Containers which have smearable surface contamination above allowable levels will be decontaminated and the smear test repeated until acceptable limits are met.

The waste container will then be moved from the packaging to the assay station. After assaying, the containers will be moved to the Remote Waste Storage Area until sufficient shipping volume has been accumulated.

Contact handled waste which has been moved to the Contact Maintenance Cell will be decontaminated, reduced in size, as necessary, and waste streams segregated. From the Contact Maintenance Cell, the $\mathrm{CH}$ waste will be moved to the Contact Waste Packaging Station where it will be packaged, weighed, smear sampled, and stored until sufficient shipping volume has been accumulated.

\subsubsection{Separations/LLW Facility}

Solid waste within the Separations/LLW Facility will flow as shown in on the Block Flow Diagram, Figure 4.1.2-1.

In general, solid waste being removed from areas within the Separations/LLW Facility will be handled with the equipment as shown on the Block Flow Diagram, Figure 4.1.2-1.

The LLW melter will be moved to the MCUC on the melter cart which is part of the melter frame. In the MCUC, the LLW melter will be cut into pieces which will fit in 55-gallon drums or other convenient sizes and which will fit on the conveyor running to the RCDC. All equipment (including the cut-up melter) which must be remote and contact handled must be moved to the RCDC. 


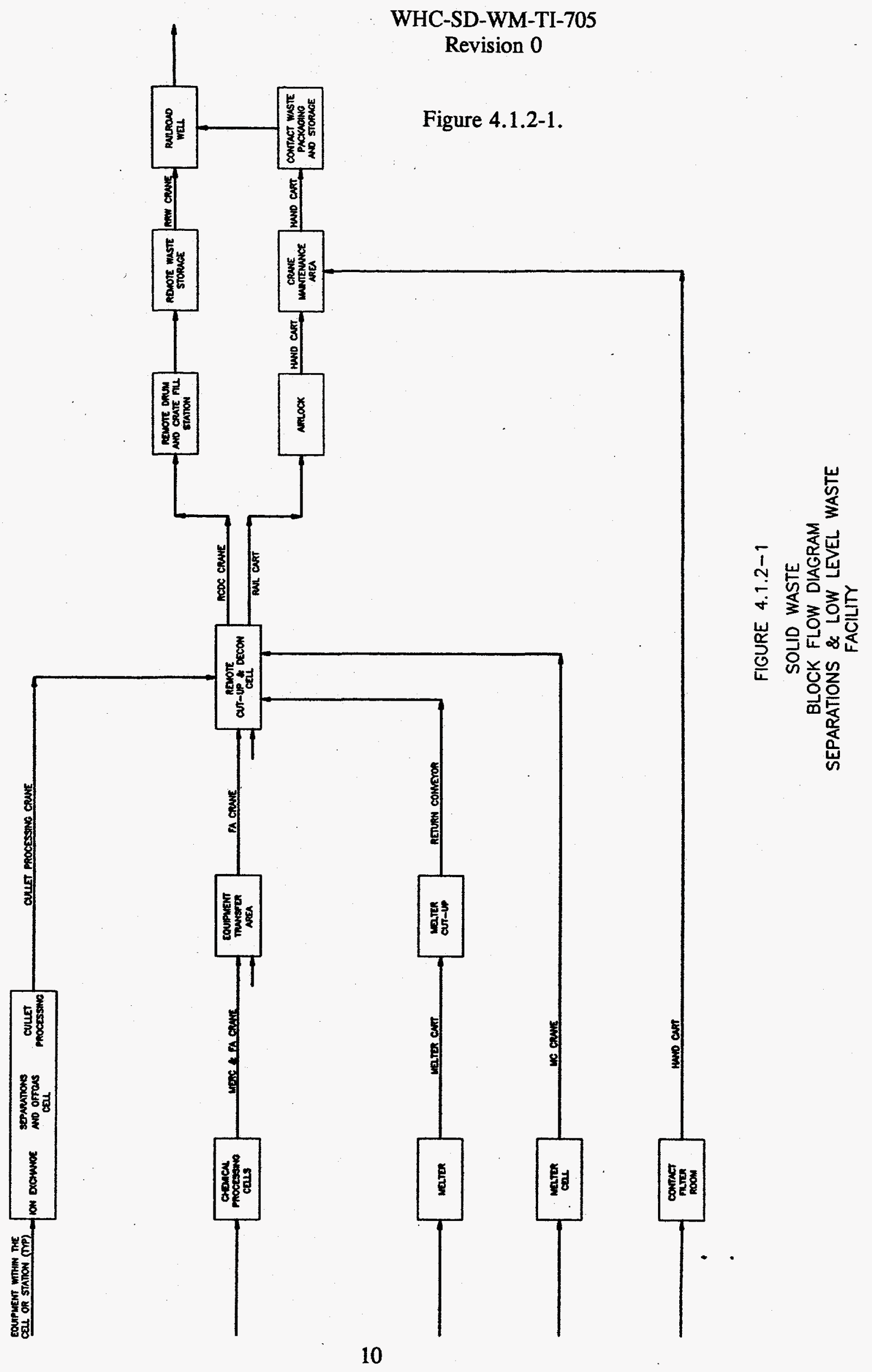


Waste that has a radiation level below $100 \mathrm{mrem} / \mathrm{h}$ will be transferred from the RCDC to the CMA. This transfer will be made using the RCDC crane, the cart operating between the RCDC and an air lock, and a hand cart to move it from the air lock to the CMA. In the RCDC is the remote waste packaging station where the waste will be handled similar to that in the HLW Facility discussed in Section 4.1.1. The $\mathrm{CH}$ waste which has been moved to the CMA will be handled similar to that in the HLW Facility discussed in Section 4.1.1.

\subsection{Handling Solid Waste at a Common Facility}

\subsubsection{Common Solid Waste Handling Facility}

This CSWHF will handle waste from all TWRS solid waste generators. This waste is projected to be 1,962,000 drums (55-gallon). These generators are shown in Table 2-2. Of this volume 29,000 drums (55-gallon) will come from Separations/LLW and HLW facilities.

This CSWHF will require many of the elements discussed in WHC-SDWM-RPT-060, Solid Waste Program Technical Baseline Description, Revision 0 , except on a smaller scale. These will include, but not be limited to the following:

- Remote Handling and Large Container Waste Processing (for both TRU and LLW) Area.

- Waste Staging and Storage Area.

- $\quad$ Mixed Waste Stabilization Area.

- Contact Handling Drain TRU Waste Processing area.

Within the above facilities will be the following areas and equipment.

- Transfer Containers - These containers will be used to move equipment from the Separations/LLW and HLW Facilities to the CSWHF. Some of these containers will be very large and require shielding.

- $\quad$ RRW - This area will be required to receive equipment, remove equipment from transfer containers, and decon transfer containers and railroad cars.

- $\quad$ RRW Crane - Large crane (100-150 MT) for unloading equipment from containers.

- Air Lock - This air lock will be used to transfer equipment from the RRW to the RCDC.

- Rail Transfer Cart - This cart will be used to transfer equipment from the air lock to the RCDC. 
- $\quad$ RCDC - This area will be the major working area of the CSWHF.

- $\quad$ RCDC Crane - This will be a large crane for handling equipment before and after disassembly and cut up.

- $\quad$ Cut Up and Disassembly Equipment - This equipment will include but not be limited to such things as shearing machines, plasma arc cutting units, circular/pipe/jig/reciprocating saws, and swivel racks.

- Decontamination Equipment - This equipment will include, but not be limited to such things as soak tanks, dry ice blasting, and steam and spray lances.

- $\quad$ Remote Handling and Packaging Station

- $\quad \mathrm{CH}$ and Packaging Station

- $\quad$ Remote Waste Assay Station

- $\quad$ Contact Cut-Up \& Decon Cell (CCDC)

- Contact Waste Assay Station

- $\quad$ Air Lock - This air lock will be used to transfer items between the RCDC and the CCDC.

- $\quad$ Rail Transfer Cart - This cart will be used to transfer items between the RCDC and the CCDC.

- $\quad$ Crane Maintenance Area for the RCDC Crane.

This CSWHF could be at a new facility constructed specifically for handling solid waste or at an existing refurbished facility such as T-Plant.

At the time of writing this report, there are no provisions for remote handling of equipment or plans to handle TRU waste at T-Plant.

T-Plant has the following basic equipment for a centralized solid waste handling facility:

- Large Crane - Designed for 100 tons, presently rated for 40 tons.

- $\quad$ Rail siding entering the canyon.

- $\quad$ Shielding walls. 


\subsubsection{High-Level Waste Facility}

Solid waste handling within the HLW Facility where cut up stream segregation and major decontamination would be at a common facility will flow as shown on the Block Flow Diagram, Figure 4.2.2-1. In general, solid waste will be removed from areas within the HLW Facility and will be handled with equipment as shown on the Block Flow Diagram, Figure 4.2.2-1.

The HLW melter will be moved to the Remote Maintenance and Decon Cell (RMDC) where some decontamination and disassembly will be accomplished. The decontamination will remove loose material from the melter to reduce the spread of contamination. Some disassembly of the melter will be accomplished to reduce the size.

No layout of a HLW Facility where solid waste decon stream segregation and packaging will be occur in a separate facility has been made. The changes that would occur to the existing layout of the HLW Facility are removal of the following areas:

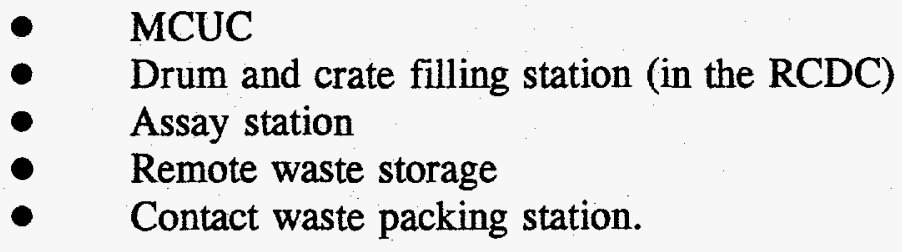

All solid waste removed from the HLW Facility would pass through the RMDC except for some $\mathrm{CH}$ waste which would be moved to the railroad well (RRW). From the RRW it would be moved to the Common Solid Waste Handling Facility (CSWHF). Some decon of all equipment would occur in the RMDC before moving the equipment to the RRW. In the RRW, the equipment would be placed in a container for movement to the CSWHF.

\subsubsection{Separations/LLW Facility}

Solid waste within the Separations/LLW Facility will flow as shown on the Block Flow Diagram, Figure 4.2.3-1. In general, solid waste being removed from areas within the Separation/LLW Facility will be handled with equipment as shown in Block Flow Diagram, Figure 4.2.3-1. The LLW melter will be moved to RMDC on the melter cart where some decontamination and disassembly will be done. 


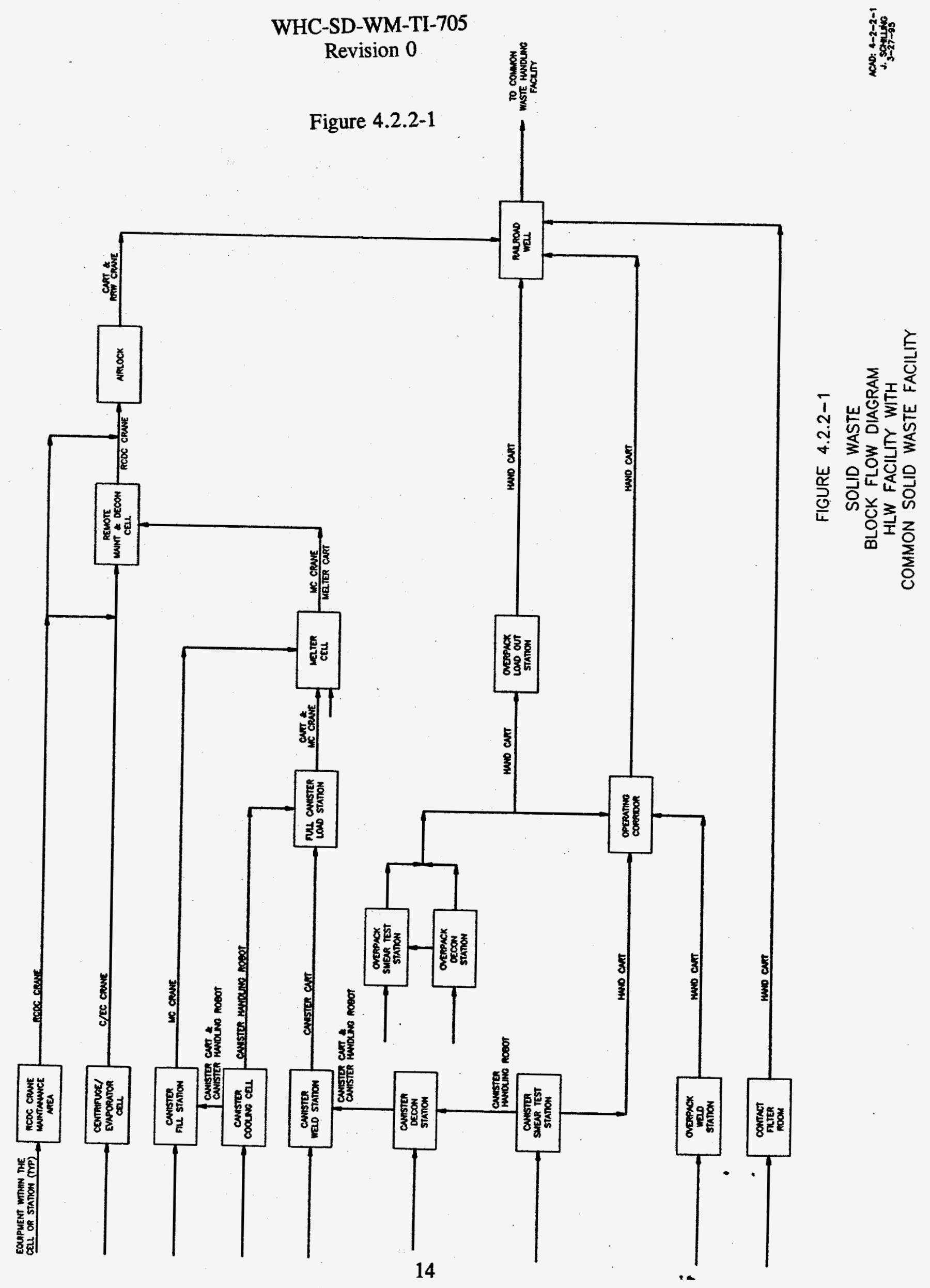




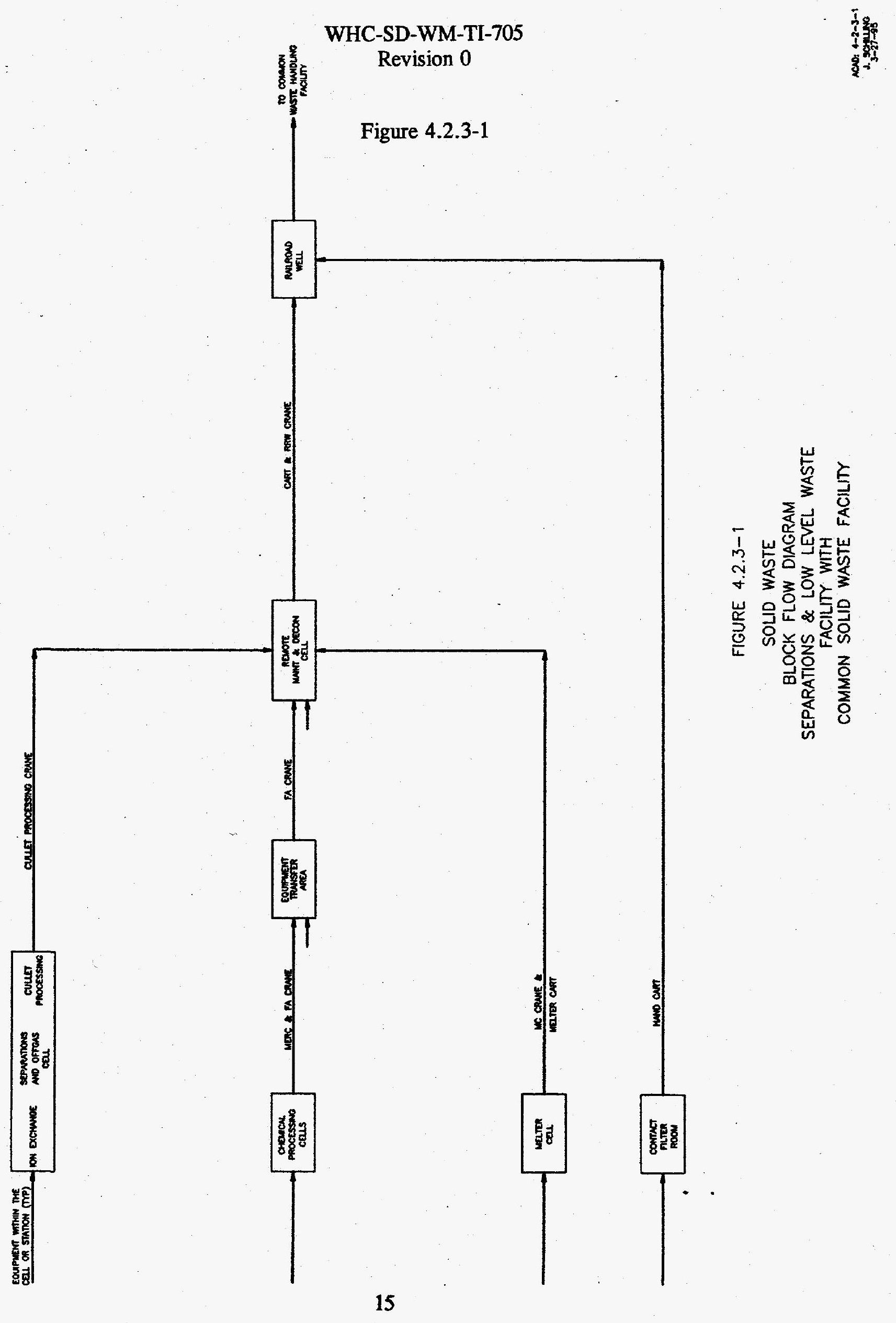


WHC-SD-WM-TI-705

Revision 0

No layout of the Separations/LLW Facility in which solid waste decon, stream segregation, and packaging would occur in a separate facility, has been completed. The changes that would occur to the existing layout of the Separations/LLW Facility are removal of the following areas:

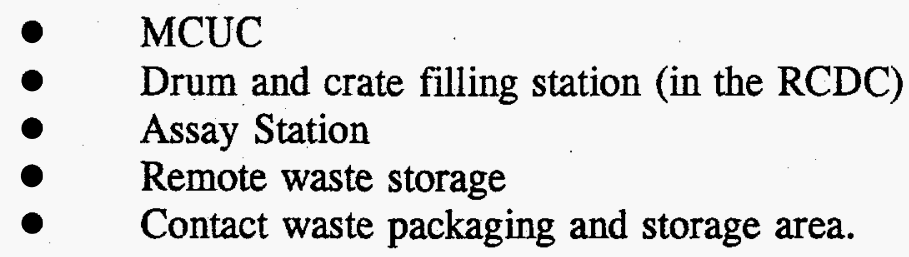

All solid waste removed from the Separations/LLW Facility would pass through the RMDC except some $\mathrm{CH}$ waste which would be moved to the RRW. From the RRW it would be moved to the CSWHF. Some decon of all equipment would occur in the RMDC before moving the equipment to the RRW. In the RRW, the equipment would be placed in containers for movement to the CSWHF. 
WHC-SD-WM-TI-705

Revision 0

\subsection{Discussion of Alternatives}

\subsection{Function and Requirements}

The function and requirements for the two methods of handling the solid waste are the same and that is to meet the requirements of WHC-EP-0063-4, Hanford Site Solid Waste Acceptance Criteria, during operation.

- Comply with all applicable transportation requirements.

- $\quad$ Prepare each radioactive package to comply with packaging requirements in WHC-EP-0063-4, the approved Storage/Disposal Approval Record (SDAR), and any applicable state and federal regulations.

- Minimize the volume and level of radiation in or from solid radioactive waste to the degree economically and technically practicable. This shall be accomplished by source reduction techniques and recycling.

- Minimize contamination of solid radioactive waste with hazardous constituents to the degree economically and technically practicable.

- Develop and implement an auditable waste reduction program to emphasize waste minimization and to prevent the generation of unnecessary waste.

- Segregate to the maximum extent feasible, TRU wastes, LLW, RMW, chemically incompatible wastes, and uncontaminated wastes to facilitate cost effective treatment, storage, and disposal.

- Characterize waste streams with sufficient accuracy to permit proper documentation of types and quantities of radionuclides, hazardous constituents, and physical and chemical characteristics.

- $\quad$ Provide a Solid Waste Storage/Disposal Record (SWSDR) and waste inventory sheet for each waste container.

- Manage radioactive waste in accordance with an approved waste certification plan.

The melters will be the most difficult pieces of equipment to disassemble, cut up, and decontaminate. The melters are refractory lined, large, and heavy. During use, the refractory will crack allowing molten glass to flow into the cracks where it will solidify. Even with purging of the melter with nonradioactive glass, it will be difficult to impossible to remove all of the highlevel glass from the melter.

A big problem with the melter will be if failure occurs and the glass can not be drained. The glass should be segregated from other waste so that it can be recycled back into the product. This could be done with out-of-specification recycled product. 
WHC-SD-WM-TI-705

Revision 0

Waste would be packaged into 55-gallon drums or Standard Waste Boxes (SWB), depending on size reduction potential. However, every attempt will be made to package waste into 55-gallon drums because waste packaged in any other containers will limit TRU assay of waste. With the proposed cut-up equipment located in the cut-up areas, all process equipment should be capable of being reduced in size to fit into 55-gallon drums.

\subsubsection{Handling Solid Waste Within Each Facility}

The advantages of handling solid waste within each facility are:

- Solid waste will be handled fewer times.

- Glass remaining in a removed melter can be recycled into the product without handling outside the vitrification building.

- After the closure of the facilities, the cut-up and decontaminated areas can be used for decontamination and decommissioning (D\&D).

- $\quad$ No large shielding/transport containers for large equipment will be required. This equipment must be decontaminated and smeared externally upon each transfer to and from the common facility.

\subsubsection{Handling Solid Waste At A Common Facility}

- $\quad$ No interference within a cut-up and decon area with maintenance of process equipment.

- $\quad$ No spread of contamination from the cut-up operations to process equipment within a maintenance, decon, and cut-up cell.

\subsection{Assumptions and Uncertainties}

\subsubsection{Assumptions}

- $\quad$ All solid waste will be packaged in accordance the WHC-EP0063-4.

- $\quad$ Solid waste will be packaged in 55-gallon drums when possible. There will be a capability of using other containers in those cases where it may not be possible to reduce the size of an item to fit in a 55-gallon drum.

- The glass in a failed melter can be segregated from other solid waste and that the glass can be recycled in the product recycle system.

- A melter container can be built that will safety transport a failed melter from the HLW or LLW facilities to the CSWHF. 
WHC-SD-WM-TI-705

Revision 0

- The melter and other large equipment containers can be loaded, externally decontaminated, and smeared in the RRW.

- With solid waste being packaged in Separations/LLW and HLW facilities, an additional TWRS solid waste facility will be required for other TWRS solid waste areas.

\subsubsection{Uncertainties}

- Ability to segregate glass from refractories for recycle of glass during cut up and disassembly of a melter.

- The effect on the operating melter of small pieces of refractory mixed in with recycled glass.

\subsection{Summary}

\subsubsection{Process Flow Sheets/Facility Design Impacts}

5.3.1.1 Handling Solid Waste Within Each Facility Requires more space and equipment within the vitrification building.

5.3.1.2 Handling Solid Waste In Common Facility - Requires an additional facility with all of its services (cranes, ventilation, breathing air, etc.).

\subsubsection{Operability Complexity}

Handling solid waste at a common facility is a little more complex in that the equipment must be removed from a vitrification facility and placed in a transfer container.

\subsubsection{Maintainability}

None.

\subsubsection{Maturity of Technology}

None.

\subsubsection{Schedule Impacts}

The requirement for an additional CSWHF should have no impact on the schedule of the Separations/LLW and HLW facilities provided the CSWHF is started at the same time as the Separations/LLW Facility. 
WHC-SD-WM-TI-705

Revision 0

\subsubsection{Regulatory Impacts}

There will be little overall regulatory impacts on the TWRS for the two methods. The reason for this is that the CSWHF will require three operating permits. One for Separations/ LLW, one for HLW, and one for the CSWHF.

Waste handling in each facility will also require three operating permits; one for Separations/LLW, one for HLW, one for HLW, and one for other TWRS facilities.

\subsubsection{Safety}

The only safety concerns between the two methods is in transferring the equipment from the vitrification to the common facility. It is assumed that this can be accomplished safely.

\subsubsection{Costs}

Handling solid waste within the two vitrification facilities and one other facility for other TWRS waste vs. a single common TWRS facility has the following effects on cost:

- Total square footage of buildings is about the same for the two options.

- Handling solid waste within the two vitrification facilities will not require large containers and rail cars to move equipment between facilities and fewer personnel will be required because the solid waste is not required to be handled as often. 
WHC-SD-WM-TI-705

Revision 0

\section{APPENDIX A}

\section{SEPARATIONS/LOW-LEVEL WASTE INVENTORY}


WHC-SD-WM-TI-705

Revision 0

This page intentionally left blank. 
$B=$ STORAGE BIN

CC = TRANSFER CART

CN $=$ CRANE

DE = DEMISTER

DY $=$ DRYER

$E$ = HEATER, CRACKER

EB = CHAMBER, INCINERATOR

EC = CONDENSER, CHILLER, COOLER

EM $=$ MELTER

EV = EVAPORATOR OR CONCENTRATOR

$F=$ FILTER, FRIT FILTER, SCRUB FILTER

$F=$ FILTER, FRIT FILTE

FH $=$ HEPA FILTER

$F M=$ METAL HEPA FILTER

$F P=$ PREFILTER, METAL PREFILTER

Page No. $05 / 22 / 95$

DESC

LLW EVAPORATOR FEED TANK PUMP

LLW Feed Evaporator CONDENSER

LLW Melter Feed Adjustment Tan

D LLW Melter Feed Adjustment Tan TK

$\omega$ LLW Melter Feed Adjustment Tan TK

LLW Mel ter Feed Adjustment Tan

Pump

Pump

Pump

LLW Melter Feed Tank

LWW Melter Feed rank

LiV Melter Feed Tank

LWW Melter Feed Tank

Pump

Pump

Pump

Pump

HEAD BIN

HEAD BIN

ROTARY STAR FEEDER

ROTARY STAR FEEDER

Weigh Feeder

ROTARY STAR FEEDER

ROTARY STAR FEEDER

LLW Mel ter

LLW Melter

Glass Separator

Glass Separator

Quench flume

Quench Flume

Roll Crusher

LLH CULLET CATCH TANK
ABREVIATIONS

EQUIPMENT IDENTIFICATION CODE

FS = SCREEN

$G=$ CENTRIFUGE

LT $=$ IN-CELLL LIGHT

$M=$ ROTARY STAR FEEDER

$M B=$ BLOWER

$M C=$ ROLL CRUSHER

MF $=$ FEEDERS

$M M=$ MIXERS

$M Q=$ QUENCH FLUME

MS = MASTER-SLAVE MANIP

MY = INSPECTIION EQUIPMENT

$P=$ PUMPS

$R=$ ABSORBER, REACTOR, REGENERATOR, REDUCER

RA = MOTORIZED HATCH

I L I S T

CASE 4C, MODIFIED FOR SOLID WASTE STUDY

MTBR TOTAL_WT EQWTEXPOSD

TRUUNIT

TRULO

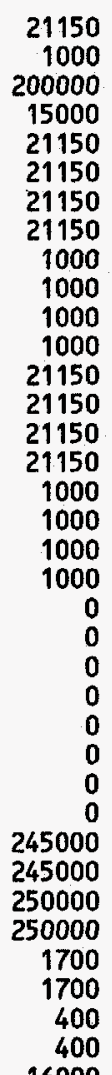

\begin{tabular}{|c|c|c|c|}
\hline $\begin{array}{l}\text { P\&OG-2 } \\
\text { P\&OG-2 } \\
\text { P\&OG-2 } \\
\text { P\&OG-2 } \\
\text { CPC-7 } \\
\text { CPC-6 } \\
\text { CPC-6 } \\
\text { CPC-6 } \\
\text { CPC-7 } \\
\text { CPC-7 } \\
\text { CPC-6 } \\
\text { CPC-6 } \\
\text { CPC-7 } \\
\text { CPC-7. } \\
\text { CPC-6 } \\
\text { CPC-6 } \\
\text { CPC-7 } \\
\text { CPC-7 } \\
\text { CPC-6 } \\
\text { CPC-6 } \\
\text { CDT } \\
\text { CDT } \\
\text { CDT } \\
\text { CDT } \\
\text { CDT } \\
\text { CDT } \\
\text { CDT } \\
\text { CDT } \\
\text { MC-1 } \\
M C-2 \\
\text { MC-1 } \\
\text { MC-2 } \\
\text { MC-1 } \\
\text { MC-2 } \\
\text { MC-1 } \\
\text { MC-2 } \\
\text { MC-1 }\end{array}$ & $\begin{array}{r}5110 \\
1825 \\
5110 \\
5110 \\
5110 \\
5110 \\
5110 \\
5110 \\
1825 \\
1825 \\
1825 \\
1825 \\
5110 \\
5110 \\
5110 \\
5110 \\
1825 \\
1825 \\
1825 \\
1825 \\
5110 \\
5110 \\
365 \\
365 \\
730 \\
730 \\
365 \\
365 \\
923 \\
923 \\
923 \\
923 \\
5110 \\
5110 \\
730 \\
730 \\
5110\end{array}$ & $\begin{array}{r}23500 \\
2000 \\
200000 \\
15000 \\
23500 \\
23500 \\
23500 \\
23500 \\
2000 \\
2000 \\
2000 \\
2000 \\
23500 \\
23500 \\
23500 \\
23500 \\
2000 \\
2000 \\
2000 \\
2000 \\
3100 \\
3100 \\
300 \\
300 \\
1500 \\
1500 \\
300 \\
300 \\
245000 \\
245000 \\
250000 \\
250000 \\
1700 \\
1700 \\
650 \\
650 \\
17750\end{array}$ & $\begin{array}{r}21150 \\
1000 \\
200000 \\
15000 \\
21150 \\
21150 \\
21150 \\
21150 \\
1000 \\
1000 \\
1000 \\
1000 \\
21150 \\
21150 \\
21150 \\
21150 \\
1000 \\
1000 \\
1000 \\
1000 \\
0 \\
0 \\
0 \\
0 \\
0 \\
0 \\
0 \\
0 \\
245000 \\
245000 \\
250000 \\
250000 \\
1700 \\
1700 \\
400 \\
400 \\
16000\end{array}$ \\
\hline
\end{tabular}

17750

16000
RE $=$ - RADIATION COUNTER

$S=$ SEPARATOR (VAPOR/LIQUID)

$S C=$ SCRUBBER

SD $=$ SHIELD DOOR

$S 2=$ WINDOW

$T E=$ TEMPERATURE PROBE

TK $=$ TANKS

$T R=$ TRAP

$T U=$ TURNTABLE

TV $=$ CCTV

WE $=$ TABLE

$\mathrm{XE}=$ PNEUMATIC TRANSFER EQUIP

MTRULOF LLCIUNIT

LLC1LOF

$\begin{array}{lllll}\text { TK } & 400 & 4 & \text { PROG-2 } & 5110 \\ \text { P } & 401 & 4 & \text { PROG-2 } & 1825 \\ \text { EV } & 402 & 4 & \text { PROG-2 } & 5110 \\ \text { EC } & 403 & 4 & \text { PROG-2 } & 5110 \\ \text { TK } & 404 A & 4 & \text { CPC-7 } & 5110 \\ \text { TK } & 404 B & 4 & \text { CPC-6 } & 5110 \\ \text { TK } & 404 C & 4 & \text { CPC-6 } & 5110 \\ \text { TK } & 4040 & 4 & \text { CPC-6 } & 5110 \\ \text { P } & 405 A & 4 & \text { CPC-7 } & 1825 \\ \text { P } & 405 B & 4 & \text { CPC-7 } & 1825 \\ \text { P } & 405 C & 4 & \text { CPC-6 } & 1825 \\ \text { P } & 4050 & 4 & \text { CPC-6 } & 1825 \\ \text { TK } & 406 A & 4 & \text { CPC-7 } & 5110 \\ \text { TK } & 406 B & 4 & \text { CPC-7 } & 5110 \\ \text { TK } & 406 C & 4 & \text { CPC-6 } & 5110 \\ \text { TK } & 4060 & 4 & \text { CPC-6 } & 5110 \\ \text { P } & 407 A & 4 & \text { CPC-7 } & 1825 \\ \text { P } & 407 B & 4 & \text { CPC-7 } & 1825 \\ \text { P } & 407 C & 4 & \text { CPC-6 } & 1825 \\ \text { P } & 407 D & 4 & \text { CPC-6 } & 1825 \\ \text { B } & 408 A & 4 & \text { CDT } & 5110 \\ \text { B } & 408 B & 4 & \text { CDT } & 5110 \\ \text { M } & 409 A & 4 & \text { CDT } & 365 \\ \text { M } & 409 B & 4 & \text { CDT } & 365 \\ \text { MF } & 410 A & 4 & \text { CDT } & 730 \\ \text { MF } & 410 B & 4 & \text { CDT } & 730 \\ \text { M } & 411 A & 4 & \text { CDT } & 365 \\ \text { M } & 411 B & 4 & \text { CDT } & 365 \\ \text { EM } & 412 A & 4 & \text { MC-1 } & 923 \\ \text { EM } & 412 B & 4 & \text { MC-2 } & 923 \\ \text { S } & 413 A & 4 & \text { MC-1 } & 923 \\ \text { S } & 413 B & 4 & \text { MC-2 } & 923 \\ \text { MQ } & 414 A & 4 & \text { MC-1 } & 5110 \\ \text { MQ } & 414 B & 4 & \text { MC-2 } & 5110 \\ \text { MC } & 415 A & 4 & \text { MC-1 } & 730 \\ \text { MC } & 415 B & 4 & \text { MC-2 } & 730 \\ \text { TK } & 416 A & 4 & \text { MC-1 } & 5110 \\ & & & & \end{array}$


Page No. 2

$05 / 22 / 95$

DESC

LLW CULLET CATCH TANK

CONDENSER

CONDENSER

PUMP

COOLER

COOLER

PUMP

LLW QUENCH WATER RECYCLE TANK

LLW QUENCH WATER RECYCLE TANK

screen

PUMP

PUMP.

PUMP

PUMP

LLW FILTER CATCH TANK

LLW FILTER CATCH TANK

LLW Cullet Day Lag Storage

LW Cullet Day Lag Storage

7 CONDENSER

LLW CONDENSATE CATCH TANK

PUMP

HEATER

BLOWER

HEATER

TU SINTERED METAL F

CYCLONE WITH SINTERED METAL FI

ROTARY STAR FEEDER

ROTARY STAR F

DAY BIN

EQID SYS EQUIPNO LOCATION

MTBR TOTAL WT EQWTEXPOSD

MC-1

$M C-1$

$M C-1$

$\mathrm{MC}-2$

P\&OG-1

P\&OG-2

P\&OG-1

P\&OG - 2

P\&OC-1

$P \& O C-2$

$\mathrm{CP}-1$

CP-2

$\mathrm{CP}-1$

$\mathrm{CP}-2$

P\&OG-1

P\&OG-2

P\&OG -

P\&OG - 1 .

P\&OG-2

$\mathrm{CP}-1$

$C P-2$
$C P-1$

$C P-2$

P\&OG-1

P\&OG - 1

CDT

CDT

CDT

CDT

CP-2

$\mathrm{CP}-1$

$C P-2$
$C P-1$

$433 \mathrm{~A}$

434A

CP-2
$17750 \quad 64000$

5110

5110

2500

64000
1250

5110

1825

537
537

537
1825

825

5110

5110

2555

2555

1825

1825

1825

1825

1825

1825
5110
5110

$5110^{\circ}$

5110

5110

5110
5110

5110

1279

4544

4544
1279

4544

5110

5110

365

365
5110

5110

$2000 \quad 1000$

$2000 \quad 1000$

$4500 \quad 2250$

$2000 \quad 1000$

$17750 \quad 16000$

$3530-1765$

$3530 \quad 1765$

$2000-1000$

$2000 \quad 1000$

17750

31000

17000

17000

9500

2000

40000

2000

3500

3500

300

300
5000

5000
TRUUNIT

TRULOF MTRUUNIT

MTRULOF

LLCIUNIT

LLC1LOF

$2000 \quad 1000$

$2000-1000$

0
0
0
0
0
0
0
0
0
0
0
0
0
0
0
0
0
0
0
0
0
0
0
0
0
0
0
0
0
0
0
0
0
0
0
0
0

$\begin{array}{ll}0 & 0 \\ 0 & 0 \\ 0 & 0 \\ 0 & 0 \\ 0 & 0 \\ 0 & 0 \\ 0 & 0 \\ 0 & 0 \\ 0 & 0 \\ 0 & 0 \\ 0 & 0 \\ 0 & 0 \\ 0 & 0 \\ 0 & 0 \\ 0 & 0 \\ 0 & 0 \\ 0 & 0 \\ 0 & 0 \\ 0 & 0 \\ 0 & 0 \\ 0 & 0 \\ 0 & 0 \\ 0 & 0 \\ 0 & 0 \\ 0 & 0 \\ 0 & 0 \\ 0 & 0 \\ 0 & 0 \\ 0 & 0 \\ 0 & 0 \\ 0 & 0 \\ 0 & 0 \\ 0 & 0 \\ 0 & 0 \\ 0 & 0 \\ 0 & 0 \\ 0 & 0 \\ & 0 \\ & 0\end{array}$

0
0
0
0
0
0
0
0
0
0
0
0
0
0
0
0
0
0
0
0
0
0
0
0
0
0
0
0
0
0
0
0
0
0
0
0

1750
1250
1250
990
990
2250
2250
990
990
1750
1750
1765
1765
990
990
990
990
490
490
17750
17750
31000
31000
8500
8500
9500
1990
0
0
0
0
3300
3300
0
0
500
500

1750

1250

1250

2772

21411

2772
2772

1750

1750

3530

3530

2772

2772
2772

2772

17750

0

3300

3300

0

0
500

500

17750 ?

3100吕

31000 o

8500 的

8500 -

$5572=$

0 웅 
Page No. 3

05/22/95

\begin{tabular}{|c|c|c|c|c|c|c|c|}
\hline DESC & EQID & SYS & EQUIPNO & LOCATION & MTBR & TOTAL_WT & EQWTEXPOSD \\
\hline $\begin{array}{l}\text { ROTARY STAR FEEDER } \\
\text { ROTARY STAR FEEDER } \\
\text { RECOVERED SULFUR STORAGE TANK } \\
\text { PUMP } \\
\text { SULFUR CEMENT MIXING TANK } \\
\text { SULFUR CEMENT MIXING TANK } \\
\text { PUMP } \\
\text { PUMP } \\
\text { MIXER } \\
\text { MIXER } \\
\text { SURGE TANK } \\
\text { SURGE TANK } \\
\text { SULFUR PUMP } \\
\text { SULFUR PUMP } \\
\text { DECANTED MOLTEN SULFUR VAULT } \\
\text { DECANTED MOLTEN SULFUR VAULT } \\
\text { HEATER } \\
\text { BLOWER } \\
\text { HEATER } \\
\text { BLOWER } \\
\text { FILTER WASH CATCH TANK } \\
\text { PUMP } \\
\text { CYCLONE WITH SINTERED METAL FI } \\
\text { CYCLONE WITH SINTERED METAL FI } \\
\text { ROTARY STAR FEEDER } \\
\text { ROTARY STAR FEEDER } \\
\text { ROLL CRUSHER } \\
\text { ROLL CRUSHER } \\
\text { RECYCLE CULLET CATCH TANK } \\
\text { RECYCLE CULLET CATCH TANK } \\
\text { PUMP } \\
\text { PUMP } \\
\text { HEATER } \\
\text { HEATER } \\
\text { BLOWER } \\
\text { LLH QUENCH TOWER }\end{array}$ & $\begin{array}{l}M \\
T K \\
P K \\
T K \\
T K \\
P \\
P \\
M M \\
M M \\
T K \\
T K \\
P \\
P \\
T K \\
T K \\
E \\
M B \\
E \\
M B \\
T K \\
A G \\
P \\
F C \\
F C \\
M \\
M \\
M C \\
M C \\
T K \\
T K \\
P \\
P \\
E \\
E \\
M B \\
T\end{array}$ & $\begin{array}{l}435 A \\
435 B \\
436 \\
437 \\
438 A \\
438 B \\
439 A \\
439 B \\
440 A \\
440 B \\
441 A \\
441 B \\
442 A \\
442 B \\
443 A \\
443 B \\
444 A \\
444 A \\
444 B \\
444 B \\
445 A \\
445 A \\
446 \\
500 A \\
500 B \\
501 A \\
501 B \\
502 A \\
502 B \\
503 A \\
503 B \\
504 A \\
504 B \\
505 A \\
505 B \\
505 B \\
609 A\end{array}$ & $\begin{array}{l}4 \\
4 \\
4 \\
4 \\
4 \\
4 \\
4 \\
4 \\
4 \\
4 \\
4 \\
4 \\
4 \\
4 \\
4 \\
4 \\
4 \\
4 \\
4 \\
4 \\
4 \\
4 \\
4 \\
4 \\
4 \\
4 \\
4 \\
4 \\
4 \\
4 \\
4 \\
4 \\
4 \\
4 \\
4 \\
4 \\
4\end{array}$ & $\begin{array}{l}\text { IX-2 } \\
\text { LLCFR } \\
\text { IX-2 } \\
\text { LLCFR } \\
\text { IX-2 } \\
\text { IX-2 } \\
\text { IX-2 } \\
\text { P\&O-1 } \\
\text { P\&OG-2 } \\
\text { P\&OG-1 } \\
\text { P\&OG-2 } \\
\text { PROG-1 } \\
\text { P\&OG-2 } \\
\text { P\&OG-1 } \\
\text { P\&OG-1 } \\
\text { P\&OG-1 } \\
\text { PROG-2 } \\
\text { P\&OG-1 } \\
\text { P\&OG-2 } \\
\text { P\&OG-2 } \\
\text { MC-1 }\end{array}$ & $\begin{array}{r}365 \\
365 \\
5110 \\
1825 \\
5110 \\
5110 \\
1825 \\
1825 \\
731 \\
731 \\
5110 \\
5110 \\
365 \\
365 \\
0 \\
0 \\
1279 \\
4544 \\
1279 \\
4554 \\
5110 \\
731 \\
1825 \\
5110 \\
5110 \\
365 \\
365 \\
730 \\
730 \\
5110 \\
5110 \\
1825 \\
1825 \\
1279 \\
1279 \\
4544 \\
5110\end{array}$ & $\begin{array}{r}300 \\
300 \\
9500 \\
2000 \\
10000 \\
10000 \\
2000 \\
2000 \\
6600 \\
6600 \\
6000 \\
6000 \\
500 \\
500 \\
0 \\
0 \\
1000 \\
28000 \\
1000 \\
28000 \\
9500 \\
5300 \\
2000 \\
5000 \\
5000 \\
300 \\
300 \\
650 \\
650 \\
23500 \\
23500 \\
2000 \\
2000 \\
1000 \\
1000 \\
28000 \\
100000\end{array}$ & $\begin{array}{r}300 \\
300 \\
8550 \\
1000 \\
9000 \\
9000 \\
1000 \\
1000 \\
5000 \\
5000 \\
5400 \\
5400 \\
250 \\
250 \\
0 \\
0 \\
1000 \\
14000 \\
1000 \\
14000 \\
8550 \\
800 \\
1000 \\
4500 \\
4500 \\
225 \\
225 \\
550 \\
550 \\
21150 \\
21150 \\
1000 \\
1000 \\
1000 \\
1000 \\
14000 \\
100000\end{array}$ \\
\hline
\end{tabular}

TRUUNIT.

TRULOF MTRUUNIT

MTRULOF LLCIUNIT

LLC1LOF

STORAGE TANK

SULFUR CEMENT MIXING TANK

SULFUR CEMENT MIXING TANK

MIXER

$D$ CYCLONE WITH SINTERED METAL FI

RECYCLE CULLET CATCH TANK

RECYCLE CULLET CATCH TANK

LLW QUENCH TOWER

0
0
0
0
0
0
0
0
0
0
0
0
0
0
0
0
0
0
0
0
0
0
0
0
0
0
0
0
0
0
0
0
0
0
0
0
0

$\therefore$

0
0
0
0
0
0
0
0
0
0
0
0
0
0
0
0
0
0
0
0
0
0
0
0
0
0
0
0
0
0
0
0
0
0
0
0
0 
Page No. 4

05/22/95

DESC

LLW QUENCH TOWER

COOLER

COOLER Filter Tank

LW Scrub Filter Tank

Pump

Pump

Pump

LLW Scrub Solution Tank

LW Scrub Solution Tank

LLW Venturi Scrubber

LW Venturi Scrubber

LLW Separator

LLW Separator

Chiller

CWI MIST ELIMINATOR

LW MIST ELIMINATOR

SCRUB SOLUTION MAKEUP TANK

Pump

HEATER

BLOWER

HEATER
BLOWER

I BEATER

BLOWER

PUMP

MELTER OFFGAS HEAT EXCHANGER

Heater
S02 Absorber

Heater

NOx Catalytic Reactor

SULFATE REDUCTION

NH3 Cracker

SO2 ABS. REGEN.

Claus Sulfur Plant

$\begin{array}{llllrrr}\text { EQID } & \text { SYS } & \text { EQUIPNO } & \text { LOCATION } & \text { MTBR } & \text { TOTAL_WT } & \text { EQWTEXPOSD } \\ \text { T } & 6098 & 4 & \text { MC-2 } & 5110 & 100000 & 100000 \\ \text { EC } & 610 A & 4 & \text { MC-1 } & 5110 & 18000 & 18000 \\ \text { EC } & 610 B & 4 & \text { MC-1 } & 5110 & 18000 & 18000 \\ \text { TK } & 611 & 4 & \text { P\&OG-2 } & 5110 & 8325 & 7500 \\ \text { P } & 612 A & 4 & \text { MC-1 } & 1825 & 2000 & 1000 \\ \text { P } & 612 B & 4 & \text { MC-2 } & 1825 & 2000 & 1000 \\ \text { P } & 613 A & 4 & \text { MC-1 } & 1825 & 3000 & 1500 \\ \text { P } & 613 B & 4 & \text { MC-2 } & 1825 & 3000 & 1500 \\ \text { TK } & 614 A & 4 & \text { MC-1 } & 5110 & 23500 & 21150 \\ \text { TK } & 614 B & 4 & \text { MC-2 } & 5110 & 23500 & 21150 \\ \text { SC } & 615 A & 4 & \text { MC-1 } & 5110 & 3000 & 3000 \\ \text { SC } & 615 B & 4 & \text { MC-2 } & 5110 & 3000 & 3000 \\ \text { S } & 616 A & 4 & \text { MC-1 } & 5110 & 2000 & 2000 \\ \text { S } & 616 B & 4 & \text { MC-2 } & 5110 & 2000 & 2000 \\ \text { EC } & 617 A & 4 & \text { MC-1 } & 5110 & 1700 & 1700 \\ \text { EC } & 617 B & 4 & \text { MC-2 } & 5110 & 1700 & 1700 \\ \text { DE } & 618 A & 4 & \text { MC-1 } & 5110 & 4000 & 3600 \\ \text { DE } & 618 B & 4 & \text { MC-2 } & 5110 & 4000 & 3600 \\ \text { TK } & 619 & 4 & \text { CDT } & 5110 & 1250 & 0 \\ \text { P } & 620 & 4 & \text { P\&OG-2 } & 1825 & 2000 & 1000 \\ \text { E } & 625 A & 4 & \text { CP-1 } & 1279 & 1000 & 1000 \\ \text { MB } & 625 A & 4 & \text { LLCFR } & 4544 & 6000 & 3000 \\ \text { E } & 625 B & 4 & \text { CP-1 } & 1279 & 1000 & 1000 \\ \text { MB } & 625 B & 4 & \text { LLCFR } & 4544 & 6000 & 3000 \\ \text { E } & 625 C & 4 & \text { CP-1 } & 1279 & 1000 & 1000 \\ \text { MB } & 625 C & 4 & \text { LLCFR } & 4544 & 6000 & 3000 \\ \text { P } & 627 & 4 & \text { CTA } & 1825 & 2000 & 1000 \\ \text { EC } & 628 & 4 & \text { LLCFR } & 5110 & 8500 & 8500 \\ \text { E } & 629 & 4 & \text { LLCFR } & 1279 & 3000 & 3000 \\ \text { R } & 630 & 4 & \text { LLCFR } & 5110 & 4000 & 4000 \\ \text { E } & 631 & 4 & \text { LLCFR } & 1279 & 2000 & 2000 \\ \text { R } & 632 & 4 & \text { LLCFR } & 5110 & 16000 & 16000 \\ \text { R } & 633 & 4 & \text { LLCFR } & 5110 & 3500 & 3500 \\ \text { E } & 634 & 4 & \text { LLCFR } & 5110 & 8000 & 8000 \\ \text { R } & 635 & 4 & \text { LLCFR } & 5110 & 4000 & 4000 \\ \text { EC } & 636 & 4 & \text { LLCFR } & 5110 & 5000 & 5000 \\ \text { CL } & 650 & 4 & \text { LLCFR } & 5110 & 4000 & 4000 \\ & & & & & & \end{array}$

TRUUNIT

TRULOF

MTRULOF

LLCIUNIT

LLC1LOF

0

0
825

825
2772

2772

4172

4350

2350

2350

2350

0

0
0
0

400

400

990

0
6000
0

0
6000

0
6000
1990

8500

3000

4000

2000

16000

3500

8000

4000

5000
0 
Page No. 5

05/22/95

\begin{tabular}{|c|c|c|c|c|c|c|c|c|c|c|c|c|c|}
\hline DESC & EQID & SYS & EQUIPNO & LOCATION & MTBR & TOTAL_WT & EQWTEXPOSD & TRUUNIT & TRULOF & MTRUUUNIT & MTRULOF & LLCIUNIT & LLC1LOF \\
\hline 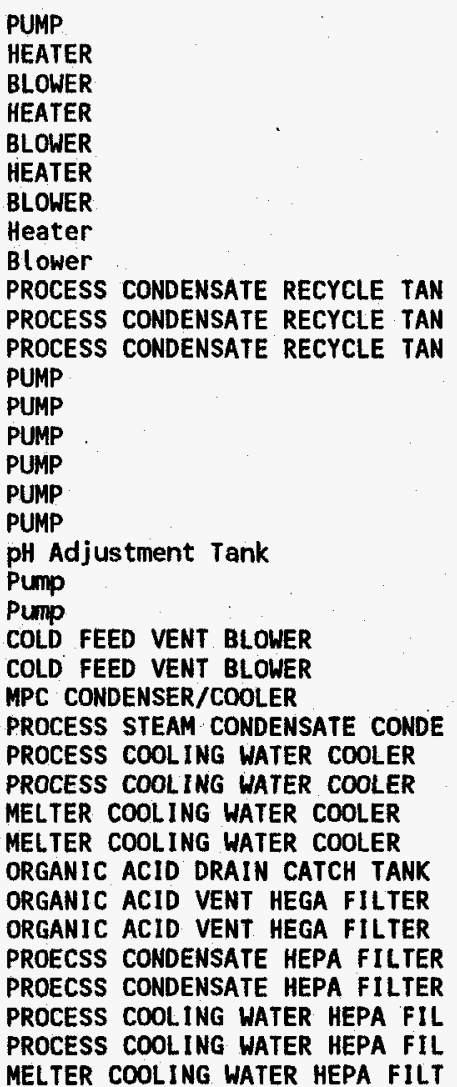 & $\begin{array}{l}P \\
E \\
M B \\
E \\
M B \\
E \\
M B \\
E \\
M B \\
T K \\
T K \\
T K \\
P \\
P \\
P \\
P \\
P \\
P \\
T K \\
P \\
P \\
M B \\
M B \\
E C \\
E C \\
E C \\
E C \\
E C \\
E C \\
F G \\
F G \\
F G \\
F H \\
F H \\
F H \\
F H \\
F H\end{array}$ & $\begin{array}{l}651 \\
700 \mathrm{~A} \\
700 \mathrm{~A} \\
700 \mathrm{~B} \\
700 \mathrm{~B} \\
701 \mathrm{~A} \\
701 \mathrm{~A} \\
701 \mathrm{~B} \\
701 \mathrm{~B} \\
800 \mathrm{~A} \\
800 \mathrm{~B} \\
800 \mathrm{C} \\
801 \mathrm{~A} \\
801 \mathrm{~B} \\
801 \mathrm{C} \\
802 \mathrm{~A} \\
802 \mathrm{~B} \\
802 \mathrm{C} \\
803 \\
804 \\
805 \\
1100 \mathrm{~A} \\
1100 \mathrm{~B} \\
1101 \\
1102 \\
1103 \mathrm{~A} \\
1103 \mathrm{~B} \\
1104 \mathrm{~A} \\
1104 \mathrm{~B} \\
1105 \\
1106 \mathrm{~A} \\
1106 \mathrm{~B} \\
1107 \mathrm{~A} \\
1107 \mathrm{~B} \\
1108 \mathrm{~A} \\
1108 \mathrm{~B} \\
1109 \mathrm{~A}\end{array}$ & $\begin{array}{l}4 \\
4 \\
4 \\
4 \\
4 \\
4 \\
4 \\
4 \\
4 \\
4 \\
4 \\
4 \\
4 \\
4 \\
4 \\
4 \\
4 \\
4 \\
4 \\
4 \\
4 \\
4 \\
4 \\
4 \\
4 \\
4 \\
4 \\
4 \\
4 \\
4 \\
4 \\
4 \\
4 \\
4 \\
4 \\
4 \\
4\end{array}$ & $\begin{array}{l}\text { CDT } \\
\text { P\&OG-1 } \\
\text { LLCFR } \\
\text { P\&OC-1 } \\
\text { LLCFR } \\
\text { IX-1 } \\
\text { LLCFR } \\
\text { IX-1 } \\
\text { LLCFR } \\
\text { CCF } \\
\text { CCF } \\
\text { CCF } \\
\text { CCF } \\
\text { CCF } \\
\text { CCF } \\
\text { CCF } \\
\text { CCF } \\
\text { CCF } \\
\text { CCF } \\
\text { CCF } \\
\text { CCF } \\
\text { VBC } \\
\text { VBC } \\
\text { VBC } \\
\text { VBC } \\
\text { VBC } \\
\text { VBC } \\
\text { VBC } \\
\text { VBC } \\
\text { CTA } \\
\text { VBC } \\
\text { VBC } \\
\text { VBC } \\
\text { VBC } \\
\text { VBC } \\
\text { VBC } \\
\text { VBC }\end{array}$ & $\begin{array}{l}1825 \\
1279 \\
4544 \\
1279 \\
4544 \\
1279 \\
4544 \\
1279 \\
4544 \\
5100 \\
5100 \\
5100 \\
1825 \\
1825 \\
1825 \\
1825 \\
1825 \\
1825 \\
5110 \\
1825 \\
1825 \\
4540 \\
4540 \\
5110 \\
5110 \\
5110 \\
5110 \\
5110 \\
5110 \\
731 \\
731 \\
731 \\
731 \\
731 \\
731 \\
731 \\
731\end{array}$ & $\begin{array}{r}200 \\
200 \\
5300 \\
200 \\
5300 \\
600 \\
7200 \\
600 \\
7200 \\
0 \\
0 \\
0 \\
2000 \\
2000 \\
2000 \\
8000 \\
8000 \\
8000 \\
0 \\
8000 \\
8000 \\
600 \\
600 \\
4500 \\
10000 \\
29000 \\
29000 \\
5100 \\
5100 \\
300 \\
300 \\
300 \\
1000 \\
1000 \\
400 \\
400 \\
600\end{array}$ & $\begin{array}{r}100 \\
200 \\
2650 \\
200 \\
2650 \\
600 \\
3600 \\
600 \\
3600 \\
0 \\
0 \\
0 \\
1000 \\
1000 \\
1000 \\
4000 \\
4000 \\
4000 \\
0 \\
4000 \\
4000 \\
300 \\
300 \\
0 \\
0 \\
0 \\
0 \\
0 \\
0 \\
0 \\
0 \\
0 \\
0 \\
0 \\
0 \\
0 \\
0\end{array}$ & $\begin{array}{l}0 \\
0 \\
0 \\
0 \\
0 \\
0 \\
0 \\
0 \\
0 \\
0 \\
0 \\
0 \\
0 \\
0 \\
0 \\
0 \\
0 \\
0 \\
0 \\
0 \\
0 \\
0 \\
0 \\
0 \\
0 \\
0 \\
0 \\
0 \\
0 \\
0 \\
0 \\
0 \\
0 \\
0 \\
0 \\
0 \\
0\end{array}$ & $\begin{array}{l}0 \\
0 \\
0 \\
0 \\
0 \\
0 \\
0 \\
0 \\
0 \\
0 \\
0 \\
0 \\
0 \\
0 \\
0 \\
0 \\
0 \\
0 \\
0 \\
0 \\
0 \\
0 \\
0 \\
0 \\
0 \\
0 \\
0 \\
0 \\
0 \\
0 \\
0 \\
0 \\
0 \\
0 \\
0 \\
0 \\
0\end{array}$ & $\begin{array}{l}0 \\
0 \\
0 \\
0 \\
0 \\
0 \\
0 \\
0 \\
0 \\
0 \\
0 \\
0 \\
0 \\
0 \\
0 \\
0 \\
0 \\
0 \\
0 \\
0 \\
0 \\
0 \\
0 \\
0 \\
0 \\
0 \\
0 \\
0 \\
0 \\
0 \\
0 \\
0 \\
0 \\
0 \\
0 \\
0 \\
0\end{array}$ & $\begin{array}{l}0 \\
0 \\
0 \\
0 \\
0 \\
0 \\
0 \\
0 \\
0 \\
0 \\
0 \\
0 \\
0 \\
0 \\
0 \\
0 \\
0 \\
0 \\
0 \\
0 \\
0 \\
0 \\
0 \\
0 \\
0 \\
0 \\
0 \\
0 \\
0 \\
0 \\
0 \\
0 \\
0 \\
0 \\
0 \\
0 \\
0\end{array}$ & $\begin{array}{r}0 \\
0 \\
5300 \\
0 \\
2650 \\
0 \\
7200 \\
0 \\
7200 \\
0 \\
0 \\
0 \\
2000 \\
2000 \\
2000 \\
8000 \\
8000 \\
8000 \\
0 \\
8000 \\
8000 \\
0 \\
0 \\
0 \\
0 \\
0 \\
0 \\
0 \\
0 \\
0 \\
300 \\
0 \\
0 \\
0 \\
0 \\
0 \\
0 \\
0\end{array}$ & $\begin{array}{r}0 \\
0 \\
5960 \\
0 \\
2980 \\
0 \\
8097 \\
0 \\
8097 \\
0 \\
0 \\
0 \\
5600 \\
5600 \\
5600 \\
22400 \\
22400 \\
22400 \\
0 \\
22400 \\
22400 \\
0 \\
0 \\
0 \\
0 \\
0 \\
0 \\
0 \\
0 \\
0 \\
0 \\
2097 \\
0 \\
0 \\
0 \\
0 \\
0 \\
0 \\
0\end{array}$ \\
\hline
\end{tabular}


Page No. 6

$05 / 22 / 95$

DESC

EQID SYS EQUIPNO LOCATION

MTBR TOTAL_WT EQWTEXPOSD

$\begin{array}{lll}11098 & 4 & \text { VBC } \\ 1110 & 4 & \text { CTA }\end{array}$

MELTER COOLING WATER HEPA FILT FH FLOOR DRAIN CATCH TANK HEPA FI FH REGULATED DRAINS CATCH TANK HE FH LIOUID WASTE COLLECTION HEPA F FH ORGANIC ACID DRAIN CATCH TANK

FLOOR DRAIN HEPA FILTER

FLOR DRAIN HEPA FIITER

FLOOR DRAIN HEPA FILTER

FLOR DRAIN MEPA FILTER

FLOOR DRAIN HEPA FILTER

LIQUID WASTE COLLECTION HEPA F

COLD FEED VENT HEPA FILTER

VIT BLDG HPS VAC SYSTEM HEPA F FH

VIT BLDG HPS VAC SYSTEM HEPA F FH

VIT BLDG HPS VAC SYSTEM HEPA F FH

VIT BLDG HPS VAC SYSTEM HEPA F FH

VIT BLDG HPS VAC SYSTEM HEPA F FH

$\begin{array}{llll}\text { VIT BLDG HPS VAC SYSTEM HEPA F } & F H \\ \text { VIT BLDG HPS VAC SYSTEM HEPA F } & \text { FH } \\ & \end{array}$

VIT BLDG HPS VAC SYSTEM HEPA F FH

OFF-GAS TREATMENT CHEMICAL FEE FL

COLD CHEMICAL TANK ROUGHING FI FL

COLD CHEMICAL TANK ROUGHING FI FL

COLD CHEMICAL TANK ROUGHING FI FL

ELECTRIC PROCESS STEAM GENERAT EV

ELECTRIC PROCESS STEAM GENERAT

ELECTRIC PROCESS STEAM GENERAT

ELECTRIC PROCESS STEAM GENERAT

STANDBY ELECTRIC HEATER

EDY ELCTRIC HEATER

STANDBY ELECTRIC HEATER

PROCESS STEAM GENERATOR CIRCUL

PROCESS STEAM GENERATOR CIRCUI

OEST

PROCESS STEAM GENERATOR CIRCUL

$$
\begin{aligned}
& 1109 \\
& 1110 \\
& 1111 \\
& 1112 \\
& 1113 \\
& 1114 \\
& 1114 \\
& 1114 \\
& 1114 \\
& 1115 \\
& 1116 \\
& 1117 \mathrm{~A} \\
& 1117 \\
& 1118 \mathrm{~A} \\
& 1118 \\
& 1118 \mathrm{C} \\
& 1118 \\
& 1118 \\
& 1118 \\
& 1118 \\
& 1118 \\
& 1120 \\
& 1121 \\
& 1122 \\
& 1123 \\
& 1124 \mathrm{~A} \\
& 1124 \\
& 1124 \\
& 1124 \\
& 1125 \mathrm{~A} \\
& 1125 \\
& 1125 \\
& 1125 \\
& 1127 \mathrm{~A} \\
& 1127 \\
& 1127 \\
& 11270
\end{aligned}
$$

1110

CTA

2.4 CTA

CTA

$\begin{array}{ll}1114 C & 4\end{array}$

$\begin{array}{ll}1115 & 4\end{array}$ CTA

$\begin{array}{lll}116 & 4 & \text { CTA }\end{array}$

VBC

VBC

1118A 4

$4118 \mathrm{C}$

11180

$118 \mathrm{E}$

(118F

$1118 \mathrm{H}$

1120

1121

1123

$1124 \mathrm{~B}$

$124 \mathrm{C}$

11240

1125A

$1125 \mathrm{~B}$

$1125 \mathrm{C}$

$1127 \mathrm{~A}$

$1127 \mathrm{~B}$

$\begin{array}{ll}1127 \mathrm{C} & 4 \\ 11270 & 4\end{array}$

$\begin{array}{rr}731 & 600 \\ 731 & 500 \\ 731 & 500 \\ 731 & 500 \\ 731 & 500 \\ 731 & 500 \\ 731 & 500 \\ 731 & 500 \\ 731 & 500 \\ 731 & 500 \\ 731 & 500 \\ 731 & 500 \\ 731 & 500 \\ 731 & 750 \\ 731 & 750 \\ 731 & 750 \\ 731 & 750 \\ 731 & 750 \\ 731 & 750 \\ 731 & 750 \\ 731 & 750 \\ 731 & 500 \\ 731 & 500 \\ 731 & 500 \\ 731 & 500 \\ 0 & 52000 \\ 0 & 52000 \\ 0 & 52000 \\ 0 & 52000 \\ 0 & 200 \\ 0 & 200 \\ 0 & 200 \\ 0 & 200 \\ 1825 & 500 \\ 1825 & 500 \\ 1825 & 500 \\ 1825 & 500\end{array}$

TRUUNIT

TRULOF MTRUUNIT

MTRULOF

LLCIUNIT

LLC1LOF 
Page No. 05/22/95

\section{DESC}

PROCESS STEAM GENERATOR CIRCUL PROCESS STEAM GENERATOR CIRCUL PROCESS STEAM GENERATOR CIRCUL PROCESS STEAM GENERATOR CIRCUL BOILER FEED WATER CHEMICAL INJ BOILER FEED WATER CHEMICAL. INJ BOILER FEED WATER CHEMICAL INJ BOILER FEED WATER CHEMICAL INJ BLOWDOWN DRUM

BLOWDOWN DRUM

BLOWDOWN DRUM

CHEMICAL ADDITION TANK

CHEMICAL ADDITION TANK

CHEMICAL ADDITIOU TAUK

CHEMICAL ADDITION TANK

MPC COLLECTION TANK PUMP

MPC COLLECTION TANK PUMP

PROCESS CONDENSATE PUMP

PROCESS CONDENSATE PUMP

PROCESS COOLING WATER PUMP

PROCESS COOLING WATER PUMP

MELTER COOLING WATER PUMP

MELTER COOLING WATER PUMP

7 FLOOR DRAIN CATCH TANK TRANSFE

FLOOR DRAIN CATCH TANK SUMP PU REGULATED DRAINS CATCH TANK TR ACID DRAIN CATCH TANK TRANSFER ACID DRAIN CATCH TANK SUMP PUM ORGANIC ACID DRAIN CATCH TANK ORGANIC ACID DRAIN CATCH TANK REGULATED DRAINS CATCH TANK SU FLOOR DRAIN SAMPLING TANK TRAN 40\% NaNO2 FEED PUMP

COLD CHEMICAL FEED PUMP

COLD CHEMICAL FEED PUMP

COLD CHEMICAL FEED PUMP

OFFGAS TREATMENT CHEMICAL FEED

EQ
$P$
$P$
$P$
$P$
$P$
$P$
$P$
$P$
$P$
$P$
$T K$
$T K$
$T K$
$T K$
$T K$
$T K$
$T K$
$T K$
$T K$
$P$
$P$
$P$
$P$
$P$
$P$
$P$
$P$
$P$
$P$
$P$
$P$
$P$
$P$
$P$
$P$
$P$
$P$
$P$
$P$
$P$
$P$
$P$
$P$
$P$
$P$

EQUIPNO LOCATION

$\begin{array}{ll}1127 \mathrm{E} & 4 \\ 1127 \mathrm{~F} & 4 \\ 1127 \mathrm{G} & 4 \\ 1127 \mathrm{H} & 4 \\ 1128 \mathrm{~A} & 4 \\ 1128 \mathrm{~B} & 4 \\ 1128 \mathrm{C} & 4 \\ 1128 \mathrm{D} & 4 \\ 1129 \mathrm{~A} & 4 \\ 1129 \mathrm{~B} & 4 \\ 1129 \mathrm{C} & 4 \\ 1129 \mathrm{D} & 4 \\ 1130 \mathrm{~A} & 4 \\ 1130 \mathrm{~B} & 4 \\ 1130 \mathrm{C} & 4 \\ 1130 \mathrm{D} & 4 \\ 1136 & 4 \\ 1137 \mathrm{~A} & 4 \\ 1137 \mathrm{~B} & 4 \\ 1138 \mathrm{~A} & 4 \\ 1138 \mathrm{~B} & 4 \\ 1139 \mathrm{~A} & 4 \\ 1139 \mathrm{~B} & 4 \\ 1140 & 4 \\ 1141 & 4 \\ 1142 & 4 \\ 1143 & 4 \\ 1144 & 4 \\ 1145 & 4 \\ 1146 & 4 \\ 1147 & 4 \\ 1148 & 4 \\ 1160 & 4 \\ 1170 & 4 \\ 1171 & 4 \\ 1172 & 4 \\ 1173 & 4 \\ 113 & 4\end{array}$
MTBR

1825

1825

1825

1825

1825

1825

1825

5110

5110

5110

5110

5110

5110

5110

1825

1825
1825

1825

1825

1825
1825

1825

1825

1825

1825

1825

1825

1825
1825

1825

1825

1825

1825

1825

1825
TOTAL_WT EQWTEXPOSD

500
500
500
500
100
100
100
100
1000
1000
1000
1000
625
625
625
625
150
1200
1200
7500
7500
1000
1000
1500
2500
2500
2500
1400
2500
1400
1400
1500
350
200
200
200
200
6

0
0
0
0
0
0
0
0
0
0
0
0
0
0
0
0
0
0
0
0
0
0
0
1500
2500
2500
2500
1400
2500
1400
1400
1500
0
0
0
0
0

TRUUNIT

TRULOF MTRUUNIT

MTRULOF

LLCIUNIT

LLC1LOF 
Page No. 8

$05 / 22 / 95$

DESC

EQID SYS EQUIPNO LOCATION

MTBR

TOTAL_WT EQWTEXPOSD

TRUUNIT

TRULOF MTRUUNIT

MTRULOF LLC1UNIT

LLC1LOF

50\% NITRIC ACID FEED PUMP NITRIC ACID DECON FEED PUMP

OXALIC ACID DECON FEED PUMP

$50 \%$ CAUSTIC FEED PUMP

PROCESS WATER BOOSTER PUMP ANT IFOAM FEED PUMP

ANTIFOAM FEED PUMP

ANTI FOAM FEED PUMP

ANTIFOAM FEED PUMP

ANTIFOAM FEED PUMP

ACID DRAIN CATCH TANK SUMP

ORGANIC ACID DRAIN CATCH TANK

FLOOR DRAIN CATCH TANK SUMP

REGULATED DRAINS CATCH TANK SU

MPC FLASH DRUM

MPC COLLECTION TANK

PROCESS CONDENSATE COLLECTION

PROCESS COOLING WATER EXPANSIO.

MELTER COOLING WATER EXPANSION

LOW PRESSURE PROCESS WATER TAN

FLOOR DRAIN CATCH TANK

7 REGULATED DRAINS CATCH TANK

$\stackrel{5}{\circ}$ ORGANIC ACID DRAIN CATCH TANK

FLOOR DRAIN SAMPLING TANK

40\% NaNO2 FEED TANK

COLD CHEMICAL FEED TANK

COLD CHEMICAL FEED TANK

50\% CITRIC L FEED TANK

NITRIC ACID DECON FEED TANK

NITRIC ACID DECON FEED TANK

OXALIC ACID DECON FEED TANK
POTASSIUM PERMANGANATE FEED TA

$50 \%$ CAUSTIC FEED TANK

$1175 \quad 4 \quad$ VBC

200
1000

$1825 \quad 1000$

$1825 \quad 200$

$\begin{array}{ll}1825 & 200 \\ 1825 & 300\end{array}$

$1825 \quad 200$

1825200

$1825-200$

$\begin{array}{ll}1825 & 200 \\ 1825 & 200\end{array}$

1182C 4 VBC

$1182 \mathrm{E} 4 \mathrm{VBC}$

su. 1183

1184
1185

FLUSH WATER FEED TANK

OFF-GAS TREATMENT CHEMICAL FEE TK 
Page No.

05/22/95

\section{DESC}

VIT BLOG HPS VACUUM BLOWER

VIT BLDG UPS VACUUM BLOUER

COLD CHEMICAL TANK ROUGHING FI

PROCESS WATER CHILLER

CULLET PNEU. TRANSFER SYSTEM

CULLET PNEU. TRANSFER SYSTEM

CULLET PNEU. TRANSFER SYSTEM

CULLET PNEU. TRANSFER SYSTEM

CEMENT RECYCLE PUMP

CEMENT RECYCLE PUMP

CEMENT RECYCLE PUMP

CEMENT RECYCLE PUMP

CEMENT RECYCLE PUMP

DUMP

CEMENT RECYCLE PUMP

CEMENT RECYCLE PUMP

CEMENT RECYCLE PUMP

CEMENT RECYCLE PUMP

CEMENT RECYCLE PUMP

CEMENT RECYCLE PUMP

CEMENT RECYCLE PUMP

CEMENT RECYCLE PUMP

$D$ CEMENT RECYCLE PUMP

CEMENT RECYCLE PUMP

CEMENT RECYCLE PUMP

CEMENT RECYCLE PUMP

CEMENT RECYCLE PUMP

CEMENT RECYCLE PUMP

CEMENT RECYCLE PUMP

CEMENT RECYCLE PUMP

CEMENT RECYCLE PUMP

CEMENT RECYCLE PUMP

CEMENT RECYCLE PUMP

CEMENT RECYCLE PUMP

CEMENT RECYCLE PUMP

CEMENT RECYCLE PUMP

CEMENT RECYCLE PUMP

$\begin{array}{llllrrrr}\text { EQID } & \text { SYS } & \text { EQUIPNO } & \text { LOCATION } & \text { MTBR } & \text { TOTAL_WT } & \text { EQWTEXPOSD } & \text { TRUUNIT } \\ \text { MB } & 1213 A & 4 & \text { VBC } & 4544 & 1800 & 0 & 0 \\ \text { MB } & 1213 B & 4 & \text { VBC } & 4544 & 1800 & 0 & 0 \\ \text { FL } & 1214 & 4 & \text { VBC } & 5110 & 750 & 0 & 0 \\ \text { EC } & 1215 & 4 & \text { VBC } & 0 & 0 & 0 & 0 \\ X E & 2001 A & 4 & \text { CP-1 } & 5110 & 15000 & 10000 & 0 \\ X & 2002 A & 4 & \text { CP-1 } & 5110 & 20000 & 13000 & 0 \\ \text { XE } & 2001 B & 4 & \text { CP-2 } & 5110 & 15000 & 10000 & 0 \\ X & 2002 B & 4 & \text { CP-2 } & 5110 & 20000 & 13000 & 0 \\ P & 2646 & 4 & \text { VA } & 5110 & 500 & 250 & 0 \\ P & 2647 & 4 & \text { VA } & 5110 & 500 & 250 & 0 \\ P & 2648 & 4 & \text { VA } & 5110 & 500 & 250 & 0 \\ P & 2649 & 4 & \text { VA } & 5110 & 500 & 250 & 0 \\ P & 2650 & 4 & \text { VA } & 5110 & 500 & 250 & 0 \\ P & 2651 & 4 & \text { VA } & 5110 & 500 & 250 & 0 \\ P & 2652 & 4 & \text { VA } & 5110 & 500 & 250 & 0 \\ P & 2653 & 4 & \text { VA } & 5110 & 500 & 250 & 0 \\ P & 2654 & 4 & \text { VA } & 5110 & 500 & 250 & 0 \\ P & 2655 & 4 & \text { VA } & 5110 & 500 & 250 & 0 \\ P & 2656 & \text { VA } & 5110 & 500 & 250 & 0 \\ P & 2656 & 4 & \text { VA } & 5110 & 500 & 250 & 0 \\ P & 2657 & 4 & \text { VA } & 5110 & 500 & 250 & 0 \\ P & 2658 & 4 & \text { VA } & 500 & 250 & 0 \\ P & 2659 & 4 & \text { VA } & 5110 & 500 & 0 \\ P & 2660 & 4 & \text { VA } & 5110 & 500 & 250 & 0 \\ P & 2661 & 4 & \text { VA } & 5110 & 500 & 250 & 0 \\ P & 2662 & 4 & \text { VA } & 5110 & 500 & 250 & 0 \\ P & 2663 & 4 & \text { VA } & 5110 & 500 & 250 & 0 \\ P & 2664 & 4 & \text { VA } & 5110 & 500 & 250 & 0 \\ P & 2665 & 4 & \text { VA } & 5110 & 500 & 250 & 0 \\ P & 2666 & 4 & \text { VA } & 5110 & 500 & 250 & 0 \\ P & 2667 & 4 & \text { VA } & 5110 & 500 & 250 & 0 \\ P & 2668 & 4 & \text { VA } & 5110 & 500 & 250 & 0 \\ P & 2669 & 4 & \text { VA } & 5110 & 500 & 250 & 0 \\ P & 2670 & 4 & \text { VA } & 5110 & 500 & 250 & 0 \\ P & 2671 & 4 & \text { VA } & 5110 & 500 & 250 & 0 \\ P & 2672 & 4 & \text { VA } & 5110 & 500 & 250 & 0 \\ P & 2673 & 4 & \text { VA } & 5110 & 500 & 250 & 0 \\ P & 2674 & 4 & \text { VA } & 5110 & 500 & 250 & 0 \\ & & & & & & & \end{array}$

TRULOF MTRUUNIT

MTRULOF

LLCIUNIT

LLC1LOF

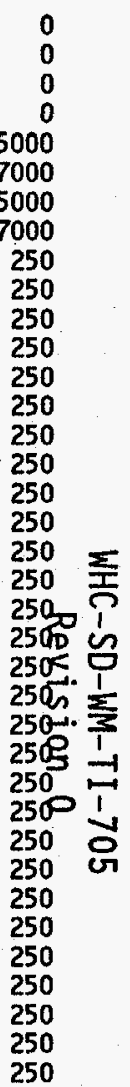


Page No.

05/22/95

DESC

EQID SYS EQUIPNO LOCATION

CEMENT RECYCLE PUMP CEMENT RECYCLE PUMP CEMENT RECYCLE PUMP CEMENT RECYCLE PUMP CEMENT RECYCLE PUMP CEMENT RECYCLE PUMP CEMENT RECYCLE PUMP CEMENT RECYCLE PUMP CEMENT RECYCLE PUMP CEMENT RECYCLE PUMP CEMENT RECYCLE PUMP CEMENT RECYCLE PUMP CEMENT RECYCLE PUMP CEMENT RECYCLE PUMP CEMENT RECYCLE PUMP CEMENT RECYCLE PUMP CEMENT RECYCLE PUMP CEMENT RECYCLE PUMP PUMP

First stage Settling Tank Second Stage Settling Tank First Wash Tank

Supernatant Accumulation Tank

$\mapsto$ Supernatant Sample and Transfe LLW Feed Accum Wash Solution Accumulation Tan HLW Feed Accumulation Tank LLW Feed Accumulation Tank Wash solution Transfer Tar HLW Feed Transfer Tank Condenser

Sondenser Cs IX Concentrator

Frit filter

Cartridge Filter
MTBR TOTAL WT EQWTEXPOSD

$5110 \quad 500$

5110

5110

5110

5110
5110

5110

5110

5110

5110

5110

5110

5110
5110

5110

5110

5110

5110

VA

IX-2

P\&OG-2

P\&OG- 1

P\&OG-2

P\&OG-1
CPC-1
TRUUNIT

TRULOF MTRUUNIT

MTRULOF LLCIUNIT

LLC1LOF

$\begin{array}{rr}500 & 250 \\ 500 & 250 \\ 500 & 250 \\ 500 & 250 \\ 500 & 250 \\ 500 & 250 \\ 500 & 250 \\ 500 & 250 \\ 500 & 250 \\ 500 & 250 \\ 500 & 250 \\ 500 & 250 \\ 500 & 250 \\ 500 & 250 \\ 500 & 250 \\ 500 & 250 \\ 500 & 250 \\ 500 & 250 \\ 2000 & 1000 \\ 0 & 0 \\ 0 & 0 \\ 0 & 0 \\ 0 & 0 \\ 0 & 0 \\ 0 & 0 \\ 0 & 0 \\ 0 & 0 \\ 0 & 0 \\ 0 & 0 \\ 0 & 0 \\ 0 & 0 \\ 7000 & 700 \\ 4500 & 4500 \\ 7000 & 7000 \\ 4500 & 4500 \\ 26000 & 2300 \\ 200 & 0\end{array}$

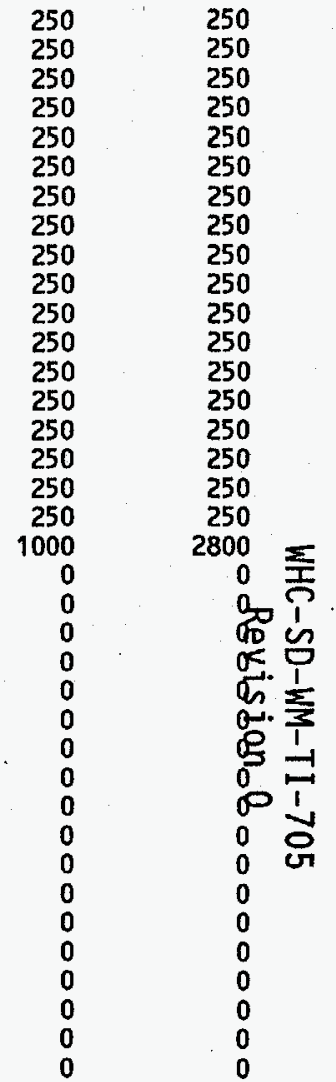


Page No. 11

$05 / 22 / 95$

DESC

Cesium I on Exchange Column Hot Air Blower

First Stage Settling Tank Deca First Stage Settling Tank slur Second Stage Settling Tank Dec Second Stage Settling Tank Dec First Wash Tank Decant Pump First Wash Tank Slurry Pump Second Wash Tank Decant Pump Second Wash Tank Pump

Supernatant Accumulation Tank Supernatant Sample and Transfe LLW Feed Accumulat ion Tank PUm LLW Feed Accumulation Tank Pum Wash Solution Accumulation Tan Wash Solution Transfer Tank PU HL Feed Accumulation Tank Pum HLW Feed Transfer Tank Pump Receipt/Sample Tank Pump Receipt/Sample Tank Punp

Evaporator Feed Tank Pump
Cs I on Exchange Feed Adjust Cs I on Exchange Feed Adjust

I Concentrated Supernatant

Concentrated Supernatant Sampl

Transfer Tank Pumo

flocculant Makeup Tank Pump Wash Solution Makeup Tank Punp Tank Farm NaNO2 Makeup Tank Pu Cs IX Feed Tank Pump

filter Bed Catch Tank Pump

Cs IX Acid Regen Feed Tan

Acid Recycle Tank Pump

Cs IX Caustic Regen Feed Tank

Cs IX Eluant Catch Tank Pump

Cesium IX Waste Tank Pump

Cs IX Waste Sample Tank Pump

$\begin{array}{ll}E Q 1 D & \text { SYS } \\ \text { IX } & 216 A \\ M B & 1558 \\ P & 102 A \\ P & 104 A \\ P & 105 A \\ P & 106 A \\ P & 108 \\ P & 109 \\ P & 112 \\ P & 114 \\ P & 116 A \\ P & 118 A \\ P & 122 A \\ P & 123 A \\ P & 124 A \\ P & 125 A \\ P & 126 A \\ P & 127 A \\ P & 132 A \\ P & 134 A \\ P & 137 \\ P & 138 \\ P & 142 \\ P & 145 A \\ P & 147 \\ P & 148 \\ P & 149 \\ P & 150 \\ P & 201 \\ P & 204 \\ P & 207 \\ P & 209 \\ P & 215 \\ P & 218 \\ P & 220 \\ P & 222 \\ P & 226 \\ & \end{array}$

EQUIPNO LOCATION

IX-2

SP

IX-2

$\mathrm{CPC}-2$

CPC -3

CPC -3

$\mathrm{CPC}-2$

CPC- 1

CPC-1

$\mathrm{CPC}-3$

CPC-4

CPC -4

CPC -4

CPC -5

$\begin{array}{rrr}\text { MTBR } & \text { TOTAL_WT } & \text { EQWTEXPOSD } \\ & & \\ 5110 & 2500 & 2250 \\ 0 & 0 & 0 \\ 0 & 0 & 0 \\ 0 & 0 & 0 \\ 0 & 0 & 0 \\ 0 & 0 & 0 \\ 0 & 0 & 0 \\ 0 & 0 & 0 \\ 0 & 0 & 0 \\ 0 & 0 & 0 \\ 0 & 0 & 0 \\ 0 & 0 & 0 \\ 0 & 0 & 0 \\ 0 & 0 & 0 \\ 0 & 0 & 0 \\ 0 & 0 & 0 \\ 0 & 0 & 0 \\ 0 & 0 & 0 \\ 1825 & 2000 & 1000 \\ 1825 & 2000 & 1000 \\ 1825 & 2000 & 1000 \\ 1825 & 2000 & 1000 \\ 1825 & 2000 & 1000 \\ 1825 & 2000 & 1000 \\ 1825 & 2000 & 1000 \\ 0 & 0 & 0 \\ 0 & 0 & 0 \\ 0 & 0 & 0 \\ 1825 & 2000 & 1000 \\ 1825 & 2000 & 1000 \\ 1825 & 2000 & 1000 \\ 1825 & 2000 & 1000 \\ 1825 & 2000 & 1000 \\ 1825 & 2000 & 1000 \\ 1825 & 2000 & 1000 \\ 1825 & 2000 & 1000 \\ 0 & 0 & 0 \\ & & \end{array}$

TRUUNIT

TRULOF MTRUUNIT

MTRULOF

LLCIUNIT

LLC1LOF

250

0 
Page No. 12

05/22/95

\section{DESC}

Resin Fluidizing Pump

Demin Water Tank Pump

Wash Solut ion Makeup Tank

Tank farm NanO2 Makeup Tank

Receipt/Sample Tank

Evaporator Feed Tank For Tank Cs I on Exchange Feed Adjust Ta Concentrated Supernatant Catch TK Concentrated Supernatant Sampl Concentrated supernatant NaNO2 Transfer Tank

Cs IX Feed Tank

Filter Bed Catch Tank

Cesium Regen. Nitric Acid Tank Cs IX Acid Regen Feed Tank

Startup Nitric Acid Tank (4.2

Acid Recycle Tank

Regen NaOH Tank $(2.0 \mathrm{M})$

Regen NaOH Tank $(.5 \mathrm{M})$

Neutralizing NaOH Solution tan

Cs IX Caustic Regen feed Tank

I Cs IX Eluant Catch Tank

$\rightarrow$ Cs IX Waste Tank

Cs IX Waste Sample Tank Cs IX Concentrator/Adjustment Resin Mixing Tank

Spent Res in Receiver

Water Knockout Drum

Demin Water Tank

First Stage Settling Tank

First Stage Settling Tank

First Stage Settling Tank

First Stage Settling Tank Deca

First Stage Settling Tank Deca

First stage Settling Tank Deca

$\begin{array}{lll}\text { EQID } & \text { SYS } & \text { EQU } \\ & & \\ \text { P } & 1551 A & 4 \\ \text { P } & 1557 A & 4 \\ \text { P } & 1574 & 4 \\ \text { TK } & 100 & 4 \\ \text { TK } & 110 & 4 \\ \text { TK } & 111 & 4 \\ \text { TK } & 131 A & 4 \\ \text { TK } & 135 & 4 \\ \text { TK } & 136 & 4 \\ \text { TK } & 141 & 4 \\ \text { TK } & 143 & 4 \\ \text { TK } & 144 & 4 \\ \text { TK } & 146 & 4 \\ \text { TK } & 200 & 4 \\ \text { TK } & 203 & 4 \\ \text { TK } & 205 & 4 \\ \text { TK } & 206 & 4 \\ \text { TK } & 208 & 4 \\ \text { TK } & 210 & 4 \\ \text { TK } & 211 & 4 \\ \text { TK } & 212 & 4 \\ \text { TK } & 213 & 4 \\ \text { TK } & 214 & 4 \\ \text { TK } & 217 & 4 \\ \text { TK } & 219 & 4 \\ \text { TK } & 221 & 4 \\ \text { TK } & 225 & 4 \\ \text { TK } & 1552 & 4 \\ \text { TK } & 1556 A & 4 \\ \text { TK } & 1559 & 4 \\ \text { TK } & 1573 & 4 \\ \text { DST } & 1010 & 4 \\ \text { DST } & 101 C & 4 \\ \text { DST } & 101 B & 4 \\ \text { P } & 102 B & 4 \\ \text { P } & 102 C & 4 \\ \text { P } & 102 D & 4 \\ & & \end{array}$

TOTAL_WT EQWTEXPOSD

TRUUNIT

achion

SP

IX -2
CPC-2

$\mathrm{CPC}-2$
$\mathrm{CPC}-3$

CPC-3

CPC-2

CPC-2
CPC-1

$\mathrm{CPC}-1$
$\mathrm{CPC}-1$

CDT

$\mathrm{CPC}-3$

CDT -3

CDT

CDT
CDT
CDT

CPC -4

CPC -4
CPC-5

1825
1825
TRULOF MTRUUNIT

MTRULOF

LLC1UNIT

LLC1LOF

$\begin{array}{rrr}2000 & 1000 & 0 \\ 1000 & 500 & 0 \\ 0 & 0 & 0 \\ 12500 & 0 & 0 \\ 15000 & 0 & 0 \\ 2500 & 0 & 0 \\ 0 & 0 & 0 \\ 89000 & 80000 & 0 \\ 35000 & 31500 & 0 \\ 35000 & 31500 & 0 \\ 35000 & 31500 & 0 \\ 12500 & 11300 & 0 \\ 35000 & 31500 & 0 \\ 35000 & 31500 & 0 \\ 5300 & 4750 & 0 \\ 0 & 0 & 0 \\ 0 & 0 & 0 \\ 0 & 0 & 0 \\ 0 & 0 & 0 \\ 0 & 0 & 0 \\ 0 & 0 & 0 \\ 0 & 0 & 0 \\ 0 & 0 & 0 \\ 0 & 0 & 0 \\ 0 & 0 & 0 \\ 0 & 0 & 0 \\ 0 & 0 & 0 \\ 1500 & 1350 & 0 \\ 600 & 540 & 0 \\ 0 & 0 & 0 \\ 0 & 0 & 0 \\ 0 & 0 & 0 \\ 0 & 0 & 0 \\ 0 & 0 & 0 \\ 0 & 0 & 0 \\ 0 & 0 & 0 \\ 0 & 0 & 0 \\ & & \end{array}$

990

450

126

0

0

0
0
9000

9000

0

0

5110 
Page No. 13

DESC

Second Stage Settling Tank Second Stage Settling Tank

Second stage Settling Tank

First stage Settling Tank slur

First stage Settling Tank slur

First Stage Settling Tank slur

Second Stage Settling Tank Dec

Second stage settling Tank DeC

second Stage Settling Tank Dec

Second Stage Settling Tank Dec

Second Stage Settling Tank DeC

Second stage settling Tank Dec

Supernatant Accumulation Tank

supernatant Accumulation Tank

supernatant Sample and Transfe

Supernatant Sample and Transfe

LLW Feed Accumulation Tank

Wash Solution Accumulation Tan DST 119

LLW Feed Accumulation Tank Pum $P$

LLW Feed Accumulation Tank Pum $P$ 123

Wash Solution Accumulation Tan $P$ 124B

Wash Solution Transfer Tank Pu P 125B

HLW Feed Accumulation Tank PUm

P HLW Feed Transfer Tank Pump

$\rightarrow$ LLH Feed Accumulation Tank

Wash Solution Transfer Tank

Receipt/Sample Tank

Receipt/Sample Tank Pump

Receipt/Sample Tank Pump

Receipt/Sample Tank Pump

Receipt/Sample Tank Pump

Receipt/Sample Tank Pump

Receipt/Sample Tank Pump

Concentrated Supernatant Sampl

Cesium Ion Exchange Column

\begin{tabular}{|c|c|c|c|c|c|c|}
\hline EQID & SYS & EQUIPNO & LOCATION & MTBR & TOTAL_UT & EQWTEXPOSD \\
\hline DST & $103 \mathrm{~B}$ & 4 & & 0 & 0 & 0 \\
\hline DST & $103 c$ & 4 & & 0 & 0 & 0 \\
\hline DST & 1030 & 4 & & 0 & 0 & 0 \\
\hline $\mathrm{P}$ & $104 B$ & 4 & & 0 & 0 & 0 \\
\hline P & $104 \mathrm{C}$ & 4 & & 0 & 0 & 0 \\
\hline P & $104 \mathrm{D}$ & 4 & & 0 & 0 & 0 \\
\hline $\mathbf{P}$ & $105 B$ & 4 & & 0 & 0 & 0 \\
\hline p & $105 c$ & 4 & & 0 & 0 & 0 \\
\hline $\mathbf{P}$ & 1050 & 4 & & 0 & 0 & 0 \\
\hline p & $106 \mathrm{~B}$ & 4 & & 0 & 0 & 0 \\
\hline $\mathbf{P}$ & 1060 & 4 & & 0 & 0 & 0 \\
\hline $\mathbf{P}$ & $106 \mathrm{C}$ & 4 & & 0 & 0 & 0 \\
\hline DST & $115 \mathrm{~B}$ & 4 & & 0 & 0 & 0 \\
\hline P & 1168 & 4 & & 0 & 0 & 0 \\
\hline DST & $117 \mathrm{~B}$ & 4 & & 0 & 0 & 0 \\
\hline P & $118 \mathrm{~B}$ & 4 & & 0 & 0 & 0 \\
\hline DST & $119 \mathrm{~B}$ & 4 & & 0 & 0 & 0 \\
\hline DST & $120 \mathrm{~B}$ & 4 & & 0 & 0 & 0 \\
\hline $\mathbf{P}$ & $122 B$ & 4 & & 0 & 0 & 0 \\
\hline P & $123 B$ & 4 & & 0 & 0 & 0 \\
\hline $\mathbf{P}$ & $124 \mathrm{~B}$ & 4 & & 0 & 0 & 0 \\
\hline P & $125 \mathrm{~B}$ & 4 & & 0 & 0 & 0 \\
\hline P & $126 \mathrm{~B}$ & 4 & & 0 & 0 & 0 \\
\hline $\mathbf{P}$ & $127 \mathrm{~B}$ & 4 & & 0 & 0 & 0 \\
\hline DST & $128 \mathrm{~B}$ & 4 & & 0 & 0 & 0 \\
\hline DST & $129 \mathrm{~B}$ & 4 & & 0 & 0 & 0 \\
\hline TK & 1318 & 4 & SP & 0 & 0 & 0 \\
\hline TK & $131 \mathrm{C}$ & 4 & SP & 0 & 0 & 0 \\
\hline TK & 1310 & 4 & SP & 0 & 0 & 0 \\
\hline$p$ & $132 B$ & 4 & $\mathbf{S P}$ & 1825 & 2000 & 1000 \\
\hline p & $132 \mathrm{C}$ & 4 & SP & 1825 & 2000 & 1000 \\
\hline P & 1320 & 4 & SP & 1825 & 2000 & 1000 \\
\hline P & $134 \mathrm{~B}$ & 4 & SP & 1825 & 2000 & 1000 \\
\hline P & $134 \mathrm{C}$ & 4 & SP & 1825 & 2000 & 1000 \\
\hline$P$ & 1340 & 4 & SP & 1825 & 2000 & 1000 \\
\hline P & $145 B$ & 4 & CPC-3 & 1825 & 2000 & 1000 \\
\hline IX & $216 B$ & 4 & $1 X-2$ & 5110 & 2500 & 2250 \\
\hline
\end{tabular}

TRULOF MTRUUNIT

MTRULOF

LLCIUNIT

LLC1LOF 
Page No. 14

$05 / 22 / 95$

DESC

\begin{tabular}{|c|c|c|c|c|c|c|c|}
\hline EQID & sYs & EQUIPNO & LOCATION & MTBR & TOTAL_HT & EQWTEXPOSD & TRUUUNIT \\
\hline IX & $216 C$ & 4 & IX-2 & 5110 & 2500 & 2250 & \\
\hline IX & 2160 & 4 & $i x-2$ & 5110 & 2500 & 2250 & \\
\hline p & $1551 B$ & 4 & & 1825 & 2000 & 1000 & \\
\hline TK & $1556 \mathrm{~B}$ & 4 & & 5110 & 600 & 540 & \\
\hline P & $1557 \mathrm{~B}$ & 4 & & 1825 & 1000 & 500 & \\
\hline EV & $1124 \mathrm{E}$ & 4 & VBC & 0 & 52000 & 0 & \\
\hline $\mathbf{E}$ & $1125 \mathrm{E}$ & 4 & VBC & 0 & 200 & 0 & \\
\hline P & $1127 \mathrm{~K}$ & 4 & VBC & 1825 & 500 & 0 & \\
\hline $\mathbf{P}$ & $1127 \mathrm{~J}$ & 4 & VBC & 1825 & 500 & 0 & \\
\hline$p$ & $1128 \mathrm{E}$ & 4 & VBC & 1825 & 500 & 0 & \\
\hline TK & $1129 E$ & 4 & VBC & 5110 & 1000 & 0 & \\
\hline TK & $1130 \mathrm{E}$ & 4 & VBC & 5110 & 625 & 0 & \\
\hline TK & 131E & 4 & $\mathrm{SP}$ & 0 & 0 & 0 & \\
\hline TK & $131 F$ & 4 & SP & 0 & 0 & 0 & \\
\hline $\mathbf{P}$ & $132 E$ & 4 & SP & 1825 & 2000 & 1000 & \\
\hline p & $132 \mathrm{~F}$ & 4 & SP & 1825 & 2000 & 1000 & \\
\hline P & $134 \mathrm{E}$ & 4 & SP & 1825 & 2000 & 1000 & \\
\hline p & $134 \mathrm{~F}$ & 4 & SP & 1825 & 2000 & 1000 & \\
\hline p & 1560 & 4 & & 0 & 0 & 0 & \\
\hline DST & 131 & 4 & & 0 & 0 & 0 & \\
\hline P & 132 & 4 & & 0 & 0 & 0 & \\
\hline DST & 133 & 4 & & 0 & 0 & 0 & \\
\hline P & 134 & 4 & & 0 & 0 & 0 & \\
\hline TK & 227 & 4 & & 0 & 0 & 0 & \\
\hline TK & 4298 & 4 & P\&OG-2 & 5110 & 9500 & 8500 & \\
\hline p & 4308 & 4 & P\&OG-2 & 1825 & 2000 & 1000 & \\
\hline TK & 626 & 4 & CTA & 5110 & 9500 & 8550 & \\
\hline TK & 702 & 4 & IX-1 & 5110 & 9500 & 8550 & \\
\hline P & $70 \overline{3}$ & 4 & $1 x-1$ & 1825 & 2000 & 1000 & \\
\hline $\mathrm{FH}$ & $1118 \mathrm{~J}$ & 4 & VBC & 731 & 750 & 0 & \\
\hline $\mathrm{FH}$ & $1118 \mathrm{~K}$ & 4 & VBC & 731 & 750 & 0 & \\
\hline $\mathrm{FH}$ & $1118 \mathrm{~L}$ & 4 & VBC & 731 & 750 & 0 & \\
\hline $\mathrm{FH}$ & $1118 \mathrm{M}$ & 4 & VBC & 731 & 750 & 0 & \\
\hline FH & $1118 \mathrm{~N}$ & 4 & VBC & 731 & 750 & 0 & \\
\hline FH & $1118 \mathrm{P}$ & 4 & VBC & 731 & 750 & 0 & \\
\hline $\mathrm{FH}$ & $1118 a$ & 4 & VBC & 731 & 750 & 0 & \\
\hline FH & $1118 R$ & 4 & VBC & 731 & 750 & 0 & \\
\hline
\end{tabular}

TRULOF MTRUUNIT

MTRULOF

LLCIUNIT

LLC1LOF

Cesium Ion Exchange column Cesium Ion Exchange Column Resin Fluidizing Pump

Spent Resin Receiver

Spent Resin Pump

SLECTRIC PROCESS STEAM GENERAT

STANDBY ELECTRIC HEATER

PROCESS STEAM GENERATOR CI

PROCESS STEAM GENERATOR CIRCL

POILER FEED WATER CHEMICAL

BLOWDOWN DRUM

CHEMICAL ADDITION TANK

Rece ipt/Sample Tank

Rece ipt/Sample Tank

Receipt/Sample Tank Pump

Rece ipt/Sample Tank Pump

Rece ipt/Sample Tank Pump

H2O PUMPOUT PUMP

CESIUM CONCENTRATED HLW FEED A DST

CESIUM CONCENTRATED HLW FEED A

CESIUM CONCENTRATED HLH FEED A P

CESIUM CONCENTRATED HLW FEED A

LLW CONDENSATE CATCH TANK

PUMP

ULW MELTER FILTER WASH CATCH T TK CVOG/VOG FILTER WASH CATCH TAN TK

VIT BLDG HPS VAC SYSTEM HEPA F

VIT BLDG UPS VAC SYSTEM HEPA F

VIT BLDG HPS VAC SYSTEM HEPA F

VIT BLDG UPS VAC SYSTEM HEPA F

VIT BLDG HPS VAC SYSTEM HEPA F

VIT BLDG HPS VAC SYSTEM HEPA F FH

VIT BLDG HPS VAC SYSTEM HEPA F FH

VIT BLDG HPS VAC SYSTEM HEPA F FH 
Page No. 15

$05 / 22 / 95$

DESC

KEROSENE FEED TANK

KEROSENE FEED PUMP

KEROSENE FEED PUMP

PROCESS CONDENSATE PUMP

PROCESS CONDENSATE PUMP

PROCESS CONDENSATE PUMP

PROCESS CONOENSATE PUMP

PROCESS CONDENSATE PUMP

PROCESS CONDENSATE PUMP

PROCESS CONDENSATE PUMP

PROCESS CONDENSATE PUMP

PROCESS COOLING WATER PUMP

PROCESS COOLING WATER

ANTIFO

MERC

MERC

MERC

MERC

MERC

MERC

TRANSFER CART

TRANSFER CART \#2

TRANSFER CART SYSTEM W/ CONTRO

TRANSFER CART SY

RETURN CONVEYOR

PREFILTER

HEPA FILTER

HEPA FILTER

PREFILTER

HEPA FILTER

HEPA FILTER

METAL HEPA FILTER

METAL MEPA FILTER

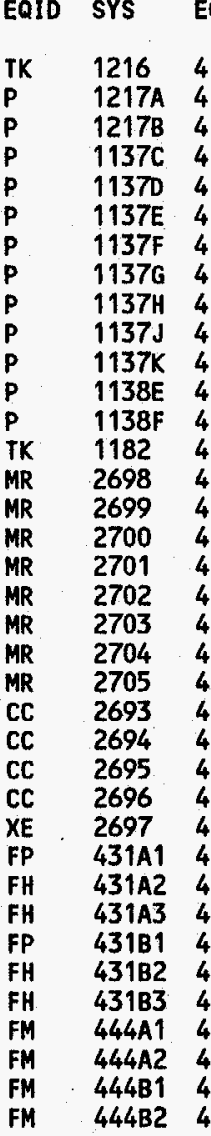

\begin{tabular}{ll} 
& 5110 \\
& 1825 \\
VBC & 1825 \\
VBC & 1825 \\
VBC & 1825 \\
VBC & 1825 \\
VBC & 1825 \\
VBC & 1825 \\
VBC & 1825 \\
VBC & 1825 \\
VBC & 1825 \\
VBC & 1825 \\
VBC & 1825 \\
WSF & 5110 \\
WSF & 5110 \\
WSF & 5110 \\
WSF & 5110 \\
FA & 5110 \\
FA & 5110 \\
FA & 5110 \\
FA & 5110 \\
MC & 5110 \\
MC & 5110 \\
& 5110 \\
& 5110 \\
CDT & 5110 \\
CDT & 5110 \\
CDT & 5110 \\
CDT & 5110 \\
CDT & 5110 \\
CDT & 5110 \\
IX-2 & 5110 \\
LLCFR & 5110 \\
IX-2 & 5110 \\
LLCFR & 5110 \\
& 5110 \\
& \\
\hline LD & 5
\end{tabular}

MTBR
5110
51825
1825
1825
1825
1825
1825
1825
1825
1825
1825
1825
1825
5110
5110
5110
5110
5110
5110
5110
5110
5110
5110
5110
5110
5110
5110
5110
5110
5110
5110
5110
5110
5110
5110
5110
5110

TOTAL_WT EQWTEXPOSD

TRUUNIT

12000

200

1200

1200

1200

1200

7500

7500

5000

45000

5000

50000

50000

200

12000

100000

100000

100000

100000

50000

50000

0
0
0
0
0
0
0
0
0
0
0
0
0
0
0
0
0
0
0
0
0
0
50000
50000
0
0
12000
0
0
0
0
0
0
45000
45000
45000
45000

MTRUUN

MTRULOF

LLCIUNIT

LLC1LOF

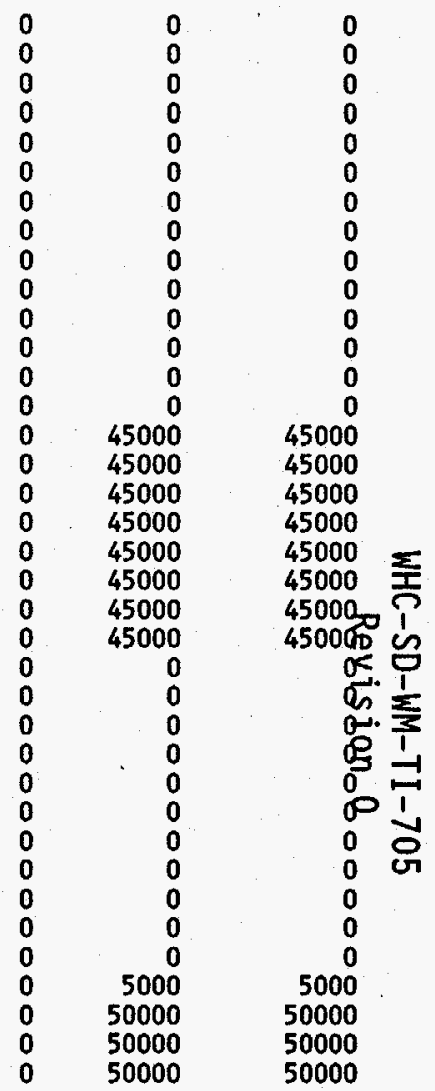


Page No. 16

05/22/95

DESC

METAL HEPA FILTER METAL HEPA FILTER METAL HEPA FILTER METAL HEPA FILTER METAL HEPA FILTER METAL HEPA FILTER METAL HEPA FILTER METAL HEPA FILTER METAL HEPA FILTER METAL HEPA FILTER METAL HEPA FILTER METAL HEPA FILTER METAL HEPA FILTER METAL HEPA FILTER Metal HEPA Filter Metal HEPA Filter Metal HEPA Filter Metal HEPA Filter LLW CULLET STORAGE LLW CULLET STORAGE LLW CULLET STORAGE LLW CULLET STORAGE LLW CULLET STORAGE I LLW CULLET STORAGE $\infty$ Coil

Agitator

\begin{tabular}{|c|c|c|c|c|c|c|c|c|c|c|c|c|}
\hline EQID & SYS & EQUIPNO & LOCATION & MTBR & TOTAL_WT & EQWTEXPOSD & TRUUNIT & TRULOF & MTRUUNIT & MTRULOF & LLCIUNIT & LLC1LOF \\
\hline FM & $505 A 1$ & 4 & P\&OG-1 & 5110 & 50000 & 45000 & 0 & 0 & 0 & 0 & 5000 & 5000 \\
\hline FM & $505 A 2$ & 4 & LLCFR & 5110 & 50000 & 45000 & 0 & 0 & 0 & 0 & 50000 & 50000 \\
\hline FM & $505 \mathrm{~B} 1$ & 4 & P\&OG-2 & 5110 & 50000 & 45000 & 0 & 0 & 0 & 0 & 5000 & 5000 \\
\hline FM & $505 \mathrm{~B} 2$ & 4 & LLCFR & 5110 & 50000 & 45000 & 0 & 0 & 0 & 0 & 50000 & 50000 \\
\hline FM & 625A1 & 4 & $I X-1$ & 5110 & 4000 & 3600 & 0 & 0 & 0 & 0 & 400 & 400 \\
\hline FM & $625 \mathrm{A2}$ & 4 & LLCFR & 5110 & 4000 & 3600 & 0 & 0 & 0 & 0 & 4000 & 4000 \\
\hline FM & $625 \mathrm{B1}$ & 4 & $I x-1$ & 5110 & 4000 & 3600 & 0 & 0 & 0 & 0 & 400 & 400 \\
\hline FM & $625 \mathrm{~B} 2$ & 4 & LLCFR & 5110 & 4000 & 3600 & 0 & 0 & 0 & 0 & 4000 & 4000 \\
\hline FM & $625 \mathrm{Cl}$ & 4 & $I X-1$ & 5110 & 4000 & 3600 & 0 & 0 & 0 & 0 & 400 & 400 \\
\hline FM & $625 \mathrm{c} 2$ & 4 & LLCFR & 5110 & 4000 & 3600 & 0 & 0 & 0 & 0 & 4000 & 4000 \\
\hline FM & $700 A 1$ & 4 & P\&OC-1 & 5110 & 4000 & 3600 & 0 & 0 & 0 & 0 & 400 & 400 \\
\hline FM & $700 A 2$ & 4 & LLCFR & 5110 & 4000 & 3600 & 0 & 0 & 0 & 0 & 400 & 400 \\
\hline FM & $700 \mathrm{~B} 1$ & 4 & P\&OG-1 & 5110 & 4000 & 3600 & 0 & 0 & 0 & 0 & 400 & 400 \\
\hline FM & $700 \mathrm{~B} 2$ & 4 & LLCFR & 5110 & 4000 & 3600 & 0 & 0 & 0 & 0 & 400 & 400 \\
\hline FM & 701A1 & 4 & $I X-1$ & 5110 & 9000 & 8100 & 0 & 0 & 0 & 0 & 900 & 900 \\
\hline FM & $701 A 2$ & 4 & LLCFR & 5110 & 9000 & 8100 & 0 & 0 & 0 & 0 & 9000 & 9000 \\
\hline FM & $701 \mathrm{B1}$ & 4 & $I X-1$ & 5110 & 9000 & 8100 & 0 & 0 & 0 & 0 & 900 & 900 \\
\hline FM & 70182 & 4 & LLCFR & 5110 & 9000 & 9000 & 0 & 0 & 0 & 0 & 9000 & 9000 \\
\hline TK & $2002 A$ & 4 & $C P-1$ & 5110 & 105000 & 94000 & 0 & 0 & 0 & 0 & 11000 & 11000 \\
\hline TK & 2002B & 4 & $C P-1$ & 5110 & 105000 & 94000 & 0 & 0 & 0 & 0 & 11000 & 11000 \\
\hline TK & $2002 A$ & 4 & CP-1 & .5110 & 105000 & 94000 & 0 & 0 & 0 & 0 & 11000 & 11000 \\
\hline TK & $2002 A$ & 4 & P\&OG-1 & 5110 & 105000 & 94000 & 0 & 0 & 0 & 0 & 11000 & $1100 \%$ \\
\hline TK & $2002 B$ & 4 & CP-2 & 5110 & 105000 & 94000 & 0 & 0 & 0 & 0 & 11000 & 11000 \\
\hline TK & $2002 B$ & 4 & P\&OG-2 & 5110 & 105000 & 94000 & 0 & 0 & 0 & 0 & 11000 & 11000 \\
\hline P & 400 & $4-1$ & P8OG-2 & 1825 & 2000 & 1000 & 0 & 0 & 0 & 0 & 1990 & 5572 \\
\hline co & 400 & $4-2$ & P\&OG-2 & 1925 & 500 & 500 & 0 & 0 & 0 & 0 & 500 & 1328 \\
\hline AG & 400 & $4-3$ & P\&OG-2 & 731 & 5300 & 800 & 0 & 0 & 0 & 0 & 5290 & $36979^{\circ}$ \\
\hline CO & $404 A$ & 4 & CPC-7 & 1925 & 500 & 500 & 0 & 0 & 0 & 0 & & \\
\hline $\begin{array}{l}A G \\
P\end{array}$ & 404A & & CPC-7 & $\begin{array}{r}731 \\
835\end{array}$ & $\begin{array}{l}5300 \\
2000\end{array}$ & 800 & 0 & 0 & 0 & 0 & 4490 & 31387 \\
\hline P & $404 \mathrm{~A}$ & & CPC-7 & 1825 & 2000 & 1000 & 0 & 0 & & 0 & 990 & 2772 \\
\hline CO & 404B & & CPC-6 & 1925 & 500 & 500 & 0 & 0 & 0 & 0 & 0 & \\
\hline AG & 404B & & CPC - 6 & 731 & 5300 & 800 & 0 & 0 & 0 & 0 & 4490 & 31387 \\
\hline P & 404B & & CPC- 6 & 1825 & 2000 & 1000 & 0 & 0 & 0 & 0 & 990 & 2772 \\
\hline co & $404 \mathrm{C}$ & & CPC-6 & 1925 & 500 & 500 & 0 & 0 & 0 & 0 & 0 & \\
\hline AG & $404 \mathrm{C}$ & & CPC -6 & 731 & 5300 & 800 & 0 & 0 & 0 & 0 & 4490 & 31387 \\
\hline $\mathbf{P}$ & $404 \mathrm{C}$ & & CPC-6 & 1825 & 2000 & 1000 & 0 & 0 & 0 & 0 & 990 & 2772 \\
\hline co & 4040 & & CPC-6 & 1925 & 500 & 500 & 0 & 0 & 0 & 0 & 0 & 0 \\
\hline
\end{tabular}


Page No. 17 05/22/95

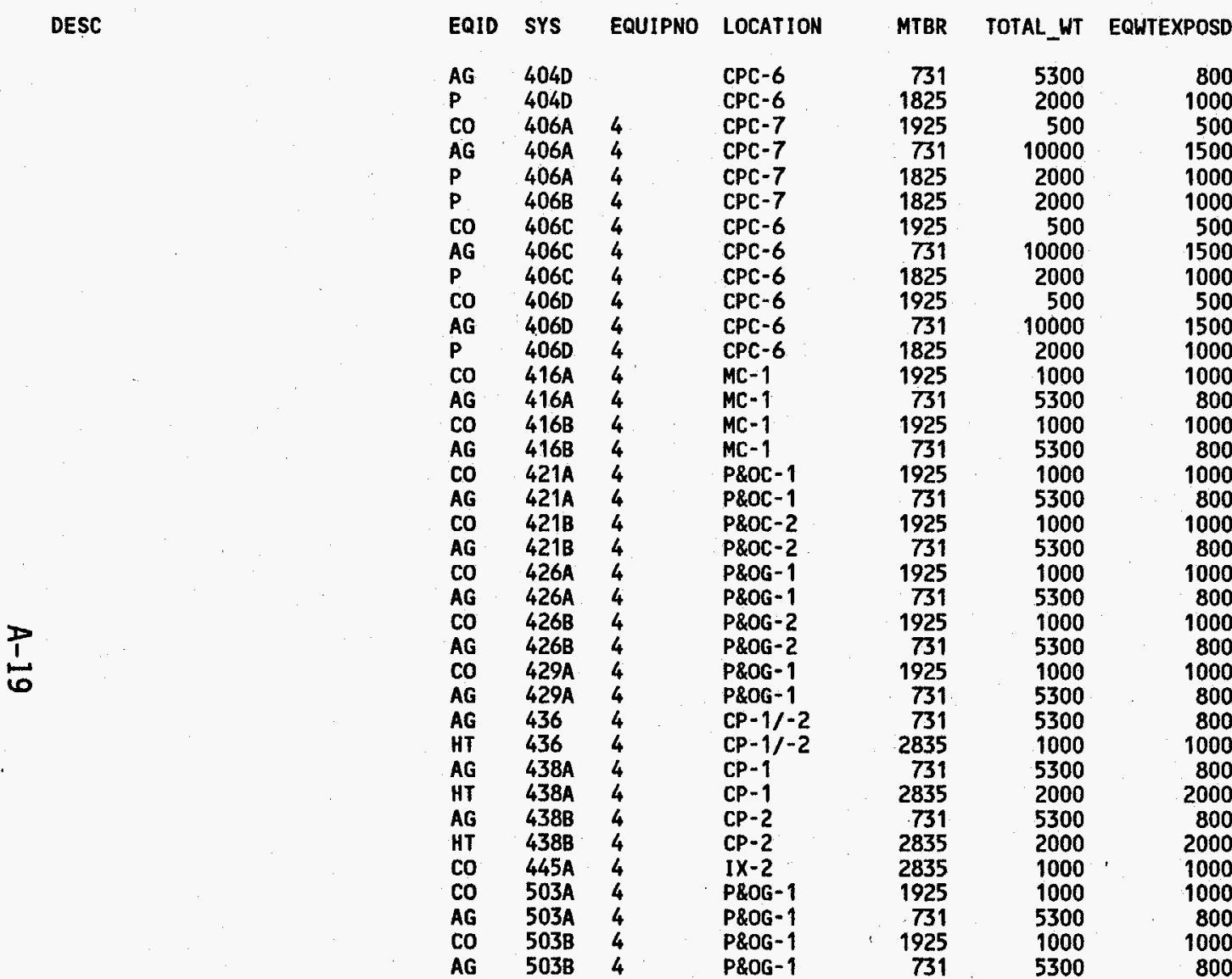

TRUUNIT TRULOF MTRUUNIT

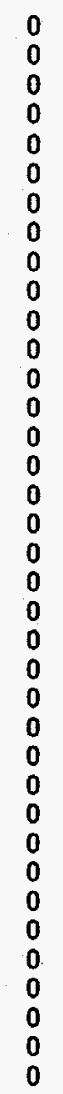

MTRULOF

0
0
0
0
0
0
0
0
0
0
0
0
0
0
0
0
0
0
0
0
0
0
0
0
0
0
0
0
0
0
0
0
0
0
0
0
0
0

LLCIUNI
4490
990
8490
990
990
890
8490
990
0
8490
990
40
4490
400
4490
4490
400
4490
1000
5290
1000
5290
1000
5290
4490
4490
4490
1000
4490
4490
4

LLC1LOF

31387 2772
0
59349 2772 50349 2772 59349 2772 0
31387 0
31387 0
31387 0
31387
2655 종 3697㛣 in 2655. I 2655 . 36979 古 o 1 31387 음 31387 1802 31387 0
31387 
Page No. 18 05/22/95

DESC

$\begin{array}{llllrrrrrrr}\text { EQID } & \text { SYS } & \text { EQUIPNO } & \text { LOCATION } & \text { MTBR } & \text { TOTAL_WT } & \text { EQWTEXPOSD } & \text { TRUUNIT } & \text { TRULOF } & \text { MTRUUNIT } & \text { MTRULOF } \\ \text { AG } & 611 & 4 & \text { P\&OG-2 } & 731 & 5300 & 800 & 0 & 0 & 0 & 0 \\ \text { CO } & 611 & 4 & \text { P\&OG-2 } & 2835 & 1000 & 1000 & 0 & 0 & 0 \\ \text { CO } & 614 A & 4 & \text { MC-1 } & 1923 & 500 & 500 & 0 & 0 & 0 \\ \text { AG } & 614 A & 4 & \text { MC-1 } & 731 & 5300 & 800 & 0 & 0 & 0 \\ \text { P } & 614 A & 4 & \text { MC-1 } & 1825 & 2000 & 1000 & 0 & 0 & 0 \\ \text { CO } & 614 B & 4 & \text { MC-2 } & 1925 & 500 & 500 & 0 & 0 & 0 \\ \text { AG } & 614 B & 4 & \text { MC-2 } & 731 & 5300 & 800 & 0 & 0 & 0 & 0 \\ \text { P } & 614 B & 4 & \text { MC-2 } & 1825 & 2000 & 1000 & 0 & 0 & 0 & 0 \\ \text { CO } & 429 B & 4 & \text { P\&OG-2 } & 1925 & 1000 & 1000 & 0 & 0 & 0 \\ \text { AG } & 429 B & 4 & \text { P\&OG-2 } & 731 & 5300 & 800 & 0 & 0 & 0 & 0 \\ \text { CO } & 626 & 4 & \text { CTA } & 1925 & 1000 & 1000 & 0 & 0 & 0 & 0 \\ \text { AG } & 626 & 4 & \text { CTA } & 731 & 5300 & 800 & 0 & 0 & 0 & 0 \\ \text { CO } & 702 & 4 & \text { IX-1 } & 1925 & 1000 & 1000 & 0 & 0 & 0 & 0 \\ \text { AG } & 702 & 4 & \text { IX-1 } & 731 & 5300 & 800 & 0 & 0 & 0 \\ \text { CO } & 406 B & 4 & \text { CPC-7 } & 1925 & 500 & 500 & 0 & 0 & 0 \\ \text { AG } & 406 B & 4 & \text { CPC-7 } & 331 & 1500 & 15000 & 0 & 0 & 0 & 0 \\ \text { MB } & 505 A & 4 & \text { P\&OG-1 } & 4544 & 28000 & 14000 & 0 & 0 & 0 & 0 \\ & & & & & & 6061285 & 3908010 & & 0 & 0 \\ \end{array}$

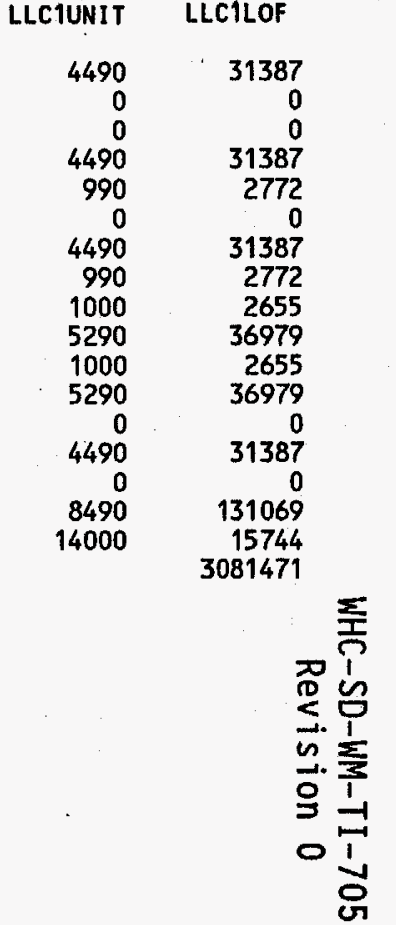

$P$
1
0 
WHC-SD-WM-TI-705

Revision 0

APPENDIX B

HIGH-LEVEL WASTE INVENTORY

B-1 
WHC-SD-WM-TI-705

Revision 0

This page intentionally left blank. 


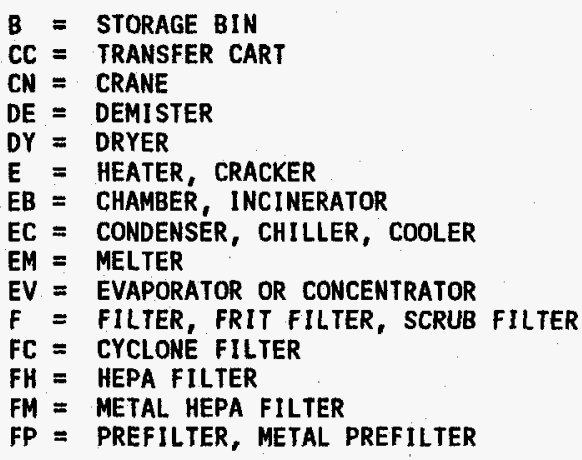

RECE IPT/SAMPLE TANK RECEIPT/SAMPLE TANK RECEIPT/SAMPLE TANK RECEIPT/SAMPLE TANK RECE IPT/SAMPLE TANK

PUMP

PUMP

PUMP

CENTRIFUGE FEED TANK

CENTRIFUGE FEED TANK

PUMP

CENTRIFUGE SOLIDS CATCH TANK CENTRIFUGE SOLIDS CATCH TANK

CENTRIFUGE

PUMP

CENTRATE CATCH TANK

CENTRATE CATCH TANK

PUMP

HLW EVAPORATOR FEED TANK

PUMP

HLW FEED EVAPORATOR

CONDENSER

HLW EVAPORATOR CATCH TANK

PUMP

EQUIPMENT ID

TK 300A 3B

TK $300 B$ 3B

TK 300C 3B

TK 300D 3B

TK 300E 3B

TK 300F 3B

P 301A 3B

P 301B 3B

P 3010 3B

P 301E 3B

TK 302A 3B

TK 302B 3B

P 303A 3B

P 303B 3B

TK 304A 3B

TK 304B 3B

G 305A 3B

G 305B 3B

$\begin{array}{lll}P & 306 A & 3 B \\ P & 306 B & 3 B\end{array}$

TK $307 A$ 3B

TK 307B 3B

$P$ 308A 3B

P 308B 3B

\begin{tabular}{lll} 
TK & 309 & 3B \\
\hline & 310 & $3 B$
\end{tabular}

$\begin{array}{lll}P & 310 & 3 B \\ & 311 & 3 B\end{array}$

EV 311 3B

EC 312 3B

$\begin{array}{lll}P & 314 & 3 B\end{array}$

HLW MELTER FEED ADJUSTMENT TAN TK 315A 3B

HLW MELTER FEED ADJUSTMENT TAN TK 315B 3B

HLH MELTER FEED TANK

HLW MELTER FEED TANK
LOCATION

ABREVIATIONS

EQUIPMENT IDENTIFICATION CODE

$F S=$ SCREEN

$G=$ CENTRI FUGE

HD $=$ DEVICE

$L T=$ IN-CELL LIGHT

$M=$ ROTARY STAR FEEDER

$M B=$ BLOWER

$M C=$ ROLL CRUSHER

$M F=$ FEEDERS

$M M=$ MIXERS

MQ $=$ QUENCH FLUME

MS = MASTER-SLAVE MANIP

$M Y=$ INSPECTION EOUIPMENT

$P=$ PUMPS

$R$ = ABSORBER, REACTOR, REGENERATOR, REDUCER

RA = MOTORIZED HATCH E U I PMEN T LIS T

CASE 3B, MODIFIED FOR SOL ID WASTE STUDY

MTBF TOTAL UT 2017

R/SC $\quad 5110$

R/SC

R/SC $\quad 5110$

R/SC $\quad 5110$

R/SC $\quad 5110$

R/SC $\quad 1825$

$\begin{array}{ll}\text { R/SC } & 1825 \\ \text { R/SC } & 1825\end{array}$

R/SC $\quad 1825$

R/SC 1825

R/SC

CEC

CEC

CEC

CEC

CEC

CEC

CEC

CEC
CEC

CEC

CEC

CEC

CEC

CEC

CEC

CEC

CEC
CEC
CEC

CEC

$\begin{array}{rr}0 & 0 \\ 0 & 0 \\ 0 & 0 \\ 0 & 0 \\ 0 & 0 \\ 0 & 0 \\ 2000 & 1000 \\ 2000 & 1000 \\ 2000 & 1000 \\ 2000 & 1000 \\ 2000 & 1000 \\ 2000 & 1000 \\ 24000 & 21600 \\ 24000 & 21600 \\ 2000 & 1000 \\ 2000 & 1000 \\ 24000 & 21600 \\ 24000 & 21600 \\ 5000 & 3750 \\ 5000 & 3750 \\ 2000 & 1000 \\ 2000 & 1000 \\ 12500 & 11250 \\ 12500 & 11250 \\ 2000 & 1000 \\ 2000 & 1000 \\ 24000 & 21600 \\ 2000 & 1000 \\ 6000 & 5400 \\ 3000 & 2700 \\ 12500 & 11250 \\ 2000 & 1000 \\ 24000 & 21600 \\ 24000 & 21600 \\ 2000 & 1000 \\ 2000 & 1000 \\ 24000 & 21600 \\ 24000 & 21600 \\ & \end{array}$

TRUUNIT

TRULO
RE = RADIATION COUNTER

$S=$ SEPARATOR (VAPOR/LIQUID)

$S C=$ SCRUBBER

SD = SHIELD DOOR

$S Z=$ WINDOW

= TOWERS

TE = TEMPERATURE PROBE

$T K=$ TANKS

$T R=$ TRAP

TU $=$ TURNTABLE

$T V=$ CCTV

WE = MELDING EOUIPMENT

XE = PNEUMATIC TRANSFER EQUIP

MTRUUNIT

MTRULOF LLCIUNIT

LLC1LOF

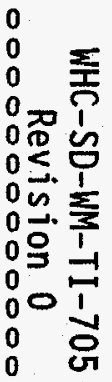


Page No. 2

05/22/95

DESC

$\begin{array}{lll}\text { EQUI PMENT } & \text { ID } \\ \text { P } & 318 A & 3 B \\ P & 318 B & 3 B \\ B & 319 & 3 B \\ M & 320 & 3 B \\ M F & 321 & 3 B \\ M & 322 & 3 B \\ \text { EM } & 323 & 3 B \\ S & 324 & 3 B \\ T & 600 & 3 B \\ \text { EC } & 601 & 3 B \\ \text { SC } & 602 & 3 B \\ S & 603 & 3 B \\ \text { EC } & 604 & 3 B \\ D E & 605 & 3 B \\ P & 606 & 3 B \\ P & 607 & 3 B \\ \text { TK } & 608 & 3 B \\ \text { TK } & 619 & 3 B \\ E & 622 A & 3 B \\ M B & 622 A & 3 B \\ E & 622 B & 3 B \\ M B & 622 B & 3 B \\ \text { EC } & 628 & 3 B \\ E & 629 & 3 B \\ E & 631 & 3 B \\ R & 632 & 3 B \\ R & 633 & 3 B \\ \text { EC } & 636 & 3 B \\ P & 652 & 3 B \\ R & 630 & 3 B \\ E & 634 & 3 B \\ R & 635 & 3 B \\ C L & 650 & 3 B \\ E & 700 A & 3 B \\ M B & 700 A & 3 B \\ E & 700 B & 3 B \\ M B & 700 B & 3 B \\ E & 701 A & 3 B \\ & & \end{array}$

$\begin{array}{lr}\text { LOCATION } & \text { MTBF } \\ \text { CEC } & 1825 \\ \text { CEC } & 1825 \\ \text { CDT } & 5110 \\ \text { CDT } & 365 \\ \text { CDT } & 5110 \\ \text { CDT } & 365 \\ \text { MC } & 923 \\ \text { MC } & 923 \\ \text { MC } & 5110 \\ \text { MC } & 5110 \\ \text { MC } & 5110 \\ \text { MC } & 5110 \\ \text { MC } & 5110 \\ \text { MC } & 5110 \\ \text { MC } & 1825 \\ \text { MC } & 1825 \\ \text { MC } & 5110 \\ \text { CDT } & 5110 \\ \text { CEC } & 1280 \\ \text { CFR } & 4544 \\ \text { CEC } & 1280 \\ \text { CFR } & 4544 \\ \text { CFR } & 5110 \\ \text { CFR } & 1280 \\ \text { CFR } & 1280 \\ \text { CFR } & 5110 \\ \text { CFR } & 5110 \\ \text { CFR } & 4544 \\ \text { CDT } & 1825 \\ \text { CFR } & 5110 \\ \text { CFR } & 1280 \\ \text { CFR } & 5110 \\ \text { CFR } & 5110 \\ \text { CEC } & 1280 \\ \text { CFR } & 4544 \\ \text { CEC } & 1280 \\ \text { CFR } & 4544 \\ \text { CEC } & 1280 \\ & \end{array}$

TOTAL_WT EQWTEXPOSD

PUMP

HEAD BIN

ROTARY STAR FEEDER

WEIGH FEEDER

RLTARY STAR

GLASS SEPARATOR

HLW QUENCH TOWER

HLW VENTURI SCRUBBER

HLW SEPARATOR

HLW MIST ELIMINATOR HOUSING

PUMP

HLW SCRUB SOLUTION TANK

SCRUB SOLUTION MAKEUP TANK

HEATER

HEATER

BLOWER

HEATER

HEATER

OX CATALYTIC REACTOR HOUSING SULFATE REDUCTION

COOLER

SO2 ABSORBER HOUSING

NH3 CRACKER

SO2 ABSORBER REGEN.

HEATER

BLOWER

BLOWER

E $701 \mathrm{~A} 3 \mathrm{~B}$

$$
2000
$$

$\begin{array}{rr}2000 & 1000 \\ 2000 & 1000 \\ 900 & 0 \\ 300 & 0 \\ 600 & 0 \\ 300 & 0 \\ 60000 & 54000 \\ 60000 & 54000 \\ 31000 & 27900 \\ 3200 & 1600 \\ 1000 & 1000 \\ 500 & 500 \\ 800 & 800 \\ 9000 & 8100 \\ 2000 & 1000 \\ 2000 & 1000 \\ 24000 & 21600 \\ 1000 & 0 \\ 800 & 800 \\ 5310 & 2655 \\ 800 & 800 \\ 5310 & 2655 \\ 3000 & 3000 \\ 600 & 600 \\ 500 & 500 \\ 2000 & 2000 \\ 500 & 0 \\ 2000 & 2000 \\ 100 & 0 \\ 500 & 500 \\ 700 & 0 \\ 500 & 0 \\ 2000 & 1000 \\ 280 & 224 \\ 1400 & 700 \\ 200 & 200 \\ 2000 & 1000 \\ 500 & 500 \\ & \end{array}$

TRULOF MTRUUNIT

MTRULOF

LLCIUNIT

LLCILOF

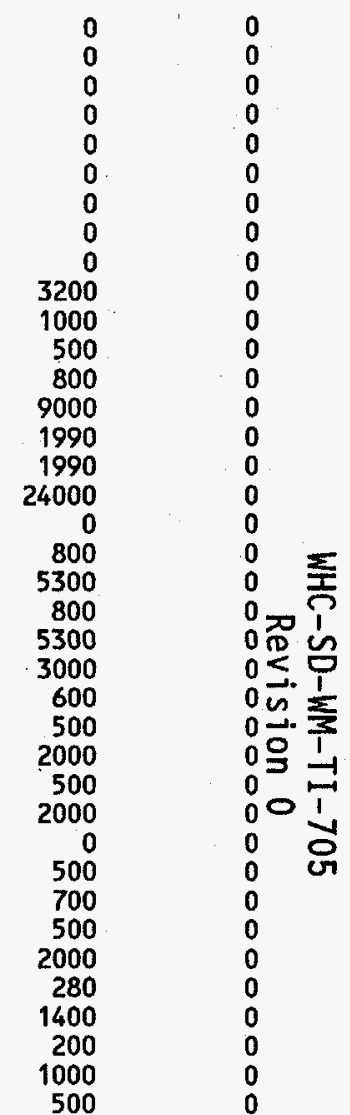


Page No. 3

05/22/95

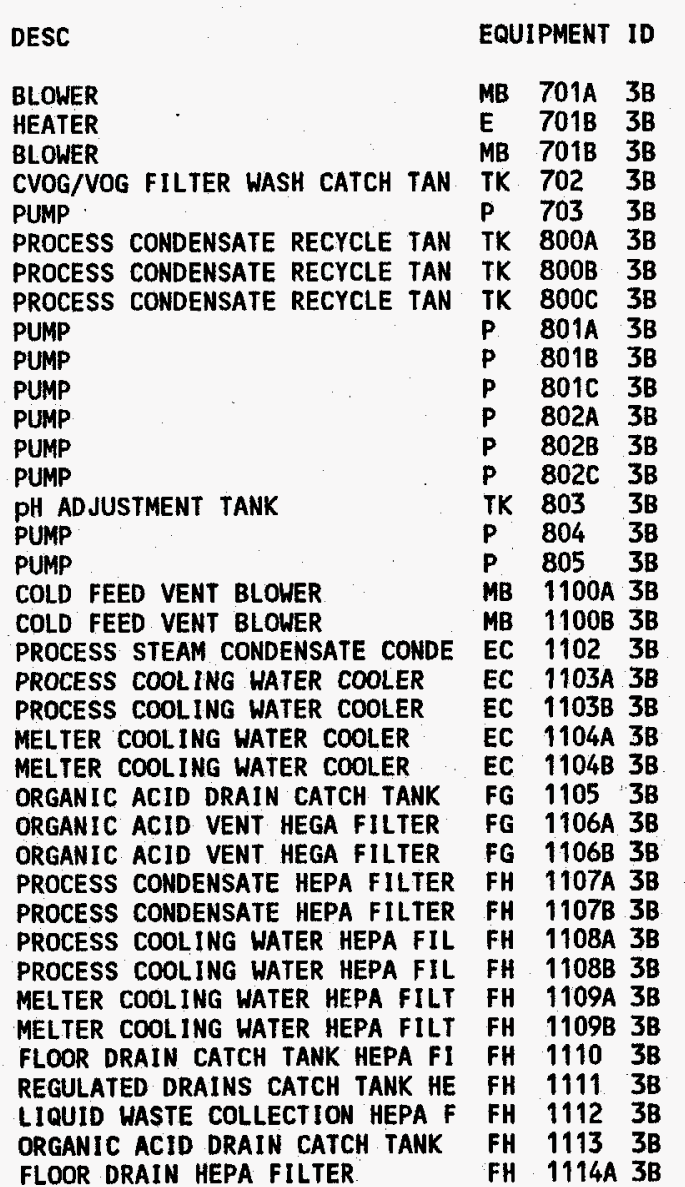

$\begin{array}{lrrr}\text { LOCATION } & \text { MTBF } & \text { TOTAL_WT } & \text { EQWTEXPOSD } \\ \text { CFR } & & & \\ \text { CEC } & 4544 & 13000 & 6500 \\ \text { CFR } & 1280 & 500 & 500 \\ \text { CEC } & 4544 & 13000 & 6500 \\ \text { CEC } & 5110 & 9500 & 8550 \\ \text { CCF } & 1825 & 2000 & 1000 \\ \text { CCF } & 5110 & 24000 & 21600 \\ \text { CCF } & 5110 & 24000 & 21600 \\ \text { CCF } & 5110 & 24000 & 21600 \\ \text { CCF } & 1825 & 2000 & 1000 \\ \text { CCF } & 1825 & 2000 & 1000 \\ \text { CCF } & 1825 & 2000 & 1000 \\ \text { CCF } & 1825 & 2000 & 1000 \\ \text { CCF } & 1825 & 2000 & 1000 \\ \text { CCF } & 1825 & 2000 & 1000 \\ \text { CCF } & 5110 & 24000 & 21600 \\ \text { CCF } & 1825 & 2000 & 1000 \\ \text { CDT } & 1825 & 2000 & 1000 \\ \text { CDT } & 4540 & 600 & 0 \\ \text { CDT } & 4540 & 600 & 0 \\ \text { CDT } & 5100 & 4500 & 0 \\ \text { CDT } & 0 & 7750 & 0 \\ \text { CDT } & 0 & 7750 & 0 \\ \text { CDT } & 0 & 4000 & 0 \\ \text { CDT } & 0 & 4000 & 0 \\ \text { CDT } & 0 & 300 & 0 \\ \text { CDT } & 0 & 300 & 0 \\ \text { CDT } & 5110 & 300 & 0 \\ \text { CDT } & 5110 & 280 & 0 \\ \text { CDT } & 5110 & 280 & 0 \\ \text { CDT } & 5110 & 280 & 0 \\ \text { CDT } & 5110 & 420 & 0 \\ \text { CDT } & 5110 & 420 & 0 \\ \text { CTA } & 5110 & 350 & 0 \\ \text { CTA } & 5110 & 350 & 0 \\ \text { CTA } & 5110 & 350 & 0 \\ \text { CTA } & 5110 & 350 & 0 \\ & 5110 & 350 & 0 \\ & & & 0 \\ & 0 & \end{array}$

TRUUNIT

TRULOF

MTRUUNIT

MTRULOF

LLC1UNIT

LLCILOF

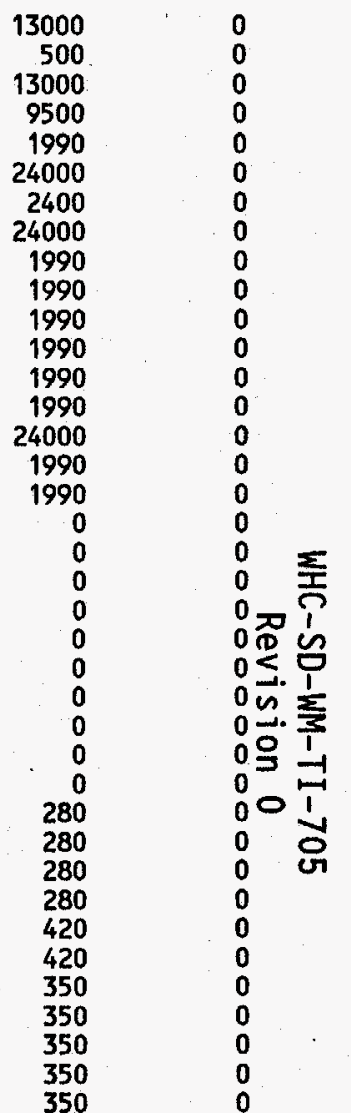


Page No. 4

$05 / 22 / 95$

DESC

EQUIPMENT ID

FH 11148 3B

FLOOR DRAIN HEPA FILTER

FLOOR DRAIN HEPA FILTER

FH $1114 C$ BB

FLOOR DRAIN IEPA FILTER FH 11140 3B

LIQUID WASTE COLLECTION HEPA F FH $1115 \quad 3 B$

LIOUID WASTE COLLECTION HEPA F FH 11163

COLD FEED VENT HEPA FILTER FH 1117 A $3 B$

COLD FEED VENT HEPA FILTER . FH 1117B $3 B$

VIT BLDG UPS VAC SYSTEM HEPA F FH 1118 B 3

IIT BLDG HPS VAC SYSTEM HEPA F FH 1118B 3B

VIT BLDG HPS VAC SYSTEM UEPA F FH T118C $3 B$

VIT BLDG HPS VAC SYSTEM HEPA F FH T118D $3 B$

VIT BLDG HPS VAC SYSTEM HEPA F FH T11BE $3 B$

VIT BLDG HPS VAC SYSTEM MEPA F FH T11BF $3 B$

VIT BLDG HPS VAC SYSTEM HEPA F FH $111863 B$

VIT BLDG HPS VAC SYSTEM HEPA F FH 1118H 3B

OFF-GAS TREATMENT CHEMICAL FEE FL 11203

COLD CHEMICAL TANK ROUGHING FI FL 1121 3B

COLD CHEMICAL TANK ROUGHING FI FL $11223 \mathrm{~B}$

COLD CHEMICAL TANK ROUGHING FI FL 1123 3B

ELECTRIC PROCESS STEAM GENERAT EV 1124A 3B

STANDBY ELECTRIC HEATER

PROCESS STEAM GENERATOR CIRCUL $P$ 1127A 38

BOILER FEED WATER CHEMICAL INJ $P$ 1128A 3B

OP BLOWDOWN DRUM

o CHEMICAL ADDITION TANK

PROCESS CONDENSATE PUMP

PROCESS CONDENSATE PUMP

PROCESS COOLING WATER PUMP

PROCESS COOLING WATER PUMP

MELTER COOLING WATER PUMP

MELTER COOLING WATER PUMP

FLOOR DRAIN CATCH TANK TRANSFE

FLOOR DRAIN CATCH TANK SUMP PU REGULATED DRAINS CATCH TANK TR ACID DRAIN CATCH TANK TRANSFER ACID DRAIN CATCH TANK SUMP PUM ORGANIC ACID DRAIN CATCH TANK ORGANIC ACID DRAIN CATCH TANK

TK 1129A 3B

TK $1130 \mathrm{~A} 3 \mathrm{~B}$

$1137 \mathrm{~A}$ 3B

$1137 \mathrm{~B}$ 3B

$1138 \mathrm{AB}$

1138B 3B

$1139 A$ 3B

$1139 \mathrm{~B} 3 \mathrm{~B}$

1140 3B

$11413 \mathrm{~B}$

114238

114338

$\begin{array}{ll}1143 & 38 \\ 1144 & 3 B\end{array}$

$\begin{array}{ll}1144 & 3 B \\ 1145 & 3 B\end{array}$

1146 3B

$\begin{array}{lrrr}\text { LOCATION } & \text { MTBF } & \text { TOTAL_WT } & \text { EQWTEXPOSD } \\ \text { CTA } & 5110 & 350 & 0 \\ \text { CTA } & 5110 & 350 & 0 \\ \text { CTA } & 5110 & 350 & 0 \\ \text { CTA } & 5110 & 350 & 0 \\ \text { CTA } & 5110 & 350 & 0 \\ \text { CDT } & 5110 & 350 & 0 \\ \text { CDT } & 5110 & 350 & 0 \\ \text { CDT } & 5110 & 525 & 0 \\ \text { CDT } & 5110 & 525 & 0 \\ \text { CDT } & 5110 & 525 & 0 \\ \text { CDT } & 5110 & 525 & 0 \\ \text { CDT } & 5110 & 525 & 0 \\ \text { CDT } & 5110 & 525 & 0 \\ \text { CDT } & 5110 & 525 & 0 \\ \text { CDT } & 5110 & 525 & 0 \\ \text { CDT } & 5110 & 350 & 0 \\ \text { CDT } & 5110 & 350 & 0 \\ \text { CDT } & 5110 & 350 & 0 \\ \text { CDT } & 5110 & 350 & 0 \\ \text { CDT } & 7300 & 52000 & 0 \\ \text { CDT } & 0 & 200 & 0 \\ \text { CDT } & 0 & 500 & 0 \\ \text { CDT } & 0 & 100 & 0 \\ \text { CDT } & 5110 & 1000 & 0 \\ \text { CDT } & 5110 & 625 & 0 \\ \text { CDT } & 1825 & 500 & 0 \\ \text { CDT } & 1825 & 500 & 0 \\ \text { CDT } & 1825 & 2000 & 0 \\ \text { CDT } & 1825 & 2000 & 0 \\ \text { CDT } & 1825 & 400 & 0 \\ \text { CDT } & 1825 & 400 & 0 \\ \text { CTA } & 1825 & 1500 & 750 \\ \text { CTA } & 1825 & 2500 & 1250 \\ \text { CTA } & 1825 & 2500 & 1250 \\ \text { CTA } & 1825 & 2500 & 1250 \\ \text { CTA } & 1825 & 1400 & 700 \\ \text { CTA } & 1825 & 2500 & 1250 \\ \text { CTA } & 1825 & 1400 & 700 \\ & & & \end{array}$

TRULOF MTRUUNIT

MTRULOF LLCIUNIT

LLC1LOF

垔

${ }_{0}^{0}$ 召

0 送

on.

0 으

00 논

우 
Page No. 5

$05 / 22 / 95$

DESC

EQUIPMENT ID

LOCATION

$\begin{array}{crr}\text { MTBF } & \text { TOTAL_WT } & \text { EOWTEXPOSD } \\ 1825 & 1400 & 0 \\ 1825 & 1500 & 0 \\ 1825 & 350 & 0 \\ 1825 & 200 & 0 \\ 1825 & 200 & 0 \\ 1825 & 200 & 0 \\ 1825 & 200 & 0 \\ 1825 & 200 & 0 \\ 1825 & 1000 & 0 \\ 1825 & 1000 & 0 \\ 1825 & 200 & 0 \\ 1825 & 200 & 0 \\ 1825 & 300 & 0 \\ 1825 & 200 & 0 \\ 1825 & 200 & 0 \\ 1825 & 200 & 0 \\ 1825 & 200 & 0 \\ 1825 & 200 & 0 \\ 5110 & 0 & 0 \\ 5110 & 0 & 0 \\ 5110 & 0 & 0 \\ 5110 & 0 & 0 \\ 5110 & 3000 & 0 \\ 5110 & 1050 & 0 \\ 5110 & 9500 & 0 \\ 5110 & 2500 & 0 \\ 5110 & 6500 & 0 \\ 5110 & 3250 & 0 \\ 5110 & 2500 & 0 \\ 5110 & 2500 & 0 \\ 5110 & 6500 & 0 \\ 5110 & 1250 & 0 \\ 5110 & 1250 & 0 \\ 5110 & 1250 & 0 \\ 5110 & 1250 & 0 \\ 5110 & 1250 & 0 \\ 5110 & 1250 & 0 \\ 5110 & 1250 & 0 \\ & & 0\end{array}$

MTRULOF

LLCIUNIT

LLC1LOF

REGULATED DRAINS CATCH TANK SU

FLOOR DRAIN SAMPLING TAMK TRAN P 1147 3B

COND DRAIN SAMPLING TANK TRAN P 1148 3B

COLD CMEMICAL FEED PUMP

COLD CHEMICAL FEED PUMP

COLD CHEMICAL FEED PUMP

CAL $\quad P$ P $11713 B$

$\begin{array}{llll} & \\ & P & 1173 & 3 B \\ \end{array}$

$\begin{array}{llll} & \\ & & \end{array}$

\begin{tabular}{llll} 
& \\
OXALIC ACID DECON FEED PUMP & $P$ & 1176 & $3 B$ \\
\hline
\end{tabular}

POTASSIUM PERMANGANATE FEED PU $P$

50\% CAUSTIC FEED PUMP $\quad P \quad 1180 \cdot 3 B$

$\begin{array}{lllll}\text { PROCESS NATER BOOSTER PUMP } & P & 1181 & 3 B \\ & P & 1182 A & 3 B\end{array}$

ANT I FOAM FEED PUMP $\quad P$ 1182A $3 B$

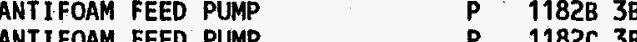

$P$ P 11820

ANTIFOAM FEED PUMP

ACID DRAIU CATCH TANK SUMP SU 1183 3B

ORGANIC ACID DRAIN CATCH TANK SU 1183 3B

FLOOR DRAIN DATCH TANK SUMP TANK 1184 3B

RLOR DRAIN CATCH TANK SUMP SU 1185 3B

PROCESS CONDENSATE TCH TAN SU SU 1186 $3 B$

Do PROCESS COOLING HATER EXPANSIO TK 1192 3B

1 MELTER COOLING WATER EXPANSION TK 1193 3B

LOW PRESSURE PROCESS WATER TAN TK 1194 3B

LOW PRESSURE PROCESS WATER TAN TK 1194 3B

$\begin{array}{llll}\text { FLOOR DRAIN CATCH TANK } & \text { TK } & 1195 & 3 B \\ \text { REGULATED DRAINS CATCH TANK } & \text { TK } & 1196 & 3 B\end{array}$

$\begin{array}{llll} & \\ \text { REGULATED DRAINS CATCH TANK } & \text { TK } & 1196 & 38 \\ \text { ACID DRAIN CATCH TANK } & \text { TK } & 1197 & 38\end{array}$

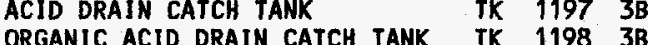

ORGANIC ACID DRAIN CATCH TANK TK 1198 3B

FLOOR DRAIN SAMPLING TANK $\quad$ TK 1199 3B

COLD CHEMICAL FEED TANK $\quad$ TK 1200 3B

COLD CHEMICAL FEED TANK $\quad$ TK 1201 3B

COLD CHEMICAL FEED TANK $\quad$ TK 1202 3B

50\% NITRIC ACID FEED TANK $\quad$ TK 1203 3B

NITRIC ACID DECON FEED TANK

TK 1205 3B

OXALIC ACID DECON FEED TANK

$\begin{array}{lll}\text { TK } & 1206 & 3 B \\ \text { TK } & 1207 & 3 B\end{array}$

$\begin{array}{ll}\text { CTA } & 1825 \\ \text { CTA } & 1825 \\ \text { CDT } & 1825 \\ \text { CDT } & 1825 \\ \text { CDT } & 1825 \\ \text { CDT } & 1825 \\ \text { CDT } & 1825 \\ \text { CDT } & 1825 \\ \text { CDT } & 1825 \\ \text { CDT } & 1825 \\ \text { CDT } & 1825 \\ \text { CDT } & 1825 \\ \text { CDT } & 1825 \\ \text { CDT } & 1825 \\ \text { CDT } & 1825 \\ \text { CDT } & 1825 \\ \text { CDT } & 1825 \\ \text { CDT } & 1825 \\ \text { CTA } & 5110 \\ \text { CTA } & 5110 \\ \text { CTA } & 5110 \\ \text { CTA } & 5110 \\ \text { CDT } & 5110 \\ \text { CDT } & 5110 \\ \text { CDT } & 5110 \\ \text { CDT } & 5110 \\ \text { CTA } & 5110 \\ \text { CTA } & 5110 \\ \text { CTA } & 5110 \\ \text { CTA } & 5110 \\ \text { CTA } & 5110 \\ \text { CDT } & 5110 \\ \text { CDT } & 5110 \\ \text { CDT } & 5110 \\ \text { CDT } & 5110 \\ \text { CDT } & 5110 \\ \text { CDT } & 5110 \\ \text { CDT } & 5110 \\ & \\ & \end{array}$


Page No. 6

05/22/95

DESC

POTASSIUM PERMANGANATE FEED TA TK 1208 3B 50\% CAUSTIC FEED TANK

FLUSH WATER FEED TANK

$\begin{array}{llll} & \text { TK } & 1211 & 3 B \\ & & \end{array}$

MB 1213A 3B

VIT BLDG HPS VACUUM BLOWER MB 1213B 3B

COLD CHEMICAL TANK ROUGHING FI FL $1214 \quad$ 3B

EL. $12153 \mathrm{~B}$

政 2201 3B

CFC CCTV W/VIEWING STATION TV 2208 3B

CFC CELL LIGHT ASSEMBLIES (8) LT 2211 3B

CWC JIB CRANE W/CONTROL PANEL CN 2213 3B

WELD EQUIPMENT TABLE

INSPECTION EQUIPMENT TABLE

CANISTER WELDER \#I W/POWER PAC

CANISTER WELDER \#2 W/POWER PAC

CWC MSM \#1

CWC MSM \#2

CWC CCTV \& VIEWING STATION

CWC CELL LIGHT ASSEMBLIES (8) WELD INSPECTION EQUIPMENT (\#1) CDC SHIELD WINDOW \#1

$\infty$ CDC SHIELD WINDOW \#2

CCTV CAMERA \#1 W/VIEWING STATI COC CELL LIGHT ASSEMBLIES (8) LT 2245 3B STC CCTV \#I W/VIEWING STATION STC CCTV \#2 W/VIEWING STATION CCTV LIFT TABLE (\#1)

CANISTER TURNTABLE H/CONTROL $P$ PNEUMATIC TRANSFER SYSTEM (PTS XE

PNEUMATIC TRANSFER SYSTEM (PTS

PNEUMATIC TRANSFER SYSTEM (PTS

PMEUMATIC TRANSFER SYSTEM (PTS

RADIATION COUNTER \#1

RADIATION COUNTER \#2

RADIATION COUNTER \#3

WB $2214 \quad 3$

$22153 \mathrm{~B}$

$2217.3 \mathrm{~B}$

E $22183 \mathrm{~B}$

MS $2220 \quad 3 \mathrm{~B}$

M2 2223 3B

TV $2225 \quad 3 B$

IT $22263 \mathrm{~B}$

MY 2227 3B

S2 2230 3B

TV $2232 \quad 3 \mathrm{~B}$

IT 2245 3B

TV 2247 3B

$\begin{array}{lll}2250 & 3 B \\ X & 3257 & 3 B\end{array}$

XE $22583 B$

XE 2259 3B

$\begin{array}{lll}\text { XE } & 2260 & 3 \mathrm{~B} \\ \text { RE } & 2261 & 3 \mathrm{~B}\end{array}$

RE 2262 3B

RE 2263 3B

$\begin{array}{lrrr}\text { LOCATION } & \text { MTBF } & \text { TOTAL_WT } & \text { EQWTEXPOSD } \\ \text { CDT } & & & \\ \text { CDT } & 5110 & 1250 & 0 \\ \text { CDT } & 5110 & 1250 & 0 \\ \text { CDT } & 5110 & 1250 & 0 \\ \text { CDT } & 5110 & 1250 & 0 \\ \text { CDT } & 4540 & 1200 & 0 \\ \text { CDT } & 4540 & 1200 & 0 \\ \text { CDT } & 5110 & 350 & 0 \\ \text { CFA } & 0 & 0 & 0 \\ \text { CFA } & 548 & 500 & 500 \\ \text { CFA } & 913 & 500 & 0 \\ \text { CWS } & 5110 & 1200 & 0 \\ \text { CWS } & 5110 & 8000 & 8000 \\ \text { CWS } & 5110 & 550 & 550 \\ \text { CWS } & 3110 & 550 & 550 \\ \text { CWS } & 365 & 200 & 200 \\ \text { CWS } & 5110 & 200 & 200 \\ \text { CWS } & 5110 & 1980 & 40 \\ \text { CWS } & 5110 & 1980 & 40000 \\ \text { CWS } & 913 & 500 & 0 \\ \text { CWS } & 5110 & 1200 & 0 \\ \text { CWS } & 5110 & 1000 & 0 \\ \text { CDS } & 5110 & 20000 & 0 \\ \text { CDS } & 5110 & 20000 & 0 \\ \text { CDS } & 913 & 500 & 0 \\ \text { CDS } & 913 & 500 & 0 \\ \text { CDS } & 5110 & 1200 & 0 \\ \text { CST } & 913 & 500 & 0 \\ \text { CST } & 913 & 500 & 0 \\ \text { CST } & 5110 & 6000 & 0 \\ \text { CST } & 5110 & 6000 & 0 \\ \text { CST } & 250 & 1000 & 0 \\ \text { CST } & 250 & 1000 & 0 \\ \text { CST } & 250 & 1000 & 0 \\ \text { CST } & 250 & 1000 & 0 \\ \text { CORRIDOR } & 0 & 0 & 0 \\ \text { CORRIDOR } & 0 & 0 & 0 \\ \text { CORRIDOR } & 0 & 0 & 0 \\ & & 0 & 0 \\ & 513 & & \end{array}$

TRULOF MTRUUNIT

MTRULOF

LLCIUNIT

LLC1LOF

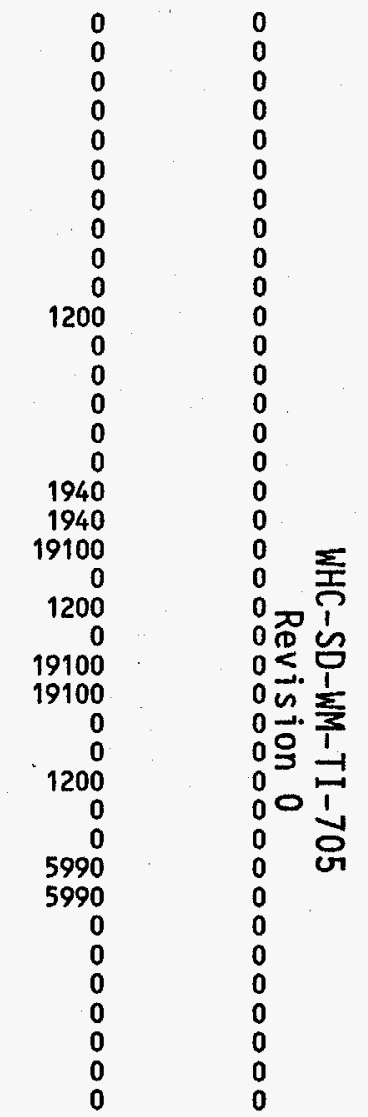


Page No. 7
$05 / 22 / 95$

DESC

RADIATION COUNTER \#4 STC SHIELD WINDOW \#1 GAMMA DETECTOR

NEUTRON DETECTOR

TEMPERATURE PROBE \& CONTROL PA

EQUIPMENT ID

$\begin{array}{lll}\text { RE } & 2264 & 3 B \\ \text { SZ } & 2265 & 3 B\end{array}$

RE 2268 3B

LT 2271 3B

STC PERSONNEL ACCESS/SHIELD DO SD 2273 3B

OVERPACK STAGING BUILDING CRAN CN 2285 3B

OVERPACK DECON STAUD

RADIATION COUNTER HL

RADIATION COUNTER \#4

OVERPACK UELDING EQUIPMENT

TRANSFER CART RAIL SYSTEM W/CO

CANISTER TRANSFER CART \#1

CANISTER TRANSFER CART \#2

CANISTER TRANSFER CART \#3

CANISTER TRANSFER CART \#4

CANISTER TRANSFER CART \#5

CANISTER TRANSFER CART \#6

CANISTER TRANSFER CART \#7

CANISTER TRANSFER CART \#8

D CANISTER HANDLING FORK LIFT

CANISTER ENTRY CRANE

CANISTER POSITIONING ARM

CANISTER POSITIONING ARM

GAMMA DETECTOR EMBED

GAMMA DETECTOR EMBED TUBES

COBALT SOURCE TREE

\begin{tabular}{lll}
$C N$ & 2285 & $3 B$ \\
$S R$ & 2286 & $3 B$ \\
\hline
\end{tabular}

RE 2287 3B

RE 2288 3B

RE 2289 3B

RE $22903 \mathrm{~B}$

CC 2292 3B

2293 3B

CC $2294 \quad 3 \mathrm{~B}$

CC 2295 3B

CC 2296 3B

CC 2297 3B

CC 2298 3B

CC 2299 3B

CC 2300 3B

CN 2301 3B

CN 2304 3B

HD $325 \mathrm{~A}$ 3B

HD 325B 3B

MY 326A 3B

MY 326B 3B

RA 327 3B

CONTRY TUNNEL MOTORIZED HATCH \& RA 2320 3B

TUNNEL LIGHT ASSEMBLIES (8) LT 2321 3B

LOAD IN CCTV W/VIEWING STATIO TV 2322 3B

PLUG INSERTION/REMOVAL DEVICE HD 2323 3B

CFC MOTORIZED HATCH (NON-SHIEL RA 2324 3B

36-POSITION WATER-COOLED CANIS SR 2325 3B

CCC CANISTER HANDLING ROBOT

$\begin{array}{lll}\text { CN } & 2326 & 3 \mathrm{~B} \\ \text { TV } & 2328 & 3 \mathrm{~B}\end{array}$

$\begin{array}{lrrr}\text { LOCATION } & \text { MTBF } & \text { TOTAL_WT } & \text { EQHTEXPOSD } \\ \text { CORRIDOR } & 0 & 0 & 0 \\ \text { CST } & 5110 & 20000 & 0 \\ \text { CST } & 0 & 0 & 0 \\ \text { CST } & 0 & 0 & 0 \\ \text { CST } & 365 & 20 & 0 \\ \text { CST } & 5110 & 1200 & 0 \\ \text { CST } & 5110 & 5300 & 0 \\ \text { C/CB } & 5110 & 50000 & 0 \\ \text { ODS } & 5110 & 5000 & 0 \\ \text { OST } & 0 & 0 & 0 \\ \text { OST } & 0 & 0 & 0 \\ \text { OST } & 0 & 0 & 0 \\ \text { OST } & 0 & 0 & 0 \\ \text { OWS } & 365 & 200 & 0 \\ \text { CWS } & 5110 & 40000 & 0 \\ \text { CFA, CWS } & 5110 & 5000 & 0 \\ \text { CFA, CWS } & 5110 & 5000 & 0 \\ \text { CFA, CWS } & 5110 & 5000 & 0 \\ \text { CFA, CWS } & 5110 & 5000 & 0 \\ \text { CFA, CWS } & 5110 & 5000 & 0 \\ \text { CFA, CHS } & 5110 & 5000 & 0 \\ \text { CFA, CWS } & 5110 & 5000 & 0 \\ \text { CFA, CWS } & 5110 & 5000 & 0 \\ \text { C/CB } & 5110 & 7500 & 0 \\ \text { C/CB } & 5110 & 2000 & 0 \\ \text { CFA } & 548 & 900 & 0 \\ \text { CFA } & 548 & 900 & 0 \\ \text { CFA } & 1574 & 4100 & 4100 \\ \text { CFA } & 2658 & 5200 & 0 \\ \text { CFA } & 5110 & 800 & 800 \\ \text { C/CB } & 5110 & 4000 & 0 \\ \text { CFA } & 5110 & 1200 & 0 \\ \text { CFA } & 913 & 500 & 0 \\ \text { CFA } & 548 & 500 & 0 \\ \text { CFA } & 5110 & 2000 & 0 \\ \text { CCC } & 5110 & 50000 & 0 \\ \text { CCC } & 5110 & 6000 & 0 \\ \text { CCC } & 913 & 500 & 0\end{array}$

TRUUNIT

MTRUUN I

MTRULOF LLCIUNIT

LLCILOF

0
0
0
0
0
0
0
0
0
0
0
0
0
0
0
4990
4990
4990
4990
4990
4990
4990
4990
0
0
0
0
0
0
800
0
0
0
500
0
5000
500
0 


\section{Page No.}

$05 / 22 / 95$

DESC

EQUIPMENT ID

CCC CELL. LIGHT ASSEMBLIES (8) LT 2329 3B CWC JIB CRANE W/ CONTROL PANEL CN 2330 3B $\begin{array}{llll}\text { CWC CART ENTRY DOOR } & \text { SD } & 2331 & 3 B \\ \text { CANISTER WELDER \#3 W/ POWER PA } & \text { WE } 2332 & 3 B\end{array}$ CANISTER WELDER \#4 W/ POWER PA WE 2333 3B WELD INSPECTION EOUIPMENT (\#2) MY 2334 3B CWC MOTORIZED HATCH (NON-SHIEL RA 2335 3B CWC MONORIZED HATCH CANISTER DECON TANK (\#1) TK 23373 CANISTER DECON TANK (\#2) $\quad$ TK 2338 3B CANISTER DECON TANK (\#2) $\quad$ TK 2338 3B $\begin{array}{llll}\text { CANISTER RINSE TANK (\#1) } & \text { TK } & 2339 & 3 B \\ \text { CANISTER RINSE TANK (\#2) } & \text { TK } & 2340 & 3 B\end{array}$ CANISTER RINSE TANK (\#2) $\quad$ TK 2340 3B CDC CART ENTRY DOOR CDC CART EXIT DOOR (SHIELDED) RA 2343 3B CDC MOTORIZED HATCH (SHIELDED) RA 2343 3B CCTV LIFT TABLE (\#2) $\quad$ HD 2344 3B CANISTER TRUNTABLE W/ CONTROL TU $23453 \mathrm{3B}$ STC CANISTER HANDLING ROBOT CN 2346 3B STC CANISTER EXIT/SHIELD DOOR SD 2347 3B CELL LIGHT ASSEMBL.IES ( 8 ) LT 2348 3B OVERPACK ENTRY CRANE $\quad$ CN 2349 38 OVERPACK ENTRY HATCH (SHIELDED RA 2350 3B CELL LIGHT ASSEMBLIES (8) $\quad$ LT 2351 3B

1 OWC WINDOW OWC CCTV \& VIEWING STATION TV 2354 3B OWC CELL LIGHT ASSEMBLIES (8) LT 2355 3B WELD INSPECTION EQUIPMENT MY 2356 3B OWC PERSONKEL ACCESS/SHIELD DO SD 2357 3B PNEUMATIC TRANSFER SYSTEM (PTS XE 2359 3B PNEUMATIC TRANSFER SYSTEM (PTS XE 2360 3B CCTV W/ VIEWING STATION TV $23613 \mathrm{~B}$ CCTV LIFT TABLE OVERPACK TURUTABLE H/ CONTROL TU 2363 3B TEMPERATURE PROBE \& CONTROL PA TE 2364 3B STC LIGHT ASSEBBL \& CONTROL PA TE 2364 38 STC LIGHT ASSEMBLIES (B) $\begin{array}{lllll}\text { STC OVERPACK HANDLING ROBOT } & \text { CN } & 2366 & 3 B \\ \text { GAMMA DETECTOR } & \text { RE } & 2368 & 3 B\end{array}$

\begin{tabular}{|c|c|c|c|}
\hline LOCATION & MTBF & TOTAL_WT & EQWTEXPOSD \\
\hline $\operatorname{ccc}$ & 5110 & 1200 & 0 \\
\hline CWS & 5110 & 8000 & 0 \\
\hline CWS & 5110 & 1200 & 0 \\
\hline CHS & 365 & 200 & 0 \\
\hline CWS & 365 & 200 & 0 \\
\hline CWS & 5110 & 1000 & 0 \\
\hline CWS & 5110 & 2000 & 0 \\
\hline CDS & 5110 & 6000 & 0 \\
\hline $\cos$ & 5110 & 2750 & 0 \\
\hline CDS & 5110 & 2750 & 0 \\
\hline $\operatorname{cDS}$ & 5110 & 2750 & 0 \\
\hline CDS & 5110 & 2750 & 0 \\
\hline CWS/CDS & 5110 & 3370 & 0 \\
\hline $\operatorname{cDS}$ & 5110 & 1200 & 0 \\
\hline CDS & 5110 & 4000 & 0 \\
\hline $\operatorname{CDS}$ & 5110 & 6000 & 0 \\
\hline CDS & 5110 & 6000 & 0 \\
\hline $\operatorname{CDS}$ & 5110 & 6000 & 0 \\
\hline CDS & 5110 & 1200 & 0 \\
\hline CDS & 5110 & 1200 & 0 \\
\hline $\mathrm{C} / \mathrm{CB}$ & 5110 & 2000 & 0 \\
\hline$C / C B$ & 5110 & 4000 & 0 \\
\hline CDS & 5110 & 1200 & 0 \\
\hline CDS & 5110 & 5300 & 0 \\
\hline OWS & 5110 & 20000 & 0 \\
\hline OWS & 913 & 500 & 0 \\
\hline OWS & 5110 & 1200 & 0 \\
\hline OWS & 5110 & 1000 & 0 \\
\hline OWS & 5110 & 5300 & 0 \\
\hline OST & 250 & 1000 & 0 \\
\hline OST & 250 & 1000 & 0 \\
\hline OST & 913 & 500 & 0 \\
\hline OST & 5110 & 6000 & 0 \\
\hline OST & 5110 & 6000 & 0 \\
\hline OST & 365 & 20 & 0 \\
\hline OST & 5110 & 1200 & 0 \\
\hline OST & 5110 & 6000 & 0 \\
\hline OST & 0 & 0 & 0 \\
\hline
\end{tabular}

\begin{tabular}{|c|c|c|c|c|c|}
\hline TRUONIT & TRULOF & MTRUUNIT & MTRULOF & LLCAUNIT & LLC1LOF \\
\hline 0 & 0 & 0 & 0 & 1200 & 0 \\
\hline 500 & 0 & 0 & 0 & 0 & 0 \\
\hline 0 & 0 & 0 & 0 & 0 & 0 \\
\hline 0 & 0 & 0 & 0 & 0 & 0 \\
\hline 0 & 0 & 0 & 0 & 0 & 0 \\
\hline 0 & 0 & 0 & 0 & 0 & 0 \\
\hline 0 & 0 & 0 & 0 & 2000 & 0 \\
\hline 500 & 0 & 0 & 0 & 5470 & 0 \\
\hline 0 & 0 & 0 & 0 & 2750 & 0 \\
\hline 0 & 0 & 0 & 0 & 2750 & 0 \\
\hline 0 & 0 & 0 & 0 & 2750 & 0 \\
\hline 0 & 0 & 0 & 0 & 2750 & 0 \\
\hline 0 & 0 & 0 & 0 & 3370 & 0 \\
\hline 0 & 0 & 0 & 0 & 1200 & 0 \\
\hline 0 & 0 & 0 & 0 & 4000 & 0 \\
\hline 0 & 0 & 0 & 0 & 5990 & 0 \\
\hline 0 & 0 & 0 & 0 & 5990 & 0 \\
\hline 500 & 0 & 0 & 0 & 5470 & 0 \\
\hline 0 & 0 & 0 & 0 & 0 & 0 \\
\hline 0 & 0 & 0 & 0 & 1200 & 0 \\
\hline 0 & 0 & 0 & 0 & 0 & 0 \\
\hline 0 & 0 & 0 & 0 & 0 & $0 \mathbb{D}$ \\
\hline 0 & 0 & 0 & 0 & 1200 & $0 \leq$ \\
\hline 0 & 0 & 0 & 0 & 5300 & 0 us \\
\hline 0 & 0 & 0 & 0 & 19100 & $0=$ \\
\hline 0 & 0 & 0 & 0 & 500 & 0 옥 \\
\hline 0 & 0 & 0 & 0 & 1200 & $0^{-3}$ \\
\hline 0 & 0 & 0 & 0 & 1000 & 00 \\
\hline 0 & 0 & 0 & 0 & 5300 & 0 \\
\hline 0 & 0 & 0 & 0 & 0 & 0 \\
\hline 0 & 0 & 0 & 0 & 0 & 0 \\
\hline 0 & 0 & 0 & 0 & 500 & 0 \\
\hline 0 & 0 & 0 & 0 & 5590 & 0 \\
\hline 0 & 0 & 0 & 0 & 5590 & 0 \\
\hline 0 & 0 & 0 & 0 & 20 & 0 \\
\hline 0 & 0 & 0 & 0 & 1200 & 0 \\
\hline 0 & 0 & 0 & 0 & 5970 & 0 \\
\hline 0 & 0 & 0 & 0 & 0 & 0 \\
\hline
\end{tabular}


Page No.
$05 / 22 / 95$

DESC

EQUIPMENT ID

LOCATION

MTBF

TOTAL_WT EQWTEXPOSD

TRUUNIT

TRULOF

MTRUUNIT

MTRULOF

LLC1UNIT

ULC1LOF

TRON DECTECTOR

$\begin{array}{lll}\text { RE } & 2369 & 3 B \\ \text { SD } & 2370 & 3 B\end{array}$

CCTV W/ VIEHING STATION

ODC LIGHT ASSEMBLIES (8) LT $2372 \quad 38$

OVERPACK LOAD OUT/WEIGH STATIO SR 2374 3B

CCTV W/ VIEWING STATION $\quad$ TV 2375 3B

LOC LIGHT ASSEMBLIES (8) LT $23763 \mathrm{~B}$

OVERPACK EXIT HATCH 2377 RB

CANISTER TRANSFER CART \#9 $\quad$ CC 2378 3B

CANISTER TRANSFER CART \#10. CC 2379 3B

CANISTER TRANSFER CART \#11. CC 2380 3B

CANISTER TRANSFER CART \#12 CC 2381 3B

TRANSFER CART RAIL SYSTEM W/ C CC 2382 3B

$\begin{array}{lllll}\text { TRANSFER CART RAIL SYSTEM W/ C CC } & 2382 & 3 B \\ \text { OVERPACK TRANSFER CART \#1 } & \text { CC } & 2383 & 3 B\end{array}$

OVERPACK TRANSFER CART \#2 $\quad$ CC 2384 3B

$\begin{array}{lllll}\text { OVERPACK TRANSFER CART \#2 } & \text { CC } & 2384 & 3 B \\ \text { OVERPACK TRANSFER CART } \# 3 & \text { CC } & 2385 & 3 B\end{array}$

OVERPACK TRANSFER CART \#4 $\quad$ CC 2386 3B

$\begin{array}{lllll}\text { OVERPACK TRANSFER CART } \# 4 & \text { CC } & 2386 & 38 \\ \text { OVEPPACK TRANSFER CART } & \text { \#5 } & \text { CC } & 2387 & 38\end{array}$

OVERPACK TRANSFE CART \#5

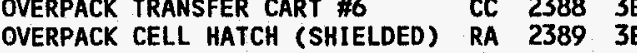

OVERPACK CELL HATCH (SHIELDED)

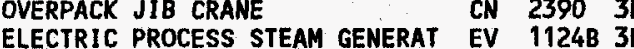

ELECTRIC PROCESS STEAM GENERAT

OP BOILER FEED WATER CHEMICAL INJ $P$ 1128B 3

TK $112983 B$

CHEMICAL ADDITION TANK TK $1130 \mathrm{~B}$ 3B

PROCESS CONDENSATE PUMP $\quad P \quad 1137 \mathrm{C} 3 \mathrm{~B}$

PROCESS CONDENSATE PUMP $\quad P$ P 1137038

KEROSENE FEED TANK

TK 1216 3B

P 1217A 3B

TK 1182 .

CC 2391 3B

KEROSENE FEED PUMP

CANISTER TRANSFER CART

CC 2392 3B

TRANSFER CART RAIL SYSTEM W/CO CC 23933 38

TRANSFER CART RAIL SYSTEM W/CO CC 23943

(CONTACT MAINT CELL) N

$\begin{array}{lrr}\text { OST } & 0 & 0 \\ \text { ODS } & 5110 & 1200 \\ \text { ODS } & 913 & 500 \\ \text { ODS } & 5110 & 1200 \\ \text { OST } & 5110 & 10000 \\ \text { OST } & 913 & 500 \\ \text { OST } & 5110 & 1200 \\ \text { OST } & 5110 & 4000 \\ \text { CFA/CWS } & 5110 & 5000 \\ \text { CFA/CWS } & 5110 & 5000 \\ \text { CFA/CWS } & 5110 & 5000 \\ \text { CFA/CWS } & 5110 & 5000 \\ \text { OWS/OST } & 5110 & 40000 \\ \text { OWS/OST } & 5110 & 5000 \\ \text { OWS/OST } & 5110 & 5000 \\ \text { OWS/OST } & 5110 & 5000 \\ \text { OWS/OST } & 5110 & 5000 \\ \text { OWS/OST } & 5110 & 5000 \\ \text { OWS/OST } & 5110 & 5000 \\ \text { C/CB } & 5110 & 4000 \\ \text { C/CB } & 5110 & 5000 \\ \text { CDT } & 7300 & 52000 \\ \text { CDT } & 0 & 200 \\ \text { CDT } & 0 & 100 \\ \text { CDT } & 5110 & 1000 \\ \text { CDT } & 5110 & 625 \\ \text { CDT } & 1825 & 500 \\ \text { CDT } & 1825 & 500 \\ \text { CDT } & 5110 & 0 \\ \text { CDT } & 1825 & 200 \\ \text { CDT } & 1825 & 200 \\ \text { CDT } & 5110 & 6000 \\ \text { CFA } & 5110 & 5000 \\ \text { CWS } & 5110 & 5000 \\ \text { CFA } & 5110 & 40000 \\ \text { CWS } & 5110 & 40000 \\ \text { CMC } & 5110 & 18400 \\ \text { RCDC-CMA } & 5110 & 18400\end{array}$


Page No. 10

$05 / 22 / 95$

DESC

EQUIPMENT ID

LOCATION

C/EC

$\begin{array}{llll}\text { CRANE (CENTRI FUGE/EVAPORATION) } & \text { CN } & 2397 & 38 \\ \text { CMA CRANE NOT REMOTE (CENTRIFU } & \text { CN } & 2398 & 38\end{array}$

CRANE (MELTER CELL) REMOTE WIT CN 2399 3B

CRANE (REDC) REMOTE WITH CCT CN $24003 \mathrm{~B}$

CRM (REDC) ON BRIDGE HITH CC CH 44013

CPANE (RAILPOAD HILL) NOT RE CN 2402 3B

CRANE (RALLROAD WILL) NOT CC CN 24023

SHIELD DOOR (CMA-RCOC) NOT RE SD 2403 3B

SHELD DOOR (CMATCETT ONE LO SD 2405 3B

RCDC CUT-UP EQUTPMENT ONE LOU SD $24053 B$

MELTER CUT UP CELL-CUT UP EQUT SO 2406 3B

MELTER CART RAIL SYSTEM W/CONT CC 2408 3B

METAL HEPA FILTER

METAL HEPA FILTER

METAL MEPA FILTER

METAL HEPA FILTER

METAL HEPA FILTER

METAL HEPA FILTER

METAL HEPA FILTER

METAL HEPA FILTER

METAL HEPA

METAL HEPA FILTER

$\underset{1}{1}$

FM 622A1 3B

FM 622A2 3B

$F M \quad 622 B 13 B$

FM $622 B 23 B$

FM 700A1 3B

FM 700A2 3B

FM 700B1 3B

FM $700 B 23 B$

FM 701A1 3B

FM 701A2 3B

FM 701B1 3B

FM 701B2 3B

AG $300 \mathrm{~A}$ 3B

P 300A 3B

CO 300A 3B

AG 300B

P $300 B \quad 3 B$

Co $300 \mathrm{~B} 3 \mathrm{~B}$

AG 300C 3B

P 300C 3B

Co 300C. 3B

AG 300D 3B

P 300D 3B

CO 300D 3B

AG $300 E$ 3B

P 300E 3B

CO $300 \mathrm{E} 3 \mathrm{~B}$

$\begin{array}{lrrr}\text { C/EC } & 5110 & 30000 & 0 \\ \text { C/E-CMA } & 5110 & 25000 & 0 \\ \text { MC } & 5110 & 40000 & 0 \\ \text { RCDC } & 5110 & 40000 & 0 \\ \text { RCDC } & 5110 & 6000 & 0 \\ \text { RRH } & 5110 & 32000 & 0 \\ \text { RCDC/CMP } & 5110 & 134000 & 0 \\ \text { C/EC } & 5110 & 96000 & 0 \\ \text { RCDC } & 5110 & 7000 & 7000 \\ \text { MCUC } & 5110 & 7000 & 7000 \\ \text { MC } & 5110 & 5500 & 0 \\ \text { CEC } & 5110 & 1500 & 1350 \\ \text { CFR } & 5110 & 1500 & 1350 \\ \text { CEC } & 5110 & 1500 & 1350 \\ \text { CFR } & 5110 & 15000 & 1350 \\ \text { CEC } & 5110 & 1200 & 1080 \\ \text { CFR } & 5110 & 1200 & 1080 \\ \text { CEC } & 5110 & 1200 & 1080 \\ \text { CFR } & 5110 & 1200 & 1080 \\ \text { CEC } & 5110 & 4500 & 2250 \\ \text { CFR } & 5110 & 4500 & 2250 \\ \text { CEC } & 5110 & 4500 & 2250 \\ \text { CFR } & 5110 & 4500 & 2250 \\ \text { R/SC } & 1825 & 1000 & 500 \\ \text { R/SC } & 1825 & 2000 & 1000 \\ \text { R/SC } & 1925 & 600 & 600 \\ \text { R/SC } & 1825 & 1000 & 500 \\ \text { R/SC } & 1825 & 2000 & 1000 \\ \text { R/SC } & 1925 & 600 & 600 \\ \text { R/SC } & 1825 & 1000 & 500 \\ \text { R/SC } & 1825 & 2000 & 1000 \\ \text { R/SC } & 1925 & 600 & 600 \\ \text { R/SC } & 1825 & 1000 & 500 \\ \text { R/SC } & 1825 & 2000 & 1000 \\ \text { R/SC } & 1925 & 600 & 600 \\ \text { R/SC } & 1825 & 1000 & 500 \\ \text { R/SC } & 1825 & 2000 & 1000 \\ \text { R/SC } & 1925 & 600 & 600 \\ & & & \end{array}$

TRUUNIT

1000

1000

1000

0
0
0
7000
7000
0
0
0
0
0
0
0
0
0
0
0
0
0
0
0
0
0
0
0
0
0
0
0
0
0
0
0
0

TRULOF MTRUUNIT MTRULOF LLCIUNIT

28970

38970

3970

$$
\begin{aligned}
& 0 \\
& 0
\end{aligned}
$$$$
0
$$$$
\begin{aligned}
& 0 \\
& 0 \\
& 0
\end{aligned}
$$$$
0
$$

1500

1500
1500

1500

1200
1200

1200

1200

4500
4500

4500

4500

990

1990

600
900

1990

600

600
990

1990

600

600
990
1990

1990

600
990

990
1990

600
LLC1LOF

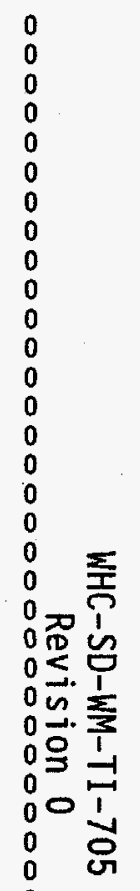


Page No. 11

05/22/95

DESC

$\begin{array}{lll}\text { EQUIPMENT } & \text { ID } \\ \text { AG } & 300 F & 3 B \\ P & 300 F & 3 B \\ C O & 300 F & 3 B \\ A G & 302 A & 3 B \\ P & 302 A & 3 B \\ C O & 302 A & 3 B \\ A G & 302 B & 3 B \\ P & 302 B & 3 B \\ C O & 302 B & 3 B \\ A G & 304 A & 3 B \\ P & 304 A & 3 B \\ C 0 & 304 A & 3 B \\ A G & 304 B & 3 B \\ P & 304 B & 3 B \\ C O & 304 B & 3 B \\ A G & 307 A & 3 B \\ P & 307 A & 3 B \\ C O & 307 B & 3 B \\ A G & 307 B & 3 B \\ P & 307 B & 3 B \\ C O & 307 A & 3 B \\ A G & 309 & 3 B \\ P & 309 & 3 B \\ C O & 309 & 3 B \\ A G & 313 & 3 B \\ P & 313 & 3 B \\ C O & 313 & 3 B \\ A G & 315 A & 3 B \\ P & 315 A & 3 B \\ C O & 315 A & 3 B \\ A G & 315 B & 3 B \\ P & 315 B & 3 B \\ C O & 315 B & 3 B \\ A G & 317 A & 3 B \\ P & 317 A & 3 B \\ C O & 317 A & 3 B \\ A G & 317 B & 3 B \\ P & 317 B & 3 B \\ & & \end{array}$

LOCATION

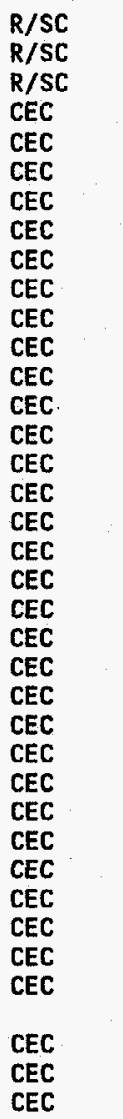

\begin{tabular}{|c|c|c|c|}
\hline MTBF & TOTAL_WT & EQWTEXPOSD & TRUUNIT \\
\hline 1825 & 1000 & 500 & 0 \\
\hline 1825 & 2000 & 1000 & 0 \\
\hline 1925 & 600 & 600 & 0 \\
\hline 731 & 4500 & 675 & 0 \\
\hline 1825 & 2000 & 1000 & 0 \\
\hline 1925 & 400 & 400 & 0 \\
\hline 731 & 4500 & 675 & 0 \\
\hline 1825 & 2000 & 1000 & 0 \\
\hline 1925 & 400 & 400 & 0 \\
\hline 731 & 10000 & 1500 & 1500 \\
\hline 1825 & 2000 & 1000 & 990 \\
\hline 1925 & 400 & 400 & 400 \\
\hline 731 & 10000 & 1500 & 1500 \\
\hline 1825 & 2000 & 1000 & 990 \\
\hline 1925 & 400 & 400 & 400 \\
\hline 731 & 5300 & 795 & 0 \\
\hline 1825 & 2000 & 1000 & 0 \\
\hline 1925 & 1500 & 1500 & 0 \\
\hline 731 & 5300 & 795 & 0 \\
\hline 1825 & 2000 & 1000 & 0 \\
\hline 1925 & 1500 & 1500 & 0 \\
\hline 731 & 5300 & 795 & 0 \\
\hline 1825 & 2000 & 1000 & 0 \\
\hline 1925 & 750 & 750 & 0 \\
\hline 731 & 5300 & 795 & 795 \\
\hline 1825 & 2000 & 1000 & 990 \\
\hline 1925 & 300 & 300 & 300 \\
\hline 731 & 10000 & 1500 & 1500 \\
\hline 1825 & 2000 & 1000 & 990 \\
\hline 1925 & 400 & 400 & 400 \\
\hline 731 & 10000 & 1500 & 1500 \\
\hline 1825 & 2000 & 1000 & 990 \\
\hline 1925 & 400 & 400 & 400 \\
\hline 731 & 10000 & 1500 & 1500 \\
\hline 1825 & 2000 & 1000 & 990 \\
\hline 1925 & 400 & 400 & 400 \\
\hline 731 & 10000 & 1500 & 1500 \\
\hline & & 1000 & \\
\hline
\end{tabular}

TRULOF MTRUUNIT.

MTRULOF

LLCIUNIT

LLC1LOF

0
1
$\omega$

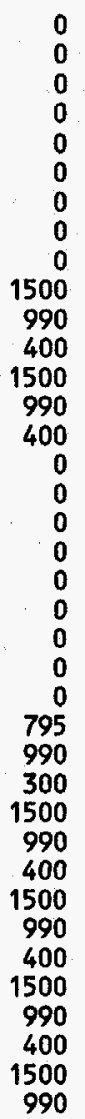


Page No. 12

05/22/95

DESC

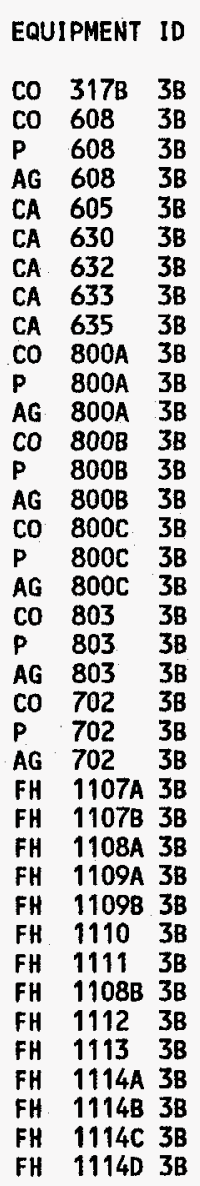

$\begin{array}{lrrr}\text { LOCATION } & \text { MTBF } & \text { TOTAL_HT } & \text { EQHTEXPOSD } \\ \text { CEC } & 1925 & 400 & 400 \\ \text { MC } & 1925 & 400 & 400 \\ \text { MC } & 1825 & 2000 & 1000 \\ \text { MC } & 1825 & 1000 & 500 \\ \text { MC } & 1095 & 9000 & 9000 \\ \text { CFR } & 1045 & 500 & 500 \\ \text { CFR } & 1095 & 2000 & 2000 \\ \text { CFR } & 1095 & 500 & 500 \\ \text { CFR } & 1095 & 500 & 500 \\ \text { CCF } & 1925 & 400 & 400 \\ \text { CCF } & 1825 & 2000 & 1000 \\ \text { CCF } & 1825 & 1000 & 500 \\ \text { CCF } & 1925 & 400 & 400 \\ \text { CCF } & 1825 & 2000 & 1000 \\ \text { CCF } & 1825 & 1000 & 500 \\ \text { CCF } & 1925 & 400 & 400 \\ \text { CCF } & 1825 & 2000 & 1000 \\ \text { CCF } & 1825 & 1000 & 500 \\ \text { CCF } & 1925 & 400 & 400 \\ \text { CCF } & 1825 & 2000 & 1000 \\ \text { CCF } & 1825 & 1000 & 500 \\ \text { CEC } & 1925 & 400 & 400 \\ \text { CEC } & 1825 & 2000 & 1000 \\ \text { CEC } & 1825 & 1000 & 500 \\ \text { CDT } & 731 & 120 & 120 \\ \text { CDT } & 731 & 120 & 120 \\ \text { CDT } & 731 & 120 & 120 \\ \text { CDT } & 731 & 180 & 180 \\ \text { CDT } & 731 & 180 & 180 \\ \text { CTA } & 731 & 150 & 150 \\ \text { CTA } & 731 & 150 & 150 \\ \text { CDT } & 731 & 120 & 120 \\ & 731 & 150 & 150 \\ \text { CTA } & 731 & 150 & 150 \\ \text { CTA } & 731 & 150 & 150 \\ \text { CTA } & 731 & 150 & 150 \\ \text { CTA } & 731 & 150 & 150 \\ \text { CTA } & 731 & 150 & 150 \\ & & & \end{array}$

TRUUNIT

400
0
0
0
9000
0
0
0
0
0
0
0
0
0
0
0
0
0
0
0
0
0
0
0
0
0
0
0
0
0
0
0
0
0
0
0
0
0

MTRUUNIT . MTRULOF LLCIUNIT

LLC1LOF

CANDLES

CATALYST

HOUSING CATALYST

HOUSING CATALYST

P.

\begin{tabular}{|c|c|c|}
\hline & & \\
\hline ELEMENT & FH & $1107 \mathrm{~B} 3 \mathrm{~B}$ \\
\hline ELEMENT & FH & $1108 \mathrm{~A} 3 \mathrm{~B}$ \\
\hline ELEMENT & FH & 1109A 3 \\
\hline LEEMENT & FH & 110983 \\
\hline ELEMENT & $\mathrm{FH}$ & 11103 \\
\hline LEMENT & FH & 11113 \\
\hline ELEMENT & FH & $1108 \mathrm{~B}$ \\
\hline ELEMENT & FH & $1112 ?$ \\
\hline ELEMENT & FH & 1113 \\
\hline ELEMENT & FH & $1114 \mathrm{~A}$ \\
\hline LEMENT & FH & $1114 \mathrm{~B}$ \\
\hline SENT & FH & $114 \mathrm{C} ?$ \\
\hline IENT & FH & 270 \\
\hline
\end{tabular}

$\begin{array}{ll}0 & 0 \\ 0 & 0 \\ 0 & 0 \\ 0 & 0 \\ 0 & 0 \\ 0 & 0 \\ 0 & 0 \\ 0 & 0 \\ 0 & 0 \\ 0 & 0 \\ 0 & 0 \\ 0 & 0 \\ 0 & 0 \\ 0 & 0 \\ 0 & 0 \\ 0 & 0 \\ 0 & 0 \\ 0 & 0 \\ 0 & 0 \\ 0 & 0 \\ 0 & 0 \\ 0 & 0 \\ 0 & 0 \\ 0 & 0 \\ 0 & 0 \\ 0 & 0 \\ 0 & 0 \\ 0 & 0 \\ 0 & 0 \\ 0 & 0 \\ 0 & 0 \\ 0 & 0 \\ 0 & 0 \\ 0 & 0 \\ 0 & 0 \\ 0 & 0 \\ 0 & 0 \\ 0 & 0 \\ & \end{array}$


Page No. 13

05/22/95

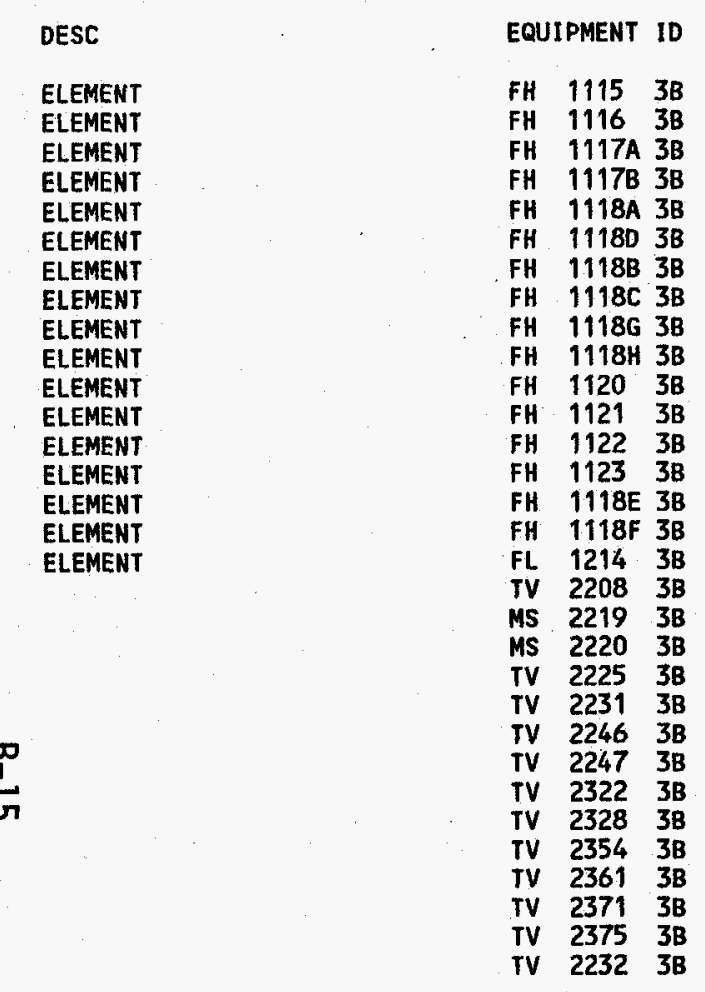

$\begin{array}{lrrr}\text { LOCATION } & \text { MTBF } & \text { TOTAL_HT } & \text { EQWTEXPOSD } \\ \text { CTA } & & 150 & 150 \\ \text { CTA } & 731 & 150 & 150 \\ \text { CDT } & 731 & 150 & 150 \\ \text { CDT } & 731 & 150 & 150 \\ \text { CDT } & 731 & 150 & 225 \\ \text { CDT } & 731 & 225 & 225 \\ \text { CDT } & 731 & 225 & 225 \\ \text { CDT } & 731 & 225 & 225 \\ \text { CDT } & 731 & 225 & 225 \\ \text { CDT } & 731 & 225 & 225 \\ \text { CDT } & 731 & 150 & 150 \\ \text { CDT } & 731 & 150 & 150 \\ \text { CDT } & 731 & 150 & 150 \\ \text { CDT } & 731 & 150 & 150 \\ \text { CDT } & 731 & 225 & 225 \\ \text { CDT } & 731 & 225 & 225 \\ \text { CDT } & 0 & 150 & 150 \\ \text { CFA } & 5110 & 500 & 0 \\ \text { CWS } & 2219 & 20 & 20 \\ \text { CWS } & 168 & 20 & 20 \\ \text { CWS } & 5110 & 500 & 0 \\ \text { CDS } & 5110 & 500 & 0 \\ \text { CST } & 5110 & 500 & 0 \\ \text { CST } & 5110 & 500 & 0 \\ \text { CFA } & 5110 & 500 & 0 \\ \text { CCC } & 5110 & 500 & 0 \\ \text { OWS } & 5110 & 500 & 0 \\ \text { OST } & 5110 & 500 & 0 \\ \text { ODS } & 5110 & 500 & 0 \\ \text { OST } & 5110 & 500 & 0 \\ \text { CDS } & 5110 & 500 & 0 \\ & * * * \star * & 2287310 & 699194\end{array}$

TRUUNIT
TRULOF MTRUUNIT

0
0
0
0
0
0
0
0
0
0
0
0
0
0
0
0
0
0
0
0
0
0
0
0
0
0
0
0
0
0
0
0

